\title{
Enzymatic C-N Bond Formation via Aerobic Nitroso Ene Reactions
}

Jan Deska, Christina Jäger

Submitted date: 09/05/2021 - Posted date: 12/05/2021

Licence: CC BY-NC-ND 4.0

Citation information: Deska, Jan; Jäger, Christina (2021): Enzymatic C-N Bond Formation via Aerobic Nitroso Ene Reactions. ChemRxiv. Preprint. https://doi.org/10.26434/chemrxiv.14562048.v1

A novel biocatalytic protocol enables the direct and selective introduction of nitrogen functionalities via activation of allylic $\mathrm{C}-\mathrm{H}$ bonds. Utilizing an oxidase/peroxidase couple for the formal dehydrogenation of $\mathrm{N}$-hydroxycarbamates and hydroxamic acids with air as terminal oxidant, acylnitroso species are generated under particularly mild aqueous conditions. The reactive intermediates undergo $\mathrm{C}-\mathrm{N}$ bond formation through an ene-type mechanism and provide high yields both in intramolecular and intermolecular enzymatic aminations. Investigations on alternative reaction pathways and labelling studies provide more insights into this unprecedented biocatalytic promiscuity of classical oxidoreductases as catalysts for nitroso ene-based transformations.

File list (2)

Nitroso_pre.pdf (1.12 MiB)

view on ChemRxiv • download file

Nitroso_ESI_pre.pdf (3.65 MiB)

view on ChemRxiv • download file 


\title{
Enzymatic C-N Bond Formation via Aerobic Nitroso Ene Reactions
}

\author{
Christina Jäger, ${ }^{a}$ and Jan Deska ${ }^{\text {a* }}$ \\ (a) Department of Chemistry, Aalto University, Espoo, Finland \\ jan.deska@aalto.fi
}

\begin{abstract}
A novel biocatalytic protocol enables the direct and selective introduction of nitrogen functionalities via activation of allylic C-H bonds. Utilizing an oxidase/peroxidase couple for the formal dehydrogenation of $\mathrm{N}$-hydroxycarbamates and hydroxamic acids with air as terminal oxidant, acylnitroso species are generated under particularly mild aqueous conditions. The reactive intermediates undergo $\mathrm{C}-\mathrm{N}$ bond formation through an ene-type mechanism and provide high yields both in intramolecular and intermolecular enzymatic aminations. Investigations on alternative reaction pathways and labelling studies provide more insights into this unprecedented biocatalytic promiscuity of classical oxidoreductases as catalysts for nitroso enebased transformations.
\end{abstract}

Nature's repertoire to introduce nitrogen moieties into molecular frameworks is generally limited to direct functional group interconversions. In addition to the welldeveloped amide-forming enzymes, the toolbox of synthetically valuable biocatalysis methods has been expanded steadily in the past years through a number of nitrogen-fixation strategies based on reductive aminations and additions catalyzed by transaminases, imine reductases, and amine dehydrogenases, to name a few.[1] In a complementary approach mimicking chemistry by biological means, most recently the biocatalytic imitation of non-natural but synthetically relevant reactions was moved into the spotlight,[2] and in particular nitrene insertionbased transformations utilizing engineered heme proteins introduced whole new pathways for the biocatalytic C-N bond formation.[3]

As a yet untapped template from the world of traditional synthesis, another attractive alternative approach for selective $\mathrm{C}-\mathrm{N}$ bond formations engages reactive nitroso species as electrophiles with allylic functionalities. First explored in the 1960's for the synthesis of allylamines using nitrosobenzene,[4] nitroso ene reactions, and the related nitroso-Diels-Alder cycloadditions, are nowadays found in a wide variety of synthetic strategies towards natural products and pharmaceuticals.[5] Due to their high reactivity, nitroso reagents are most commonly created in situ through oxidation of amines or hydroxylamines, or the reduction of nitro moieties.[6] Among the different derivatives, particularly acylnitroso species have been proven as versatile reaction partners, as these electrophiles offer a a amine synthesis through functional group interconversion (natural mode)

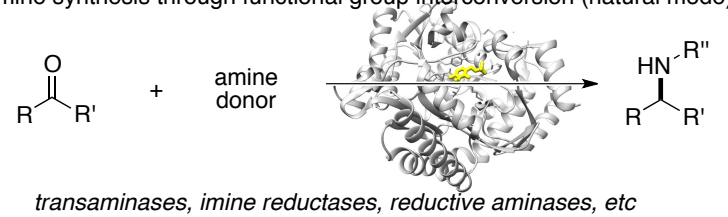

b $\mathrm{C}-\mathrm{N}$ bond formation via nitrene $\mathrm{C}-\mathrm{H}$ insertion (reverse biomimetics)
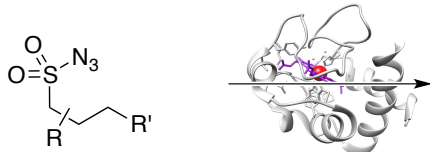

$\mathrm{O}=\stackrel{\mathrm{O}}{\mathrm{S}}-\mathrm{NH}$

engineered heme proteins

c nitroso ene-type amination by promiscuous oxidoreductases (this work)

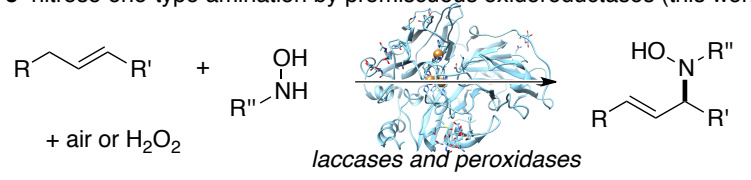

Scheme 1. Approaches for $\mathrm{C}-\mathrm{N}$ bond formation mediated by enzyme catalysts: a) established biocatalytic amination through transferases and oxidoreductases; b) designer biocatalysts enabling nitrene insertion chemistry; c) ene-type functionalization by laccases and peroxidases.

good compromise between reactivity and selectivity.[7] As the $\mathrm{C}-\mathrm{N}$ bond formation through nitroso ene reactions proceeds with specificity on allylic fragments even on more functionalized molecules, a variety of different methodologies for the synthesis and trapping of acylnitroso species have been developed over the years. Common approaches include the thermal dissociation, ${ }^{[8]}$ photooxidations, ${ }^{[9]}$ or the application stoichiometric oxidizing agents the likes of peroxides,[10] diacetoxyiodobenzene,[11] NMO,[12] and periodates.[13] Logically, those methods were subsequently supplemented by a variety of catalytic versions employing transition metal complexes as mediators for the oxidative or reductive generation of the nitroso electrophiles, covering protocols based on iridium, ruthenium, rhodium, molybdenum or palladium.[14] Particularly mild conditions have been achieved by rather simple catalytic systems utilizing copper[15] or iron[16] catalysts in combination with oxygen or hydrogen peroxide as terminal oxidants which provide effective $\mathrm{C}-\mathrm{N}$ bond forming reactions both in intra- and intermolecular reactions. Although singular examples of catalytic-enantioselective methods have been reported for nitroso-Diels-Alder cycloadditions, ${ }^{[17]}$ the application of the nitroso ene reaction for the synthesis of optically active 
amines has so far been limited to auxiliary-controlled diastereoselective transformations.[15c,18] In our endeavor to discover new enzymatic tools that are inspired by traditional organic chemistry, we envisaged that oxidative biocatalysts could act as mediators for this attractive $\mathrm{C}-\mathrm{N}$ coupling reaction. While ensuring mild conditions and benign oxidants, the potential enzyme catalysts would need to provide a protective environment for the reactive nitroso electrophiles, that, if successful, could also serve as starting point for protein engineering efforts to develop enantioselective biocatalyst variants.

With both copper and iron-based homogeneous systems described in literature, our investigation on the biocatalytic nitroso ene reaction started with a broad screening over a series of redox-active metalloproteins featuring either of these two elements as active site motif. As one of the most prominent copper-dependent enzyme classes with precedence as tool in organic synthesis, oxygen-activating laccases were initially taken into the focus of our study. While laccase from Rhus vernicifera did not engage in any kind of activation of the model substrate 1a (Table 1, entry 1), the multi-copper proteins from Agaricus bisporus, Myceliophthora thermophila, Trametes versicolor and Pleurotus ostreatus could all in fact transform the $N$-hydroxy carbamate and provide 2a in mediocre to acceptable yields (Table 1, entries 2-5). The contrast between full conversion and low yields however raises the question of selectivity and it appears that subsequent further oxidation and decomposition of the $\mathrm{N}$-hydroxy oxazolidinone 2a may hamper the process. The wellestablished laccase from $T$. versicolor distinguished itself as most effective copper protein, but variability in isolated yields of 2 a raised the question of reliability of a black box catalyst (Table 1 , entry 5). Studies on the true role of laccases in this transformation are currently part of a more biotechnological investigation that is however outside the scope of this article. Tyrosinase as alternative oxidizing copper protein proved to be inactive in the desired reaction (Table 1, entry 6). Succeeding those somewhat ambiguous results, we turned our attention to a bi-enzymatic system that was previously employed by us successfully in the aerobic oxidative transformation of furans and allenes.[19] Combining glucose oxidase (GOx) as oxygen-activating biocatalyst with peroxidases or peroxygenases to mediate the oxidation of the substrate, we imagined that also these biocatalysts could generally qualify to in situ generate the reactive acylnitroso species. In presence of glucose, GOx and air, little to no product formation was observed with peroxygenase and lactoperoxidase (Table 1, entries 7 \& 8). In contrast, with chloroperoxidase from $C$. fumago full conversion of 1 a was achieved within 29 hours. A yield of $64 \%$ of $2 a$ however indicated that also with this biocatalyst, similar to the most effective laccases, overoxidation remained a problem (Table 1, entry 9). Gratifyingly, supplementing horseradish peroxidase (HRP) resulted in not only fast conversion but also an excellent isolated yield of $97 \%$ (Table 1, entry 10). Although solubility of 1a in the phosphate buffer was not an issue, cosolvent solutions were taken into consideration, as structural variations on related
$N$-hydroxy carbamates and hydroxamic acids could affect substrate lipophilicity unfavorably. The GOx/HRP system proved to be very robust and neither addition of the watermiscible dioxane nor the two-phase solution featuring ethyl acetate caused significant deterioration of reactivity or selectivity (Table 1, entry $11 \& 12$ ). In absence of added peroxidase, no reaction was taking places, ruling out any action by the glucose oxidase additive itself (Table 1, entry 13).

Table 1. Enzyme-mediated oxidation-induced cyclization of 1a.

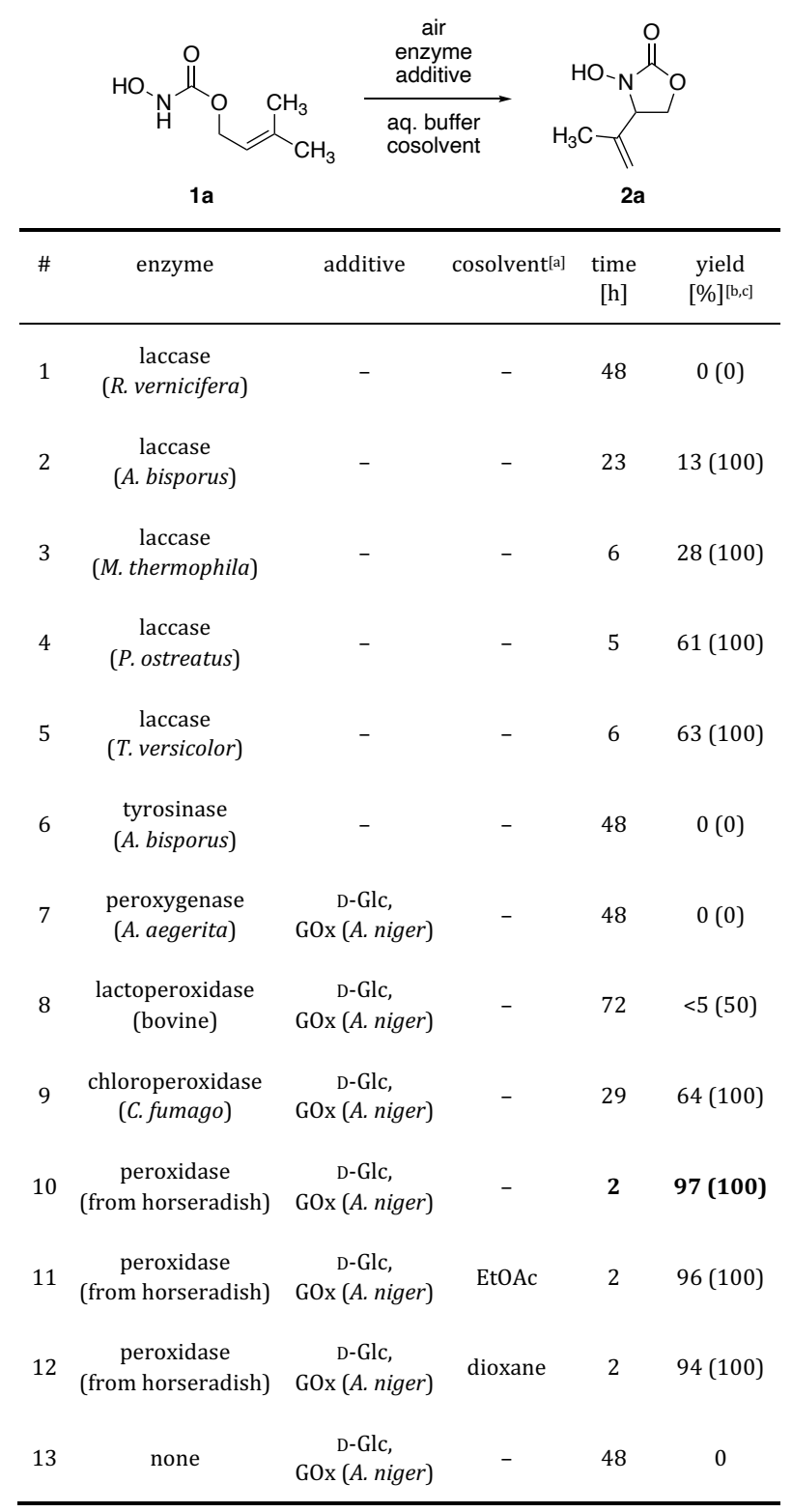

Reaction conditions, for laccases/tyrosinase: 1a (10 mM), laccase or tyrosinase (100 U), phosphate buffer (pH 7.0, $100 \mathrm{mM}, 7 \mathrm{~mL}), 25^{\circ} \mathrm{C}$; for peroxidases: 1a $(10 \mathrm{~mm}), \mathrm{D}$-glucose $(50 \mathrm{~mm})$, glucose oxidase $(70 \mathrm{U})$, peroxidase $(70 \mathrm{U})$, phosphate buffer $(\mathrm{pH} 7.0,100 \mathrm{~mm}, 7 \mathrm{~mL}), 25^{\circ} \mathrm{C}$. [a] $10 \mathrm{vol} \%$. [b] Isolated yields of 2a. [c] Conversion in parenthesis.

Apparently, the conversion of $\mathbf{1 a}$ to $\mathbf{2 a}$ includes formation of an asymmetric centre and naturally, enantioselectivity is almost taken for granted in biocatalysis. A strong stereochemical induction, however, 
would require a distinct Lewis-acidic binding site for the reactive nitroso intermediate, that, given the nature of activation by peroxidases through electron transfer into compound I, is unavailable in the heme proteins. In contrast, the laccase's mononuclear T1 copper may indeed act as substrate binding motif. Consequently, all peroxidasecatalyzed reactions yielded racemic products whereas moderate enantiomeric excesses from up to $72 \%$ were achieved with laccase from $T$. versicolor. Thus, an enantioselective methodology for the nitroso ene reaction will likely rely on future protein engineering efforts with the blue-copper enzymes.

The peroxidase-based cyclization protocol was subsequently examined regarding the tolerated substrate scope and structural limitations of the methodology (Scheme 2). Changing from the $\mathrm{N}$-hydroxy carbamate motif to a hydroxamic acid in $\mathbf{1 b}$, good reactivity could be maintained and the $N$-hydroxy lactame $\mathbf{2 b}$ was obtained in $77 \%$ yield. Similarly, variation of the substitution pattern around the olefinic double bond was generally tolerated as indicated by moderate to very high yields of products $\mathbf{2 c - 2 e}$. All reactions proceeded well at room temperature which poses a stark contrast to the original chemical template that required up to $100{ }^{\circ} \mathrm{C}$ to achieve comparable yields.[16] Utilizing chiral $\mathrm{N}$-hydroxy carbamates, good to excellent induced diastereoselectivity could be observed and the spirocyclic product $\mathbf{2 g}$ was isolated in $97 \%$ yield as $92: 8$ mixture of diastereomers. In contrast, no reaction was observed for the verbenol-derived $\mathbf{1 h}$ or the 3 methylcinnamyl substrate $E-\mathbf{1 i}$, which could be either attributed to an excessive steric demand or unfavorable geometrical constraints.
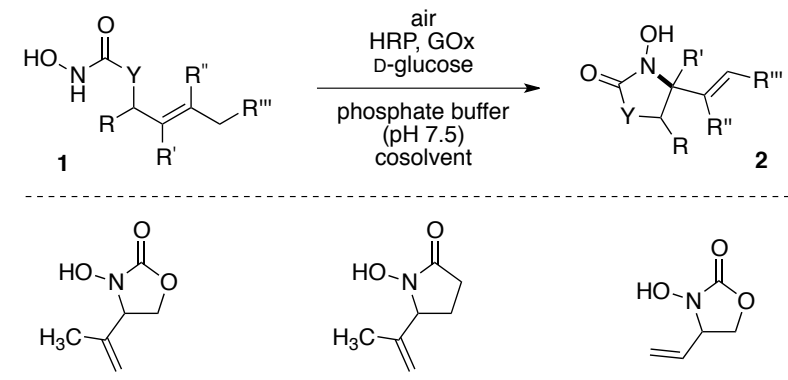

2a, $97 \%$ yield

$$
\text { 2b, } 77 \% \text { yield }
$$

2c, $53 \%$ yield

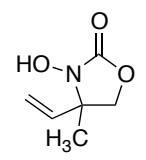

2d, $91 \%$ yield

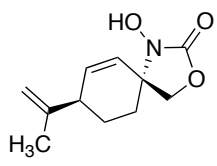

$2 \mathrm{~g}, 97 \%$ yield $92 \%$ trans

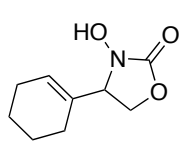

2e, $77 \%$ yield

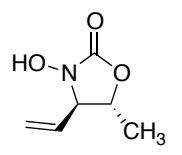

2f, $52 \%$ yield $68 \%$ trans

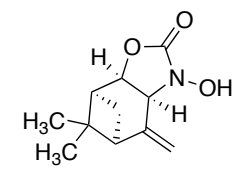

$2 \mathrm{~h}, 0 \%$ yield

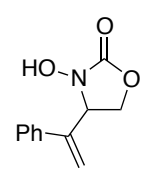

$2 \mathbf{i}, 0 \%$ yield (from $E-1 \mathrm{i})$
Scheme 2. Scope of the biocatalytic aerobic nitroso ene cyclization.
The cis or trans arrangement between the intermediate nitroso group and the reactive $\mathrm{C}-\mathrm{H}$ bond across the olefinic double bond has not been recognized as major selectivity factor in previous studies, however, significantly higher reaction temperatures were commonly applied in classical, chemical nitroso ene reactions. To get a clearer picture on the potential geometrical bias of the HRP-catalyzed cyclization, the two isomeric 2-hexenyl $N$-hydroxy carbamates $E-\mathbf{1 j}$ and $Z-\mathbf{1} \mathbf{j}$ were reacted under identical conditions (Scheme 3). Here, the $E$-configured isomer delivered the expected oxazolidinone $\mathbf{2} \mathbf{j}$ in a good yield of $66 \%$. With a rotationally flexible $\mathrm{CH}_{2}$ unit in allylic position, the product was obtained as a 3-to-1 E/Z-mixture. Quite differently, no cyclization product could be detected with the opposite stereoisomeric substrate and $Z$-1j jas instead quantitatively decomposed.

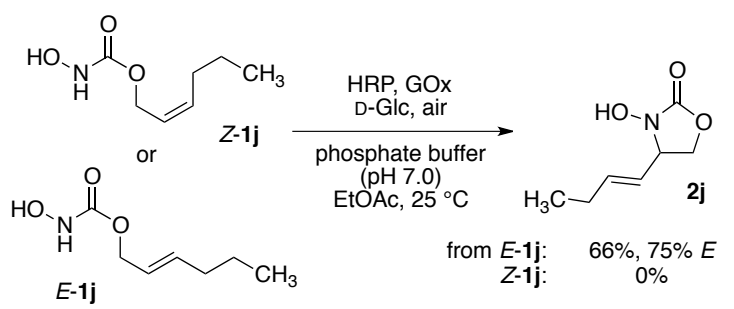

Scheme 3. Selectivity in the biocatalytic conversion of olefinic isomers.

The half-life of acylnitroso species in the aqueous reaction medium is likely limited as the they are generally characterized as short-lived electrophiles. In a recent study by Goldstein, ${ }^{[20]}$ the rates of hydrolysis of in situ prepared nitroso carbonyls, and reactions with other nucleophiles, were investigated and half-lives of a few minutes were observed. In the HRP-catalyzed cyclization, the intramolecular nature and a potential protective function of the protein may explain the good to excellent yields. When moving to an intermolecular system, however, the exposure of the reactive intermediate is unavoidable. Not surprisingly, initial attempts to conduct a bimolecular coupling between $N$-hydroxy carbamate 3 and tetramethylethylene (4) in equimolar amounts under the previously optimized conditions with the oxidase/ peroxidase couple resulted in full conversion in $2 \mathrm{~h}$, but with a mediocre yield of only $30 \%$. To our delight, simply swapping the organic cosolvent from ethyl acetate to tetramethylethylene itself resulted in identical kinetics and disappearance of $\mathbf{3}$ within $2 \mathrm{~h}$. In this case however, the $\mathrm{C}-\mathrm{N}$-coupling product 5 was isolated in an excellent yield of $86 \%$ (Scheme 4). Though practical for some olefinic reaction partners, the use of excess reactants is certainly not the most elegant approach.

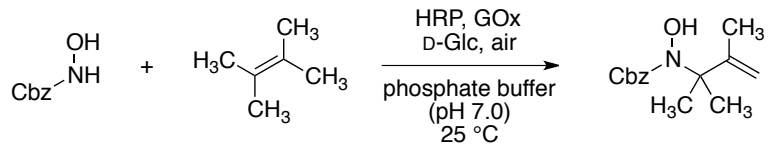

$$
\begin{aligned}
& 3 \\
& 4 \\
& \mathbf{5}, 86 \% \text { yield }
\end{aligned}
$$

Scheme 4. Enzymatic intermolecular nitroso ene reaction. 
Thus, it will be necessary to further adjust the reaction conditions for this intermolecular nitroso ene reaction, either through reaction medium engineering,[19c] or through modulation of the reactivity by variation of the electronics of the enophile.[7]

With a highly effective biocatalytic protocol in hand to prepare and react acylnitroso species in situ under mild aerobic conditions, the extension to related reactions as probe for the synthetic potential of this enzymatic tool appeared to be a logical next step. With a proven activity in both intra- and intermolecular ene-type reaction, we assumed that the peroxidase could likewise act as catalyst in nitroso-Diels-Alder reactions. Utilizing $\mathrm{N}$ hydroxycarbamate 1n featuring a diene moiety and a geometry that would rule out competing ene reactivities, our established method indeed translated well into an intramolecular [4+2] cycloaddition yielding bicycle $\mathbf{5}$ as major product (Scheme 5a).

More surprisingly, the peroxidase-mediated oxidation of the benzoate-derived hydroxamic acid $\mathbf{1 l}$ resulted in a slightly different reaction outcome, providing amidohydroxylated species $\mathbf{7}$ selectively as the sole product, alongside with unreacted starting material (Scheme 5b). Even though similar $\mathrm{N}, \mathrm{O}$-difunctionalizations of olefins are not unknown, [21] to the best of our knowledge, this bifurcation has so far not been observed in the previous nitroso ene studies and could indicate an interesting additional avenue for future investigations. Noteworthy, none of the other substrates tested in this work have led to similar amidohydroxylation products. While the current yield of $20 \%$ would certainly require more optimization efforts to present the reaction as serious synthetic method, this deviation from the expected product outcome might help to shed some light on potential pathways of the nitroso ene reaction under the herein described aqueous enzymatic conditions (vide infra).

a Diels-Alder-selective

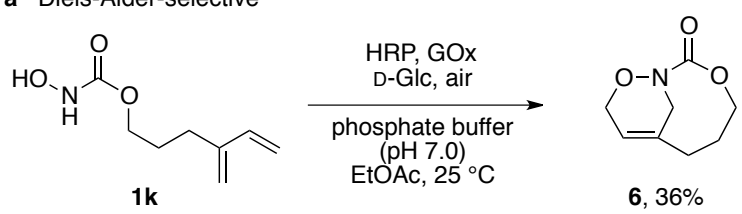

b amidohydroxylation-selective<smiles>CC(C)=Cc1ccccc1C(=O)NO</smiles>

11

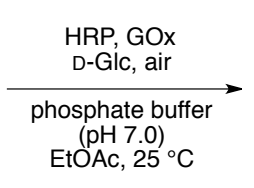

EtOAc, $25^{\circ} \mathrm{C}$

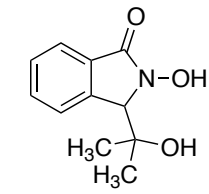

7, $20 \%$
Scheme 5. Cycloaddition and amidohydroxylation-selective conversions through HRP/GOx-mediated aerobic oxidation.

While the nitroso-Diels-Alder and the nitroso-ene reactions are identical in how the reactive R-NO species are formed, the ene-type reaction is believed to follow a stepwise reaction pathway as opposed to the concerted
[4+2] cycloaddition of the Diels-Alder mechanism. The underlying process of these kinds of ene reactions is still under debate, and several feasible mechanisms have been proposed over the years. Most plausible pathways, based on experimental and/or computational studies, are proceeding via zwitterionic or diradical intermediates, concerted pathways, as well as via intermediary aziridine $\mathrm{N}$-oxides (ANO).[22-26] Although not unchallenged, the current established view assumes a combination of hypotheses with a polarized diradical pathway that does not rule out the ANO as an 'innocent bystander'.[23,26] However, these mechanistic studies mostly refer to the intermolecular ene reaction of nitroso compounds, and are likely not fully transferable to our system due to the unusual aqueous reaction environment.

In order to gain some insights into mechanistic details of the uncommon aqueous nitroso ene chemistry, a series of isotopically labelled substrates were prepared to study the intramolecular conversion of $\mathbf{1 a}$ to the cyclic $\mathrm{N}$ hydroxycarbamate 2a. A symmetrically deuterated derivative 1a- $\mathrm{d}_{6}$ was investigated, and comparison of initial rates of conversion of deuterated and non-deuterated substrates revealed a strong inverse isotope effect $\left(k_{\mathrm{H}} / k_{\mathrm{D}}=\right.$ 0.79 ) (Scheme 2a). This isotope effect likely arises from the hybridization change of carbon $\mathrm{C} 2$ in the double bond ( $\mathrm{sp}^{2}$ to $\mathrm{sp}^{3}$ ) during the rate-limiting step. Similar inverse $\mathrm{b}$ secondary effects have not been previously observed experimentally in nitroso ene reaction, though they were also not ruled out in the first place. As competing diradical or dipolar pathways would most certainly lead to more significant normal isotope effects, it is believed that a $\beta$ secondary isotope effect could not be recognized.[22-26] These expected effects of diradical or non-ANO zwitterionic pathways are therefore not consistent with our observation leading to the exclusion of these mechanistic options. Hence, the formation of an ANO as an intermediate instead of an inoperative bystander could be the logic conclusion. The absence of any primary KIE indicates a stepwise mechanism with irreversible formation of an intermediate in the rate-limiting step followed by the hydrogen migration. Similar effects were observed by Orfanopoulos in the ene reaction of triazolinediones with phorone- $d_{6}$ and styrene-like substrates, who concluded an $\mathrm{S}_{\mathrm{N}} 2$-type addition of the $\mathrm{N}=\mathrm{N}$ enophile to the double bond forming a three-membered ANO-like intermediate in the ratedetermining step. [27]

The clear on/off-selectivity in the conversion of stereochemically defined isomers ( $E$ vs $Z$ ) was already illustrated in Scheme 3; a feature that is in line with a geometrically rigid intermediate such as the aziridine $\mathrm{N}$ oxide. At the same time, this specificity stands in contrast to other protocols that do allow the transformation of $Z$ olefins in intramolecular nitroso ene reactions, supporting the possible deviation in pathways between polar-protic and the more commonly used lipophilic media. To probe the expected selectivity for the cleavage of $E$-oriented $\mathrm{C}-\mathrm{H}$ bonds also in a sterically truly unbiased system, we furthermore synthesized the unsymmetrically labelled $Z$ 1a- $\mathrm{d}_{3}$ and subjected it to the established GOx/HRP- 
catalyzed cyclization. The thus obtained oxazolidinone $\mathbf{2 a -}$ $\mathrm{d}_{3}$ carried the deuterium label specifically in the remaining methyl group (Scheme 6b). Likewise, specific formation of the methylene-labelled $\mathbf{2 a}-\mathrm{d}_{2}$ was observed when starting from the isomeric $E-\mathbf{1 a}-\mathrm{d}_{3}$.

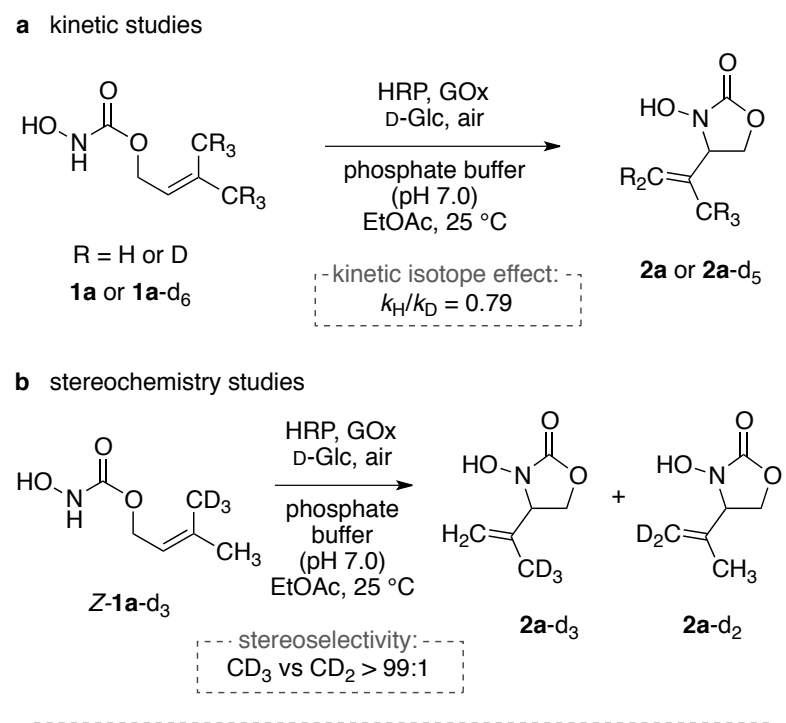

c mechanistic rational for the observed bifurcation

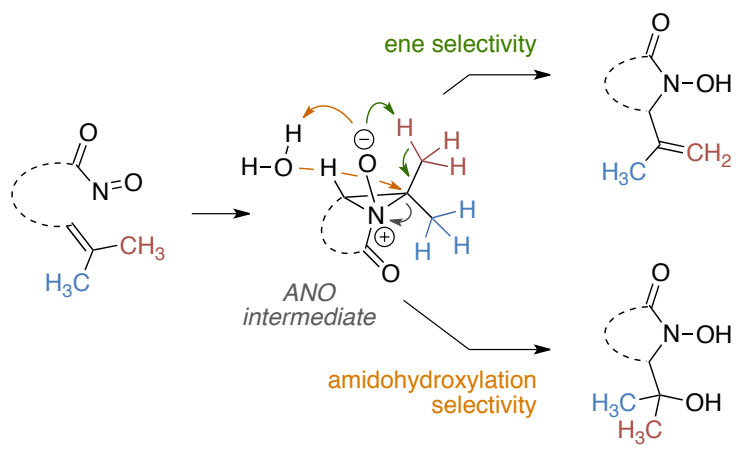

Scheme 6. The HRP-mediated cyclization of isotopomers of 1a provides hints on the underlying reaction pathway of aqueous nitroso ene reactions.

Combining the different findings - the inverse KIE, the stereospecificity and the unexpected formation of amidohydroxylation product $\mathbf{7}$ - the previously proposed aziridine $N$-oxide as relevant reaction intermediate seems plausible providing a rational for both the unusual limitation to $E$-configured olefins and the bifurcation via water addition to the electrophilic aziridinium species (Scheme 6c).

To conclude, a very mild $C-N$ bond-forming method based on a nitroso ene pathway was developed, utilizing a robust and reliable enzymatic couple consisting of horseradish peroxidase and glucose oxidase. As another important example for catalytic promiscuity, the biocatalytic protocol generates and transforms reactive acylnitroso intermediates in a highly selective manner, allowing both intra- and intermolecular aminations to take place with high yields in an aqueous medium. Our study further revealed that also certain laccases provide the necessary redox profile and protective environment to conduct nitroso ene-type transformations and offers a first blueprint for the engineering of enantioselective versions of this reaction. In addition to the promising starting point for stereochemical optimizations, the observation of side reactivities such as [4+2] cycloadditions and oxidative 1,2amidohydroxylations underline the yet untapped potential of this unprecedented biocatalytic activation pathway that will be addressed in much more detail in our future investigations.

\section{Acknowledgements}

We gratefully acknowledge financial support by the European Research Council (865885) and the Academy of Finland (298250 \& 324976). CJ thanks the Aalto School of Chemical Technology, as well as the Finnish Foundation for Technology Promotion and the Orion Research Foundation sr for personal grants.

\section{Keywords}

biocatalysis $\bullet$ ene reaction $\bullet$ heterocycles $\bullet$ amination $\bullet$ cyclization

\section{References}

[1] a) T. Knaus, W. Böhmer, F. G. Mutti, Green Chem. 2017, 19, 453-463; b) J. H. Schrittwieser, S. Velikogne, W. Kroutil, $A d v$. Synth. Catal. 2015, 357, 1655-1685; c) F. Guo, P. Berglund, Green Chem. 2017, 19, 333-360; d) I. Slabu, J. L. Galman, R. C. Lloyd, N. J. Turner, ACS Catal. 2017, 7, 8263-8284.

[2] a) P. N. Devine, R. M. Howard, R. Kumar, M. P. Thompson, M. D. Truppo, N. J. Turner, Nat. Rev. Chem. 2018, 2, 409-421; b) J. B. Siegel, A. Zanghellini, H. M. Lowick, G. Kiss, A. R. Lambert, J. L. St. Clair, J. L. Gallaher, D. Hilvert, M. H. Gelb, B. L. Stoddard, K. N. Houk, F. E. Michael, D. Baker, Science 2010, 329, 309313; c) P. S. Coelho, E. M. Brustad, A. Kannan, F. H. Arnold, Science 2013, 339, 307-310; d) S. B. J. Kan, R. D. Lewis, K. Chen, F. H. Arnold, Science 2016, 354, 1048-1051; e) Y.-C. Liu, C. Merten, J. Deska, Angew. Chem. Int. Ed. 2018, 57, 1215112156.

[3] a) N. W. Goldberg, A. M. Knight, R. K. Zhang, F. H. Arnold, J. Am. Chem. Soc. 2019, 141, 19585-19588; b) M. A. Vila, V. Steck, S. Rodriguez Giordano, I. Carrera, R. Fasan, ChemBioChem 2020, 21, 1981-1987.

[4] R. E. Banks, M. G. Barlow, R. N. Hazeldine, J. Chem. Soc. 1965, 4714-4718.

[5] a) W. Adam, O. Krebs, Chem. Rev. 2003, 103, 4131-4146; b) M. Baidya, H. Yamamoto, Synlett 2013, 45, 1931-1938; c) G. E. Keck, R. R. Webb, J. Am. Chem. Soc. 1981, 103, 3173-3177; d) J. Ouyang, X. Mi, Y. Wang, R. Hong, Synlett 2017, 28, 762772.

[6] a) E. Bamberger, R. Hübner, Ber. Dtsch. Chem. Ges. 1903, 36, 3803-3822; b) B. G. Gowenlock, G. B. Richter-Addo, Chem. Rev. 2004, 104, 3315-3340.

[7] M. Johannsen, K. A. Jørgensen, Chem. Rev. 1998, 98, $1689-1708$

[8] G. E. Keck, R. R. Webb, J. B. Yates, Tetrahedron 1981, 37, 4007-4016. 
[9] a) P. Quadrelli, M. Mella, P. Caramella. Tetrahedron Lett. 2000, 41, 2019-2022.

[10] S. Uraoka, I. Shinohara, H. Shimizu, K. Noguchi, A. Yoshimura, V. V. Zhdankin, A. Saito, Eur. J. Org. Chem. 2018, 6199-6203.

[11] W. Adam, N. Bottke, O. Krebs, C. R. Saha-Möller, Eur. J. Org. Chem. 1999, 1963-1965.

[12] P. Quadrelli, A. Gamba Invernizzi, P. Caramella, Tetrahedron Lett. 1996, 37, 1909-1912.

[13] L. Zhai, X. Tian, C. Wang, Q. Cui, S.-H. Huang, Z.-X. Yu, R. Hong, Angew. Chem. Int. Ed. 2017, 56, 11599-11603;

[14] a) A. Fakhruddin, S. Iwasa, H. Nishiyama, K. Tsutsumi, Tetrahedron Lett. 2004, 45, 9323-9326; b) P. E. O'Bannon, W. P. Dailey, Tetrahedron Lett. 1988, 29, 5719-5722; c) S. Liebeskind, K. B. Sharpless, R. D. Wilson, J. Am. Chem. Soc. 1978, 100, 7061-7063; d) F. Ragaini, S. Cenini, D. Brignoli, M. Gasperini, E. Galllo, Org. Chem. 2003, 68, 460-466; e) M. A. ElAtawy, D. Formenti, F. Ferretti, F. Ragaini, ChemCatChem 2018, 10, 4707-4717.

[15] a) R. Liu, S. R. Herron, S. A. Fleming, J. Org. Chem. 2007, 72, 5587-5591; b) J. Zhang, S. T. Kohlbouni, B. Borhan, Org. Lett. 2019, 21, 14-17; c) C. P. Frazier, J. R. Engelking, J. Read de Alaniz, J. Am. Chem. Soc. 2011, 133, 10430-10433; d) D. J. Fisher, G. L. Burnett, R. Velasco, J. Read de Alaniz, J. Am. Chem. Soc. 2015, 137, 11614-11617.

[16] D. Atkinson, M. A. Kabeshov, M. Edgar, A. V. Malkov, Adv. Synth. Catal. 2011, 353, 3347-3351.

[17] a) B. Maji, H. Yamamoto, J. Am. Chem. Soc. 2015, 137, 1595715963; b) C. K. Jana, A. Studer, Chem. Eur. J. 2008, 14, 63266328.
[18] Y. Liu, Z. Ruan, Y. Wang, S.-H. Huang, R. Hong, Tetrahedron 2019, 75, 1767.

[19] a) D. Thiel, D. Doknić, J. Deska, Nat. Commun. 2014, 5, 5278; b) D. Thiel, F. Blume, C. Jäger, J. Deska, Eur.J. Org. Chem. 2018, 20, 2717-2725; c) J. Naapuri, J. D. Rolfes, J. Keil, C. Manzuna Sapu, J. Deska, Green Chem. 2017, 19, 447-452.

[20] E. Maimon, A. Lerner, A. Samuni, S. Goldstein, J. Phys. Chem. A 2018, 122, 7006-7013.

[21] M. Bruncko, G. Schlingloff, K. B. Sharpless, Angew. Chem. Int. Ed. 1997, 36, 1483-1486.

[22] G. T. Knight, M. J. R. Loadman, J. Chem. Soc. B 1971, 21072112.

[23] a) A. G. Leach, K. N. Houk, J. Am. Chem. Soc. 2002, 124, 14820 14821; b) A. G. Leach, K. N. Houk, Chem. Commun. 2002, 1243-255; c) A. G. Leach, K. N. Houk, Org. Biomol. Chem. 2003, 1,1389-1403.

[24] X. Lu, Org. Lett. 2014, 6, 2813-2815.

[25] a) C. A. Seymour, F. D. Greene, J. Org. Chem. 1982, 47, 52265227; b) W. Adam, N. Bottke, B. Engels, O. Krebs, J. Am. Chem. Soc. 2001, 123, 5542-5548; c) W. Adam, O. Krebs, M. Orfanopoulos, M. Stratakis, G. C. Vougioukalakis, J. Org. Chem. 2003, 68, 2420-2425.

[26] M. G. Memeo, C. Re, F. Aimone, P. Quadrelli, ACS Omega 2018 , 3, 682-690.

[27] a) G. Vassilikogiannakis, M. Stratakis, M. Orfanopoulos, Org. Lett. 2000, 2, 2245-2248. b) G. C. Vougioukalakis, M. Orfanopoulos, Synlett 2005, 5, 713-731. 
Electronic Supporting Information

\title{
Enzymatic C-N Bond Formation via Aerobic Nitroso Ene Reactions
}

\author{
Christina Jäger, Jan Deska*
}

\begin{abstract}
A novel biocatalytic protocol enables the direct and selective introduction of nitrogen functionalities via activation of allylic $\mathrm{C}-\mathrm{H}$ bonds. Utilizing an oxidase/peroxidase couple for the formal dehydrogenation of $\mathrm{N}$-hydroxycarbamates and hydroxamic acids with air as terminal oxidant, acylnitroso species are generated under particularly mild aqueous conditions. The reactive intermediates undergo $\mathrm{C}-\mathrm{N}$ bond formation through an ene-type mechanism and provide high yields both in intramolecular and intermolecular enzymatic aminations. Investigations on alternative reaction pathways and labelling studies provide more insights into this unprecedented biocatalytic promiscuity of classical oxidoreductases as catalysts for nitroso ene-based transformations.
\end{abstract}




\section{Table of Contents}

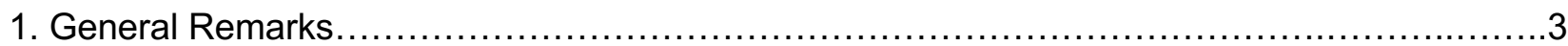

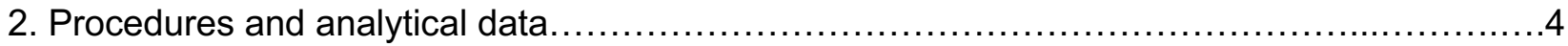

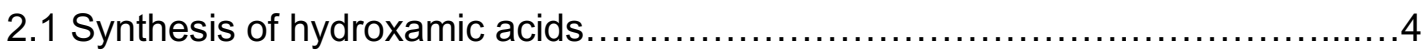

2.2 Enzymatic intramolecular nitroso ene reactions using GOx/HRP $\ldots \ldots \ldots \ldots \ldots \ldots 14$

2.3 Enzymatic intramolecular nitroso-Diels-Alder reactions using GOx/HRP.........19

2.4 Enzymatic intermolecular nitroso ene reactions using GOx/HRP ...............19

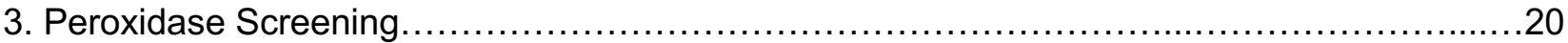

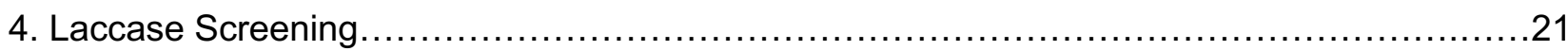

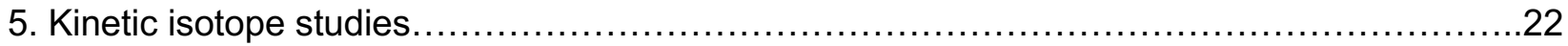

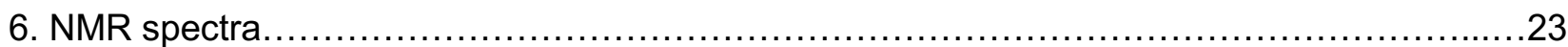

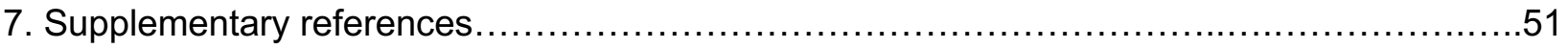




\section{General Remarks}

Commercially available reagents were used without further purification. Acetone- $d 6$ was purchased from eurisotop. Glucose oxidase (type II, Aspergillus niger), horseradish peroxidase, chloroperoxidase (Caldariomyces fumago), bovine lactoperoxidase and all laccases were purchased from Sigma Aldrich.

All reactions were carried out under argon atmosphere if not stated different and performed with dry solvents. Solvents were dried with the help of a solvent drying system MB-SPS-800 from M. Braun. All enzymatic reactions were carried out under non-inert conditions.

Silica gel from Merck (Millipore 60, 40-60 $\mu \mathrm{m}, 240-400$ mesh) was used for column chromatography and silica pad filtrations. Reactions were monitored via thin layer chromatography (TLC) using precoated silica gel plates from Machery-Nagel (TLC Silica gel $60 \mathrm{~F}_{254}$ ). The spots were identified using irradiation with UV light and a staining solution (basic potassium permanganate solution).

${ }^{1} \mathrm{H}$ - and ${ }^{13} \mathrm{C}-\mathrm{NMR}$ sprecta were measured with a Bruker Avance NEO 400 at $20{ }^{\circ} \mathrm{C}$. The chemical shifts are reported in ppm related to the signal of residual solvent of $\mathrm{CDCl}_{3}\left({ }^{1} \mathrm{H}:\left(\mathrm{CDCl}_{3}\right)=7.26 \mathrm{ppm},{ }^{13} \mathrm{C}\right.$ : $\left.\left(\mathrm{CDCl}_{3}\right)=77.2 \mathrm{ppm}\right)$. Infrared spectra were recorded on a Bruker Alpha Eco ATR FTIR device. High resolution mass spectrometry was performed on an Agilent 6530 QTOF spectrometer. Melting points were measured on a Bibby Scientific Stuart melting point SMP30 with an error of $\pm 0.5^{\circ} \mathrm{C}$. Melting points were determined by three different measurements for one substance obtaining the temperature of the melting start and the fully melted state. The median of these two temperatures is considered to be the melting point. The average of the three measured melting points is the one reported in this supporting information. 


\section{Procedures and Analytical Data}

\subsection{Synthesis of hydroxamic acids}

Representative general procedure: To a $0.2 \mathrm{M}$ solution of alcohol (1.0 eq.) in dry acetonitrile was added carbonyl diimidazole (CDI) (1.5 eq.) under argon atmosphere. After full conversion of the alcohol (followed by TLC) imidazole (4.0 eq) and hydroxylamine hydrochloride (5.0 eq.) were added. After observing full conversion of the intermediate, the solvent was removed under reduced pressure. The resulted solid was dissolved in EtOAc and $1 \mathrm{M} \mathrm{HCl}$ solution. The phases were separated and the aqueous phase was washed $3 x$ with EtOAc. The combined organic phases were dried over $\mathrm{Na}_{2} \mathrm{SO}_{4}$, filtered and the solvent was removed under reduced pressure. The crude was purified via flash column chromatography on silica gel..$^{[1]}$

\section{3-methylbut-2-en-1-yl N-hydroxycarbamate (1a)}<smiles>CC(C)=CCOC(=O)NO</smiles>

According to the representative general procedure, 3-methylbut-2-en-1-ol (1.2 mL, $1.03 \mathrm{~g}, 11.98 \mathrm{mmol})$ was reacted. The crude was purified via column chromatography on silica gel $\left(4: 1 n\right.$-Hep/EtOAc; $R_{f}=$ 0.32 (3:2 $n$-Hep/EtOAc)) to yield $1 \mathrm{a}$ as a colorless oil $(1.62 \mathrm{~g}, 11.18 \mathrm{mmol}, 145.16 \mathrm{~g} / \mathrm{mol}, 93 \%)$. Spectral data are in agreement with literature precedent. ${ }^{[1]}$

${ }^{1} \mathrm{H}-\mathrm{NMR}\left(400 \mathrm{MHz}, \mathrm{CDCl}_{3}\right) \delta[\mathrm{ppm}]=7.23(\mathrm{~s}, 1 \mathrm{H},-\mathrm{NH}-), 6.85(\mathrm{bs}, 1 \mathrm{H},-\mathrm{OH}), 5.41-5.27(\mathrm{~m}, 1 \mathrm{H}), 4.65(\mathrm{~d}$, $J=7.3 \mathrm{~Hz}, 2 \mathrm{H}), 1.76(\mathrm{~d}, J=0.8 \mathrm{~Hz}, 3 \mathrm{H}), 1.71(\mathrm{~d}, J=0.9 \mathrm{~Hz}, 3 \mathrm{H}) \cdot{ }^{13} \mathrm{C}-\mathrm{NMR}\left(100 \mathrm{MHz}, \mathrm{CDCl}_{3}\right) \delta[\mathrm{ppm}]=$

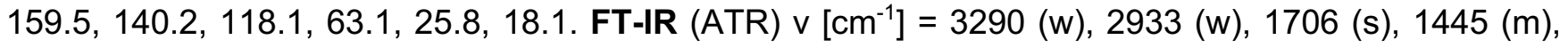
$1259(\mathrm{~m}), 1101$ (s).

\section{3-(methyl-d $\left.d_{3}\right)-4,4,4-d_{3}-$ but-2-en-1-yl N-hydroxycarbamate (1a-d $\left.d_{6}\right)$}

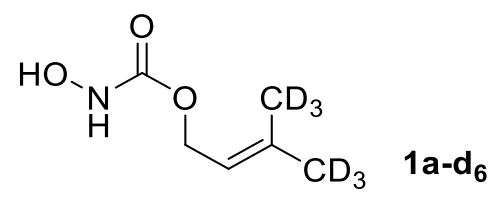

Step 1/3: To a solution of triethyl phosphonoacetate $(4.1 \mathrm{~mL}, 20.4 \mathrm{mmol}, 1.5$ eq.) in $35 \mathrm{~mL}$ THF was added $n$-BuLi $\left(7.6 \mathrm{~mL}, 1.4 \mathrm{eq}, 2.5 \mathrm{M}\right.$ in hexanes) at $0{ }^{\circ} \mathrm{C}$. After full addition, the reaction mixture was allowed to warm to room temperature. After $30 \mathrm{~min}$ acetone- $d 6(1 \mathrm{~mL}, 13.6 \mathrm{mmol}, 1.0$ eq.) was added. After $5 \mathrm{~h}$, the reaction was quenched with saturated $\mathrm{NH}_{4} \mathrm{Cl}$ solution. The aqueous phase was extracted $3 \mathrm{x}$ with $\mathrm{Et}_{2} \mathrm{O}$. The combined organic phases were washed with brine, dried over $\mathrm{Na}_{2} \mathrm{SO}_{4}$, filtered and the solvent was removed under reduced pressure. The crude was purified via column chromatography on silica gel $\left(2: 1 \mathrm{n}\right.$-Pen/Et $\left.\mathrm{t}_{2} \mathrm{O}\right)$ to yield ethyl 3-(methyl- $\left.\mathrm{d}_{3}\right)-4,4,4-\mathrm{d}_{3}$-but-2-enoate $(1.54 \mathrm{~g}, 11.5 \mathrm{mmol}$, $134.21 \mathrm{~g} / \mathrm{mol}, 85 \%)$ Spectral data are in agreement with literature precedent. ${ }^{[8]}$

${ }^{1} \mathrm{H}-\mathrm{NMR}\left(400 \mathrm{MHz}, \mathrm{CDCl}_{3}\right): \delta[\mathrm{ppm}]=5.67(\mathrm{~s}, 1 \mathrm{H}), 4.14(\mathrm{q}, \mathrm{J}=7.1 \mathrm{~Hz}, 2 \mathrm{H}), 1.27(\mathrm{t}, \mathrm{J}=7.1 \mathrm{~Hz}, 3 \mathrm{H})$.

Step 2/3: To a solution of 3-(methyl- $\left.\mathrm{d}_{3}\right)-4,4,4-\mathrm{d}_{3}$-but-2-enoate $(1.12 \mathrm{~g}, 8.9 \mathrm{mmol}, 1.0$ eq.) in $10 \mathrm{~mL} \mathrm{DCM}$ was added DIBAL-H (27 mL, 3.0 eq., $1 \mathrm{M}$ in $c-H e x)$ at $0{ }^{\circ} \mathrm{C}$. After $2 \mathrm{~h}$ the reaction was quenched with 
$\mathrm{MeOH}$. The mixture was poured to $30 \mathrm{~mL} \mathrm{Et}_{2} \mathrm{O}$ and $30 \mathrm{~mL}$ of $2 \mathrm{M} \mathrm{HCl}$ solution was added. The aqueous phase was extracted $3 \mathrm{x}$ with $\mathrm{Et}_{2} \mathrm{O}$. The combined organic layers were washed with $1 \mathrm{M} \mathrm{HCl}$ solution and $2 x$ with brine, dried over $\mathrm{Na}_{2} \mathrm{SO}_{4}$, filtered and the solvent was removed under reduced pressure. The crude was purified via bulb-to-bulb distillation to afford 3-(methyl- $\left.\mathrm{d}_{3}\right)-4,4,4-\mathrm{d}_{3}$-but-2-en-1-ol (450 mg, $4.9 \mathrm{mmol}, 92.17 \mathrm{~g} / \mathrm{mol}, 55 \%)$. Spectral data are in agreement with literature precedent. ${ }^{[9]}$

${ }^{1} \mathrm{H}-\mathrm{NMR}\left(400 \mathrm{MHz}, \mathrm{CDCl}_{3}\right): \delta[\mathrm{ppm}]=5.41(\mathrm{t}, J=7.1 \mathrm{~Hz}, 1 \mathrm{H}), 4.12(\mathrm{~d}, J=7.0 \mathrm{~Hz}, 2 \mathrm{H}), 1.21(\mathrm{~s}, 1 \mathrm{H},-$ $\mathrm{OH})$.

Step 3/3: According to the representative general procedure, 3-(methyl- $\left.\mathrm{d}_{3}\right)-4,4,4-\mathrm{d}_{3}$-but-2-en-1-ol (200 mg, $2.2 \mathrm{mmol})$ was reacted. The crude was purified via column chromatography on silica gel (2:1 $n$-Pen/Et ${ }_{2} \mathrm{O} ; \mathrm{R}_{\mathrm{f}}=0.15(2: 1 \mathrm{n}$-Hep/EtOAc $\left.)\right)$ to yield $1 \mathrm{a}-\mathrm{d}_{6}$ as a colorless oil $(151.2 \mathrm{mg}, 1.5 \mathrm{mmol}$, $229.4 \mathrm{~g} / \mathrm{mol}, 69 \%, D_{6} \geq 99 \%$ ).

${ }^{1} \mathrm{H}-\mathrm{NMR}\left(400 \mathrm{MHz}, \mathrm{CDCl}_{3}\right): \delta[\mathrm{ppm}]=7.26(\mathrm{~s}, 1 \mathrm{H},-\mathrm{NH}-), 7.06(\mathrm{~s}, 1 \mathrm{H},-\mathrm{OH}), 5.34(\mathrm{t}, J=7.3 \mathrm{~Hz}, 1 \mathrm{H}), 4.65$

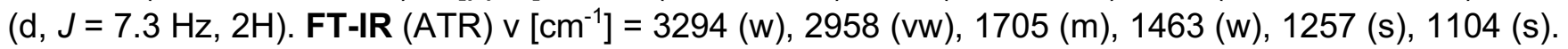
HRMS (ESI): $\mathrm{m} / \mathrm{z}\left[\mathrm{M}+\mathrm{Na}^{+}\right]$calcd for $\mathrm{C}_{6} \mathrm{H}_{5} \mathrm{D}_{6} \mathrm{NO}_{3}:$ 174.1008; found: 174.1014.

\section{E-3-methyl-4,4,4-d ${ }_{3}-$ but-2-en-1-yl N-hydroxycarbamate $\left(E-1 a-d_{3}\right)$}<smiles>CCCCC(C)(C)C#CCOC(=O)NO</smiles>

Step 1/4: To a solution of thiophenol (1.7 g, $15.44 \mathrm{mmol}, 1.2$ eq.) in $30 \mathrm{~mL}$ EtOH was added $\mathrm{NaOH}$ (618 mg, $15.44 \mathrm{mmol}, 1.2 \mathrm{eq}$.). After stirring for $30 \mathrm{~min}$ at room temperature, ethyl but-2-ynoate $(1.5 \mathrm{~mL}$, $12.87 \mathrm{mmol}, 1.0$ eq.) in $5 \mathrm{~mL}$ EtOH was added. After $4 \mathrm{~h}$ the reaction was slightly acidified with diluted acetic acid. The aqueous phase was extracted $3 \mathrm{x}$ with $\mathrm{Et}_{2} \mathrm{O}$ and the combined organic phases were washed with $4 \% \mathrm{NaOH}$ solution, $\mathrm{H}_{2} \mathrm{O}$, brine and dried over $\mathrm{Na}_{2} \mathrm{SO}_{4}$, filtered and the solvent was removed under reduced pressure. The crude was purified via column chromatography $\left(n\right.$-Hep/EtOAc 30:1; $R_{f}=$ $0.54 \& 0.44(6: 1 \mathrm{n}$-Hep/EtOAc)) to yield and separate ethyl Z-3-(phenylthio)but-2-enoate (460 mg, $2.07 \mathrm{mmol}, 222.3 \mathrm{~g} / \mathrm{mol} 16 \%$ ) and ethyl E-3-(phenylthio)but-2-enoate $(1.88 \mathrm{~g}, 8.47 \mathrm{mmol}, 222.3 \mathrm{~g} / \mathrm{mol}$ $66 \%$ ). Spectral data are in agreement with literature precedent. ${ }^{[18]}$

E-Isomer: ${ }^{1} \mathrm{H}-\mathrm{NMR}\left(400 \mathrm{MHz}, \mathrm{CDCl}_{3}\right)$ : $\delta$ [ppm] = 7.45-7.41 (m, 2H), 7.39-7.34 (m, 3H), $5.19(\mathrm{~d}$, $J=1.1 \mathrm{~Hz}, 1 \mathrm{H}), 4.02(\mathrm{q}, J=7.1 \mathrm{~Hz}, 2 \mathrm{H}), 2.37(\mathrm{~d}, J=1.1 \mathrm{~Hz}, 3 \mathrm{H}), 1.15(\mathrm{t}, J=7.1 \mathrm{~Hz}, 3 \mathrm{H}) .{ }^{13} \mathrm{C}-$ $\operatorname{NMR}\left(100 \mathrm{MHz}, \mathrm{CDCl}_{3}\right): \delta[\mathrm{ppm}]=165.6,159.8,135.6,130.0,129.9,111.1,59.7,20.2,14.4$.

Z-Isomer: ${ }^{1} \mathrm{H}-\mathrm{NMR}\left(400 \mathrm{MHz}, \mathrm{CDCl}_{3}\right): \delta[\mathrm{ppm}]=7.57-7.48(\mathrm{~m}, 2 \mathrm{H},-\mathrm{Ph}), 7.45-7.32(\mathrm{~m}, 3 \mathrm{H},-\mathrm{Ph})$, $5.85(\mathrm{~d}, J=1.1 \mathrm{~Hz}, 1 \mathrm{H}, \mathrm{H}-2), 4.22(\mathrm{q}, J=7.1 \mathrm{~Hz}, 2 \mathrm{H}, \mathrm{H}-5), 1.81$ (d, $J=1.1 \mathrm{~Hz}, 3 \mathrm{H}, \mathrm{H}-4), 1.30$ $(\mathrm{t}, J=7.1 \mathrm{~Hz}, 3 \mathrm{H}, \mathrm{H}-6) .{ }^{13} \mathrm{C}-\mathrm{NMR}\left(100 \mathrm{MHz} \mathrm{CDCl}_{3}\right)$ : $\delta[\mathrm{ppm}]=166.3,158.3,136.1,130.9,129.5$, $129.1,111.9,59.9,25.1,14.4$.

Step 2/4: Cul (648 mg, $3.4 \mathrm{mmol}, 2.0$ eq.) was dispensed in $18 \mathrm{~mL}$ THF. $\mathrm{CD}_{3} \mathrm{Mgl}$ (9 mL, 5.0 eq., $1 \mathrm{M}$ in $\mathrm{Et}_{2} \mathrm{O}$ ) was slowly added at $-78{ }^{\circ} \mathrm{C}$ and the reaction mixture was stirred for $15 \mathrm{~min}$ at that temperature. Ethyl E-3-(phenylthio)but-2-enoate ( $400 \mathrm{mg}, 1.8 \mathrm{mmol}, 1.0$ eq.) in $9 \mathrm{~mL}$ THF was slowly added at $-78{ }^{\circ} \mathrm{C}$. The reaction mixture was stirred for $8 \mathrm{~h}$ at the same temperature and was then quenched with saturated $\mathrm{NH}_{4} \mathrm{Cl}$ solution at $0{ }^{\circ} \mathrm{C}$. The aqueous phase was extracted $2 \mathrm{x}$ with $\mathrm{Et}_{2} \mathrm{O}$. The combined organic phases 
were washed with $5 \% \mathrm{NaOH}$ solution, $\mathrm{H}_{2} \mathrm{O}$, brine and dried over $\mathrm{Na}_{2} \mathrm{SO}_{4}$, filtered and the solvent was removed under reduced pressure ( $\max .350 \mathrm{mbar}$ at $30{ }^{\circ} \mathrm{C}$ ). The crude was purified via column chromatography ( $n$-Pen/Et ${ }_{2} \mathrm{O} 30: 1 ; \mathrm{R}_{\mathrm{f}}=0.76\left(2: 1 n\right.$-Hep/EtOAc)) to yield ethyl $E$-3-methyl-4,4,4- $\mathrm{d}_{3}$-but2-enoate in residual $\mathrm{Et}_{2} \mathrm{O}$. Spectral data are in agreement with literature precedent. ${ }^{[18]}$

${ }^{1} \mathrm{H}-\mathrm{NMR}\left(400 \mathrm{MHz}, \mathrm{CDCl}_{3}\right): \delta[\mathrm{ppm}]=5.66(\mathrm{~d}, J=1.0 \mathrm{~Hz}, 1 \mathrm{H}), 4.13(\mathrm{q}, J=7.1 \mathrm{~Hz}, 2 \mathrm{H}), 2.15(\mathrm{~d}, J=1.2$ $\mathrm{Hz}, 3 \mathrm{H}), 1.26(\mathrm{t}, J=7.1 \mathrm{~Hz}, 3 \mathrm{H})$.

Step 3/4: To a solution of the obtained ethyl E-3-methyl-4,4,4- $\mathrm{d}_{3}$-but-2-enoate in residual $E \mathrm{t}_{2} \mathrm{O}$ and $1 \mathrm{~mL}$ DCM was added DIBAL-H (3.2 mL, 3.0 eq., $1 \mathrm{M}$ in $c$-Hex) at $0{ }^{\circ} \mathrm{C}$. After full coversion (followed by TLC), the reaction was quenched with $\mathrm{MeOH}$ followed by $1 \mathrm{M} \mathrm{HCl}$. The aqueous phase was extracted $2 \mathrm{x}$ with $\mathrm{Et}_{2} \mathrm{O}$. The combined organic phases were washd with brine, dried over $\mathrm{Na}_{2} \mathrm{SO}_{4}$, filtered and the solvent was removed under reduced pressure (volatile!). The crude was purified via bulb to bulb destillation to yield $E$-3-methylbut-2-en-4,4,4- $\mathrm{d}_{3}-1-\mathrm{ol}$ in residual $\mathrm{Et}_{2} \mathrm{O}$. Spectral data are in agreement with literature precedent. $^{[18]}$

${ }^{1} \mathrm{H}-\mathrm{NMR}\left(400 \mathrm{MHz}, \mathrm{CDCl}_{3}\right): \delta[\mathrm{ppm}]=5.41(\mathrm{td}, J=7.1,1.3 \mathrm{~Hz}, 1 \mathrm{H}), 4.13(\mathrm{~d}, J=7.1 \mathrm{~Hz}, 2 \mathrm{H}), 1.68(\mathrm{~s}$, $3 \mathrm{H})$.

Step 4/4: According to the representative general procedure, E-3-methylbut-2-en-4,4,4-d $\mathrm{d}_{3}-1$-ol in residual $\mathrm{Et}_{2} \mathrm{O}$ was reacted. The crude was purified via column chromatography on silica gel (3:1 $n$-Hep/EtOAc; $\mathrm{R}_{\mathrm{f}}=0.21(2: 1 \mathrm{n}$-Hep/EtOAc) $)$ to yield $E-1 \mathrm{a}-\mathrm{d}_{3}$ as a colorless oil $(49 \mathrm{mg}, 10.33 \mathrm{mmol}, 148.18 \mathrm{~g} / \mathrm{mol}, 18 \%$ over 3 steps, $D_{3} \geq 95 \%$ ).

${ }^{1} \mathrm{H}-\mathrm{NMR}\left(400 \mathrm{MHz}, \mathrm{CDCl}_{3}\right): \delta[\mathrm{ppm}]=7.18(\mathrm{~s}, 1 \mathrm{H}), 6.58(\mathrm{~s}, 1 \mathrm{H}), 5.35(\mathrm{td}, J=7.3,1.2 \mathrm{~Hz}, 1 \mathrm{H}), 4.66(\mathrm{~d}, J$ = 7.3 Hz, 2H), $1.72(\mathrm{~d}, J=0.7 \mathrm{~Hz}, 3 \mathrm{H})$. FT-IR (ATR) $\vee\left[\mathrm{cm}^{-1}\right]=3295(\mathrm{w}), 2917(\mathrm{vw}), 1705(\mathrm{~m}), 1456(\mathrm{w})$, $1257(\mathrm{~m}), 1102$ (s). HRMS (ESI): m/z [M+H'] calcd for $\mathrm{C}_{6} \mathrm{H}_{8} \mathrm{D}_{3} \mathrm{NO}_{3}$ : 149.1000; found: 149.1007.

\section{Z-3-methyl-4,4,4-d ${ }_{3}$-but-2-en-1-yl N-hydroxycarbamate $\left(Z-1 a-d_{3}\right)$}<smiles>[Z16][14C](C)([14CH3])/C=C\COC(=O)NO</smiles>

Z-3-methylbut-2-en-4,4,4-d 3 -1-ol was synthesized from ethyl Z-3-(phenylthio)but-2-enoate like described before. ${ }^{[18]}$ According to the representative general procedure, Z-3-methylbut-2-en-4,4,4- $d_{3}-1-0$ in residual $\mathrm{Et}_{2} \mathrm{O}$ was reacted. The crude was purified via column chromatography on silica gel $(3: 1 \mathrm{n}$ Hep/EtOAc; $R_{f}=0.37\left(1: 1 n\right.$-Hep/EtOAc)) to yield $1 \mathrm{a}-Z-\mathbf{d}_{3}$ as a colorless oil $(75 \mathrm{mg}, 0.5 \mathrm{mmol}$, $148.18 \mathrm{~g} / \mathrm{mol}, 28 \%$ over 3 steps, $D_{3} \geq 95 \%$ ).

${ }^{1} \mathrm{H}-\mathrm{NMR}\left(400 \mathrm{MHz}, \mathrm{CDCl}_{3}\right): \delta[\mathrm{ppm}]=7.21(\mathrm{~s}, 1 \mathrm{H}), 6.73(\mathrm{~s}, 1 \mathrm{H}), 5.35(\mathrm{t}, J=7.3 \mathrm{~Hz}, 1 \mathrm{H}), 4.65(\mathrm{dd}, J=$ 7.3, 0.7 Hz, 2H), $1.76(\mathrm{~s}, 3 \mathrm{H})$. FT-IR (ATR) v [ $\left.\mathrm{cm}^{-1}\right]=3298(\mathrm{w}), 2915(\mathrm{vw}), 1705(\mathrm{~m}), 1445(\mathrm{w}), 1289(\mathrm{~m})$, 1112 (s). HRMS (ESI): $\mathrm{m} / z$ [M+H $\mathrm{H}^{+}$calcd for $\mathrm{C}_{6} \mathrm{H}_{8} \mathrm{D}_{3} \mathrm{NO}_{3}$ : 149.1000; found: 149.0986 . 


\section{N-hydroxy-5-methylhex-4-enamide (1b)}<smiles>CC(C)=CCCC(=O)NO</smiles>

Methyl 5-methylhex-4-enoate was prepared from 2-methylbut-3-en-2-ol according to literature precedent. ${ }^{[17]}$ To $30 \mathrm{~mL}$ of a $2 \mathrm{M}$ solution of hydroxylamine hydrochloride in $\mathrm{MeOH}$ was added $30 \mathrm{~mL}$ of a $4 \mathrm{M}$ solution of $\mathrm{KOH}$ in $\mathrm{MeOH}$ at $0{ }^{\circ} \mathrm{C}$. The formed $\mathrm{KCl}$ was filtered off and the mixture was added to methyl 5-methylhex-4-enoate $(1.0 \mathrm{~g}, 7.03 \mathrm{mmol})$ and adjusted to $\mathrm{pH} 10.0$ using a solution of $\mathrm{KOH}$ in $\mathrm{MeOH}$. The reaction mixture was stirred for $4 \mathrm{~h}$ and then adjusted to $\mathrm{pH} 5.0$ with a $5 \mathrm{M} \mathrm{HCl}$ solution. The solvent was removed under reduced pressure and the resulting solid was dissolved in $\mathrm{MeOH}$. Remaining insoluble solid was removed via filtration. The solvent was again removed under reduced pressure. This step was repeated with DCM. The crude was purified via column chromatography $(\mathrm{DCM}+4 \% \mathrm{MeOH}$; $\left.\mathrm{R}_{\mathrm{f}}=0.28(\mathrm{DCM}+3 \% \mathrm{MeOH})\right)$ to yield $\mathbf{1 b}$ as a white solid $(338.3 \mathrm{mg}, 2.36 \mathrm{mmol}, 143.19 \mathrm{~g} / \mathrm{mol}, 34 \%)$. Spectral data are in agreement with literature precedent. ${ }^{[4]}$

${ }^{1} \mathrm{H}-\mathrm{NMR}\left(400 \mathrm{MHz}, \mathrm{CDCl}_{3}\right): \delta[\mathrm{ppm}]=8.54(\mathrm{bs}, 2 \mathrm{H},-\mathrm{NH}-,-\mathrm{OH}), 5.06(\mathrm{t}, J=6.7 \mathrm{~Hz}, 1 \mathrm{H}), 2.32(\mathrm{q}, J=7.0$ $\mathrm{Hz}, 2 \mathrm{H}), 2.18(\mathrm{t}, J=7.2 \mathrm{~Hz}, 2 \mathrm{H}), 1.69(\mathrm{~s}, 3 \mathrm{H}), 1.61(\mathrm{~s}, 3 \mathrm{H}) .{ }^{13} \mathrm{C}-\mathrm{NMR}\left(100 \mathrm{MHz}, \mathrm{CDCl}_{3}\right): \delta[\mathrm{ppm}]=171.3$, 134.1, 121.9, 33.2, 25.7, 23.8, 17.7. FT-IR (ATR) v [ $\left.\mathrm{cm}^{-1}\right]=3200(\mathrm{~m}), 2910$ (m), 1624 (vs), 1539 (s), 1067 (s). Melting point: $59.8^{\circ} \mathrm{C}$.

\section{E-but-2-en-1-yl N-hydroxycarbamate (1c)}<smiles>C/C=C\COC(=O)NO</smiles>

According to the representative general procedure, crotyl alcohol $(0.5 \mathrm{ml}, 5.9 \mathrm{mmol})$ was reacted. The crude was purified via column chromatography on silica gel $\left(n\right.$-Hep/EtOAc $4: 1 ; R_{f}=0.26(2: 1 n$ Hep/EtOAc)) to yield 1c as a colorless oil (49.8 mg, $0.37 \mathrm{mmol}, 131.13 \mathrm{~g} / \mathrm{mol}, 6 \%$ ). Spectral data are in agreement with literature precedent. ${ }^{[2]}$

${ }^{1} \mathrm{H}-\mathrm{NMR}\left(400 \mathrm{MHz}, \mathrm{CDCl}_{3}\right): \delta[\mathrm{ppm}]=7.23(\mathrm{~s}, 1 \mathrm{H},-\mathrm{NH}-), 6.72(\mathrm{bs}, 1 \mathrm{H},-\mathrm{OH}), 5.90-5.76(\mathrm{~m}, 1 \mathrm{H}), 5.65-$ $5.51(\mathrm{~m}, 1 \mathrm{H}), 4.58(\mathrm{~d}, J=6.6 \mathrm{~Hz}, 2 \mathrm{H}), 1.72(\mathrm{dd}, J=6.6,1.3 \mathrm{~Hz}, 3 \mathrm{H}) .{ }^{13} \mathrm{C}-\mathrm{NMR}\left(100 \mathrm{MHz}, \mathrm{CDCl}_{3}\right): \delta$ $[\mathrm{ppm}]=132.4,124.6,66.9,17.8$. FT-IR $($ ATR $) \vee\left[\mathrm{cm}^{-1}\right]=3290(\mathrm{w}), 2945(\mathrm{vw}), 1705(\mathrm{~s}), 1449(\mathrm{~m}), 1260$ (m), 1105 (s).

\section{E-2-methylbut-2-en-1-yl N-hydroxycarbamate (1d)}<smiles>CC=C(C)COC(=O)NO</smiles>

Step 1/2: To a solution of E-2-methylbut-2-enal $(0.5 \mathrm{~mL}, 5.17 \mathrm{mmol})$ in $8 \mathrm{~mL} \mathrm{MeOH}$ was added $\mathrm{NaBH}_{4}$ (391 $\mathrm{mg}, 10.34 \mathrm{mmol}$ ) at $0{ }^{\circ} \mathrm{C}$. After $1 \mathrm{~h}$, the reaction mixture was quenched with water and extracted $2 \mathrm{x}$ with DCM. The combined organic phases were washed with brine, dried over $\mathrm{MgSO}_{4}$, filtered and the 
solvent was removed under reduced pressure. The crude was purified via bulb-to-bulb distillation to afford E-2-methylbut-2-en-1-ol (358 mg, $4.16 \mathrm{mmol}, 80 \%$ ).

${ }^{1} \mathrm{H}-\mathrm{NMR}\left(400 \mathrm{MHz}, \mathrm{CDCl}_{3}\right): \delta[\mathrm{ppm}]=5.57-5.40(\mathrm{~m}, 1 \mathrm{H}), 3.99(\mathrm{~d}, J=3.7 \mathrm{~Hz}, 2 \mathrm{H}), 1.67(\mathrm{~s}, 3 \mathrm{H}), 1.62$ (ddd, $J=6.7,2.1,1.0 \mathrm{~Hz}, 3 \mathrm{H}), 1.35$ (bs, $1 \mathrm{H},-\mathrm{OH}) .{ }^{13} \mathrm{C}-\mathrm{NMR}\left(100 \mathrm{MHz}, \mathrm{CDCl}_{3}\right): \delta[\mathrm{ppm}]=135.6,120.8$, $69.2,13.5,13.2$.

Step 2/2: According to the representative general procedure, E-2-methylbut-2-en-1-ol (200 mg, $2.3 \mathrm{mmol}$ ) was reacted. The crude was purified via column chromatography on silica gel ( $n$-Hep/EtOAc $4: 1 ; R_{\mathrm{f}}=0.21(2: 1 \mathrm{n}$-Hep/EtOAc) $)$ to yield $1 \mathrm{~d}$ as a colorless oil $(70.3 \mathrm{mg} \mathrm{g}, 0.48 \mathrm{mmol}, 145.16 \mathrm{~g} / \mathrm{mol}$, $21 \%)$.

${ }^{1} \mathrm{H}-\mathrm{NMR}\left(400 \mathrm{MHz}, \mathrm{CDCl}_{3}\right): \delta[\mathrm{ppm}]=7.31(\mathrm{~s}, 1 \mathrm{H},-\mathrm{NH}-), 7.09(\mathrm{bs}, 1 \mathrm{H},-\mathrm{OH}), 5.67-5.47(\mathrm{~m}, 1 \mathrm{H}), 4.53(\mathrm{~s}$, 2H), 1.64-1.62 (m, 6H). ${ }^{13} \mathrm{C}-\mathrm{NMR}\left(100 \mathrm{MHz}, \mathrm{CDCl}_{3}\right): \delta[\mathrm{ppm}]=159.5,130.4,125.0,72.1,13.5,13.3 . \mathrm{FT}-$

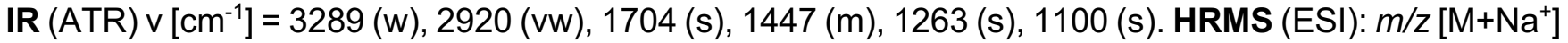
calcd for $\mathrm{C}_{6} \mathrm{H}_{11} \mathrm{NO}_{3}$ : 168.0631; found: 168.0634 .

\section{E-pent-3-en-2-yl N-hydroxycarbamate (1e)}<smiles>C/C=C/C(C)OC(=O)NO</smiles>

According to the representative general procedure, E-pent-3-en-2-ol (357 $\mathrm{mg}, 4.2 \mathrm{mmol}$ ) was reacted. The crude was purified via column chromatography on silica gel ( $n$-Hep/EtOAc $4: 1 ; R_{f}=0.16(2: 1 n$ Hep/EtOAc)) to yield $1 \mathrm{e}$ as a white solid (382 $\mathrm{mg} \mathrm{g}, 2.6 \mathrm{mmol}, 145.16 \mathrm{~g} / \mathrm{mol}, 63 \%)$. Spectral data are in agreement with literature precedent. ${ }^{[5]}$

${ }^{1} \mathrm{H}-\mathrm{NMR}\left(400 \mathrm{MHz}, \mathrm{CDCl}_{3}\right): \delta[\mathrm{ppm}]=7.11(\mathrm{~s}, 1 \mathrm{H},-\mathrm{NH}-), 6.43(\mathrm{~s}, 1 \mathrm{H},-\mathrm{OH}), 5.83-5.68(\mathrm{~m}, 1 \mathrm{H}), 5.47$ (dddd, $J=15.3,7.0,3.2,1.5 \mathrm{~Hz}, 1 \mathrm{H}), 5.29(\mathrm{p}, J=6.6 \mathrm{~Hz}, 1 \mathrm{H}), 1.69$ (d, $J=6.5 \mathrm{~Hz}, 3 \mathrm{H}), 1.32$ (d, $J=6.4$ $\mathrm{Hz}, 3 \mathrm{H}) .{ }^{13} \mathrm{C}-\mathrm{NMR}\left(100 \mathrm{MHz}, \mathrm{CDCl}_{3}\right): \delta[\mathrm{ppm}]=159.1,130.2,129.1,73.7,20.4,17.7$. FT-IR (ATR) v $\left[\mathrm{cm}^{-1}\right]=3343(\mathrm{w}), 3242(\mathrm{w}), 2982(\mathrm{vw}), 1697(\mathrm{~s}), 1505(\mathrm{~m}), 1276(\mathrm{~m}), 1114(\mathrm{~s})$. Melting point: $41.2^{\circ} \mathrm{C}$.

\section{2-cyclohexylideneethyl $\mathrm{N}$-hydroxycarbamate (1f)}<smiles>O=C(NO)OCC=C1CCCCC1</smiles>

$1 f$

Step 1/3: To a solution of cyclohexanone (3.24 g, $33.0 \mathrm{mmol}, 1.0 \mathrm{eq}$.) in $45 \mathrm{~mL}$ toluene was added Methyl (triphenylphosphoranylidene)acetate $(13.24 \mathrm{~g}, 39.6 \mathrm{mmol}, 1.2 \mathrm{eq}$.). The reaction mixture was stirred for $23 \mathrm{~h}$ at $110^{\circ} \mathrm{C}$. The solid was filtered off and washed with EtOAc. The solvent was removed under reduced pressure and the resulted solid was again filtered off and washed with EtOAc. The solvent was again removed under reduced pressure and the crude was purified via column chromatography (8:1 nHep/EtOAc $+3 \%$ TEA) to afford methyl 2-cyclohexylideneacetate as a yellow oil ( $2.15 \mathrm{~g}$, $14.0 \mathrm{mmol}, 42 \%)$. Spectral data are in agreement with literature precedent. ${ }^{[6]}$ 
${ }^{1} \mathrm{H}-\mathrm{NMR}\left(400 \mathrm{MHz}, \mathrm{CDCl}_{3}\right): \delta[\mathrm{ppm}]=5.67-5.53(\mathrm{~m}, 1 \mathrm{H}), 3.67(\mathrm{~s}, 2 \mathrm{H}), 2.82(\mathrm{~m}, 2 \mathrm{H}), 2.23-2.14(\mathrm{~m}, 2 \mathrm{H})$, 1.70-1.54 (m, 6H). ${ }^{13} \mathrm{C}-\mathrm{NMR}\left(100 \mathrm{MHz}, \mathrm{CDCl}_{3}\right): \delta[\mathrm{ppm}]=167.4,164.0,112.7,50.9,38.1,30.0,28.8$, 28.0, 26.4 .

Step 2/3: To a solution of 2-cyclohexylideneacetate $(2.11 \mathrm{~g}, 13.7 \mathrm{mmol}, 1.0$ eq.) in $56 \mathrm{~mL} \mathrm{DCM}$ was added DIBAL-H $(38.4 \mathrm{~mL}, 38.4 \mathrm{mmol}, 1 \mathrm{M}$ in $\mathrm{c}-\mathrm{Hex})$ at $-78^{\circ} \mathrm{C}$. The reaction mixture was allowed to warm to $0{ }^{\circ} \mathrm{C}$ after $3 \mathrm{~h}$. The reaction was quenched with water after $25 \mathrm{~h}$. The mixture was washed with $1 \mathrm{M}$ $\mathrm{HCl}$ solution. The aqueous phase was extracted $3 \mathrm{x}$ with DCM. The combined organic phases were dried over $\mathrm{Na}_{2} \mathrm{SO}_{4}$, filtered and the solvent was removed under reduced pressure. The crude was purified via silica pad filtration (2:1 $\mathrm{n}$-Hep/EtOAc) to afford 2-cyclohexylideneethan-1-ol as a colorless oil (1.57 g, $12.4 \mathrm{mmol}, 91 \%)$. Spectral data are in agreement with literature precedent. ${ }^{[7]}$

${ }^{1} \mathrm{H}-\mathrm{NMR}\left(400 \mathrm{MHz}, \mathrm{CDCl}_{3}\right): \delta[\mathrm{ppm}]=5.34(\mathrm{t}, J=7.1,1 \mathrm{H}), 4.12(\mathrm{~d}, J=7.1 \mathrm{~Hz}, 2 \mathrm{H}), 2.17(\mathrm{t}, J=5.6 \mathrm{~Hz}$, $2 \mathrm{H}), 2.10(\mathrm{t}, J=5.7 \mathrm{~Hz}, 2 \mathrm{H}), 1.47-1.57(\mathrm{~m}, 6 \mathrm{H}), 1.39(\mathrm{t}, J=6.2 \mathrm{~Hz}, 1 \mathrm{H}) .{ }^{13} \mathrm{C}-\mathrm{NMR}\left(100 \mathrm{MHz}, \mathrm{CDCl}_{3}\right): \delta$ $[\mathrm{ppm}]=144.50,120.4,58.6,37.2,29.0,28.5,28.0,26.81$.

Step 3/3: According to the representative general procedure, 2-cyclohexylideneethan-1-ol (500 g, $3.96 \mathrm{mmol}$ ) was reacted. The crude was purified via column chromatography on silica gel ( $n$-Hep/EtOAc $3: 1 ; R_{f}=0.44(1: 1 n$-Hep/EtOAc)) to yield 1 as a white solid (530 mg g, $2.87 \mathrm{mmol}, 185.22 \mathrm{~g} / \mathrm{mol}, 73 \%$ ). Spectral data are in agreement with literature precedent. ${ }^{[3]}$

${ }^{1} \mathrm{H}-\mathrm{NMR}\left(400 \mathrm{MHz}, \mathrm{CDCl}_{3}\right): \delta[\mathrm{ppm}]=7.28(\mathrm{~s}, 1 \mathrm{H},-\mathrm{NH}-), 7.13(\mathrm{~s}, 1 \mathrm{H},-\mathrm{OH}), 5.28(\mathrm{t}, J=7.4 \mathrm{~Hz}, 1 \mathrm{H}), 4.66$ $(\mathrm{d}, J=7.4 \mathrm{~Hz}, 2 \mathrm{H}), 2.19(\mathrm{~s}, 2 \mathrm{H}), 2.11(\mathrm{~s}, 2 \mathrm{H}), 1.55(\mathrm{~s}, 6 \mathrm{H}) .{ }^{13} \mathrm{C}-\mathrm{NMR}\left(100 \mathrm{MHz}, \mathrm{CDCl}_{3}\right): \delta[\mathrm{ppm}]=159.6$, 148.0, 114.6, 62.4, 37.0, 29.0, 28.3, 27.7, 26.6. FT-IR (ATR) $\vee\left[\mathrm{cm}^{-1}\right]=3267(\mathrm{w}), 2928(\mathrm{w}), 1714(\mathrm{~m})$, $1442(\mathrm{~m}), 1258(\mathrm{~m}), 1104(\mathrm{~s})$. Melting point: $67.0^{\circ} \mathrm{C}$.

\section{S-(4-(prop-1-en-2-yl)cyclohex-1-en-1-yl)methyl N-hydroxycarbamate (1g)}<smiles>C=C(C)C1CC=C(COC(=O)NO)CC1</smiles>

According to the representative general procedure, $S$-(-)-perillyl alcohol $(0.5 \mathrm{~mL}, 3.2 \mathrm{mmol})$ was reacted. The crude was purified via column chromatography on silica gel $\left(n\right.$-Hep/EtOAc $4: 1 \rightarrow 2.1 ; R_{\mathrm{f}}=0.56$ (1:1 $n$-Hep/EtOAc)) to yield $1 \mathrm{~g}$ as a white solid (632 $\mathrm{mg} \mathrm{g}, 3.0 \mathrm{mmol}, 211.26 \mathrm{~g} / \mathrm{mol}, 95 \%$ ).

${ }^{1} \mathrm{H}-\mathrm{NMR}\left(400 \mathrm{MHz}, \mathrm{CDCl}_{3}\right): \delta[\mathrm{ppm}]=7.27(\mathrm{~s}, 1 \mathrm{H},-\mathrm{NH}-), 6.90(\mathrm{~s}, 1 \mathrm{H},-\mathrm{OH}), 5.78(\mathrm{~s}, 1 \mathrm{H}), 4.72(\mathrm{~d}, J=$ $10.2 \mathrm{~Hz}, 2 \mathrm{H}), 4.54(\mathrm{~s}, 2 \mathrm{H}), 2.22-1.80(\mathrm{~m}, 6 \mathrm{H}), 1.73(\mathrm{~s}, 3 \mathrm{H}), 1.54-1.41(\mathrm{~m}, 1 \mathrm{H}) .{ }^{13} \mathrm{C}-\mathrm{NMR}(100 \mathrm{MHz}$, $\left.\mathrm{CDCl}_{3}\right): \delta[\mathrm{ppm}]=159.5,149.5,132.3,126.7,108.9,70.2,40.7,30.4,27.2,26.3,20.8$. FT-IR (ATR) v $\left[\mathrm{cm}^{-1}\right]=3321(\mathrm{vw}), 3231(\mathrm{vw}), 2916(\mathrm{vw}), 1694(\mathrm{~s}), 1518(\mathrm{~m}), 1280(\mathrm{~m}), 1118(\mathrm{~s})$. Melting point: $103.0^{\circ} \mathrm{C}$. HRMS (ESI): $\mathrm{m} / \mathrm{z}\left[\mathrm{M}+\mathrm{Na}^{+}\right]$calcd for $\mathrm{C}_{11} \mathrm{H}_{17} \mathrm{NO}_{3}: 234.1101$; found: 234.1105 . 


\section{4,6,6-trimethylbicyclo[3.1.1]hept-3-en-2-yl N-hydroxycarbamate (1h)}<smiles>CC1CC2CC(OC(=O)NO)C1C2</smiles>

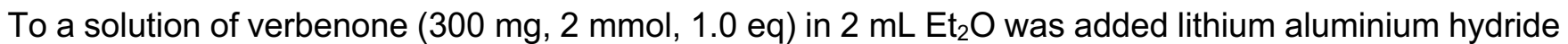
( $2 \mathrm{mmol}, 1.0$ eq.) at $-78{ }^{\circ} \mathrm{C}$. After stirring for $30 \mathrm{~min}$, the reaction mixture was allowed to warm to $0{ }^{\circ} \mathrm{C}$. After $3 \mathrm{~h}$ the mixture was quenched with $\mathrm{H}_{2} \mathrm{O}$. The phases were separated and the aqueous phase was extracted $2 \mathrm{x}$ with $\mathrm{Et}_{2} \mathrm{O}$. The combined organic phase were dried over $\mathrm{Na}_{2} \mathrm{SO}_{4}$, filtered and the solvent was removed under reduced pressure. The crude was used for the next step after a silica-pad filtration (EtOAc). According to the representative general procedure, crude Verbenol was reacted. The crude was purified via column chromatography on silica gel (n-Hep/EtOAc 4:1 $\rightarrow$ 2:1; $R_{f}=0.41(1: 1 n$ Hep/EtOAc)) to yield $1 \mathrm{~h}$ as a colorless oil (221 mg, $1.15 \mathrm{mmol}, 220.8 \mathrm{~g} / \mathrm{mol}, 52 \%$ ).

${ }^{1} \mathrm{H}-\mathrm{NMR}\left(400 \mathrm{MHz}, \mathrm{CDCl}_{3}\right): \delta[\mathrm{ppm}]=7.15(\mathrm{~s}, 1 \mathrm{H}), 6.74(\mathrm{bs}, 1 \mathrm{H}), 5.55-5.49(\mathrm{~m}, 1 \mathrm{H}), 5.41-5.34(\mathrm{~m}, 1 \mathrm{H})$, 2.55-2.48 (m, 1H), 2.45-2.38 (m, 1H), $2.03(\mathrm{t}, J=5.4 \mathrm{~Hz}, 1 \mathrm{H}), 1.77(\mathrm{t}, J=1.6 \mathrm{~Hz}, 3 \mathrm{H}), 1.44-1.40(\mathrm{~m}, 1 \mathrm{H})$, $1.36(\mathrm{~s}, 3 \mathrm{H}), 1.00(\mathrm{~s}, 3 \mathrm{H}) .{ }^{13} \mathrm{C}-\mathrm{NMR}\left(100 \mathrm{MHz}, \mathrm{CDCl}_{3}\right): \delta[\mathrm{ppm}]=159.4,150.3,115.2,77.7,47.5,45.6$, 39.7, 35.7, 26.6, 22.7, 22.6. FT-IR (ATR) $\vee\left[\mathrm{cm}^{-1}\right]=3291(\mathrm{vw}), 2926(\mathrm{w}), 1712(\mathrm{~m}), 1442(\mathrm{w}), 1249(\mathrm{~m})$, 1103 (s). HRMS (ESI): $m / z\left[M+\mathrm{H}^{+}\right]$calcd for $\mathrm{C}_{11} \mathrm{H}_{17} \mathrm{NO}_{3}: 212.1282$; found: 212.1283 .

\section{Z-3-phenylbut-2-en-1-yl N-hydroxycarbamate (1i)}<smiles>C/C(=C/COC(=O)NO)Pc1ccccc1</smiles>

Step 1/3: To a suspension of Cul (0.43 g, $0.22 \mathrm{mmol}, 0.05$ eq.) and $\mathrm{LiCl}(0.19 \mathrm{~g}, 0.45 \mathrm{mmol}, 0.1$ eq.) in $34 \mathrm{~mL}$ THF was stirred for $30 \mathrm{~min}$ at $-78{ }^{\circ} \mathrm{C}$. Ethylbut-2-ynoate $(0.5 \mathrm{~g}, 4.46 \mathrm{mmol}, 1.0 \mathrm{eq}$.) and TMSOTf (1.04 g, $4.69 \mathrm{mmol}, 1.05 \mathrm{eq}$.) were added and stirred for additional $5 \mathrm{~min}$ followed by a dropwise addition of $\mathrm{PhMgBr}(0.91 \mathrm{~g}, 5.45 \mathrm{mmol}, 1.2 \mathrm{eq}$.). The reaction was followed by TLC and TFA $(0.61 \mathrm{~g}, 5.35 \mathrm{mmol}$, 1.2 eq.) was added after full conversion of the substrate. The organic phase was washed with saturated $\mathrm{NaHCO}_{3}$ solution. The combined aqueous phases were extracted $3 x$ with EtOAc. The combined organic phases were washed with water and brine, dried over $\mathrm{Na}_{2} \mathrm{SO}_{4}$, filtered and the solvent was removed under reduced pressure. The crude was purified via column chromatography $\left(19: 1 n\right.$-Pen/Et $\left.{ }_{2} \mathrm{O}\right)$ to yield ethyl E-3-phenylbut-2-enoate $(0.11 \mathrm{~g}, 0.58 \mathrm{mmol}, 13 \%)$ and ethyl Z-3-phenylbut-2-enoate $(0.28 \mathrm{~g}$, $1.47 \mathrm{mmol}, 33 \%)$ as colorless oils. Spectral data are in agreement with literature precedent. ${ }^{[14]}$

Z-Isomer: ${ }^{1} \mathrm{H}$ NMR $\left(400 \mathrm{MHz}, \mathrm{CDCl}_{3}\right): \delta[\mathrm{ppm}]=7.38-7.30(\mathrm{~m}, 3 \mathrm{H}), 7.23-7.18(\mathrm{~m}, 2 \mathrm{H}), 5.92(\mathrm{q}, \mathrm{J}=1.4$ $\mathrm{Hz}, 1 \mathrm{H}), 4.00(\mathrm{q}, J=7.1 \mathrm{~Hz}, 2 \mathrm{H}), 2.18(\mathrm{~d}, J=1.5 \mathrm{~Hz}, 3 \mathrm{H}), 1.08(\mathrm{t}, J=7.1 \mathrm{~Hz}, 3 \mathrm{H}) .{ }^{13} \mathrm{C} \mathrm{NMR}(100 \mathrm{MHz}$, $\left.\mathrm{CDCl}_{3}\right): \delta[\mathrm{ppm}]=166.0,155.4,140.9,127.9,127.7,126.8,117.8,59.7,27.2,14.0$.

E-Isomer: ${ }^{1} \mathrm{H}-\mathrm{NMR}\left(400 \mathrm{MHz}, \mathrm{CDCl}_{3}\right): \delta[\mathrm{ppm}]=7.50-7.46(\mathrm{~m}, 2 \mathrm{H}), 7.41-7.34(\mathrm{~m}, 3 \mathrm{H}), 6.14(\mathrm{q}, \mathrm{J}=1.3$ $\mathrm{Hz}, 1 \mathrm{H}), 4.22(\mathrm{q}, J=7.1 \mathrm{~Hz}, 1 \mathrm{H}), 2.58(\mathrm{~d}, J=1.4 \mathrm{~Hz}, 3 \mathrm{H}), 1.32(\mathrm{t}, J=7.0 \mathrm{~Hz}, 3 \mathrm{H}) .{ }^{13} \mathrm{C}-\mathrm{NMR}(100 \mathrm{MHz}$, $\left.\mathrm{CDCl}_{3}\right): \delta[\mathrm{ppm}]=167,155.6,142.4,129.1,128.6,126.4,117.3,60.0,18.1,14.5$. 
Step 2/3: To a solution of ethyl Z-3-phenylbut-2-enoate $(0.52 \mathrm{~g}, 2.72 \mathrm{mmol}, 1.0$ eq.) in $11 \mathrm{~mL}$ DCM was added DIBAL-H $(7.7 \mathrm{~mL}, 7.7 \mathrm{mmol}, 2.8 \mathrm{eq} .1 \mathrm{M}$ in $\mathrm{c}$-Hex $)$ at $-78^{\circ} \mathrm{C}$. After $1.5 \mathrm{~h}$ the reaction mixture was allowed to warm $0{ }^{\circ} \mathrm{C}$ and quenched with EtOAc and water. The mixture was was washed with $1 \mathrm{M} \mathrm{HCl}$ solution. The phases were separated and the aqueous phase was extracted $3 x$ with DCM. The combined organic phases were dried over $\mathrm{Na}_{2} \mathrm{SO}_{4}$, filtered and the solvent was removed under reduced pressure. The crude was purified via column chromatography (2:1 $n$-Hep/EtOAc) to yield Z-3-phenylbut-2-en-1-ol $(0.37 \mathrm{~g}, 2.59 \mathrm{mmol}, 96 \%)$ as a colorless oil. Spectral data are in agreement with literature precedent. ${ }^{[15]}$

${ }^{1} \mathrm{H}-\mathrm{NMR}\left(400 \mathrm{MHz}, \mathrm{CDCl}_{3}\right): \delta[\mathrm{ppm}]=7.39-7.24(\mathrm{~m}, 3 \mathrm{H}), 7.20-7.14(\mathrm{~m}, 2 \mathrm{H}), 5.71$ (tq, $J=7.0,1.3 \mathrm{~Hz}$, 1H), $4.07(\mathrm{~d}, J=7.0 \mathrm{~Hz}, 2 \mathrm{H}), 2.09(\mathrm{dd}, J=2.4,1.0 \mathrm{~Hz}, 3 \mathrm{H}) .{ }^{13} \mathrm{C}-\mathrm{NMR}\left(100 \mathrm{MHz}, \mathrm{CDCl}_{3}\right): \delta[\mathrm{ppm}]=140.8$, $140.2,128.2,127.8,127.2,126.1,60.3,25.4$.

Step 3/3: According to the representative general procedure, Z-3-phenylbut-2-en-1-ol $(0.32 \mathrm{~g}$, $2.16 \mathrm{mmol}$ ) was reacted. The crude was purified via column chromatography on silica gel ( $\mathrm{n}$-Hep/EtOAc $4: 1 \rightarrow 2.1 ; R_{\mathrm{f}}=0.18(2: 1 \mathrm{n}$-Hep/EtOAc) $)$ to yield $1 \mathrm{i}$ as a white solid $(0.38 \mathrm{~g}, 1.86 \mathrm{mmol}, 207.23 \mathrm{~g} / \mathrm{mol}$, $86 \%) .^{[19]}$

${ }^{1} \mathrm{H}-\mathrm{NMR}\left(400 \mathrm{MHz}, \mathrm{CDCl}_{3}\right): \delta[\mathrm{ppm}]=7.40-7.27(\mathrm{~m}, 3 \mathrm{H},-\mathrm{Ph}), 7.21-7.14(\mathrm{~m}, 2 \mathrm{H},-\mathrm{Ph}), 7.12(\mathrm{~s}, 1 \mathrm{H},-\mathrm{NH}-)$, $6.20(\mathrm{~s}, 1 \mathrm{H},-\mathrm{OH}), 5.67(\mathrm{td}, J=7.2,1.5 \mathrm{~Hz}, 1 \mathrm{H}), 4.59$ (dd, $J=7.2,0.9 \mathrm{~Hz}, 2 \mathrm{H}), 2.10(\mathrm{~d}, J=1.3 \mathrm{~Hz}, 3 \mathrm{H})$. ${ }^{13} \mathrm{C}-\mathrm{NMR}\left(100 \mathrm{MHz}, \mathrm{CDCl}_{3}\right): \delta[\mathrm{ppm}]=159.2,143.7,140.2,128.3,127.7,127.5,120.5,64.1,25.5$. FTIR $($ ATR $) \vee\left[\mathrm{cm}^{-1}\right]=3298(\mathrm{w}), 1703(\mathrm{~m}), 1482(\mathrm{~m}), 1266(\mathrm{~m}), 1126(\mathrm{~s}), 761(\mathrm{~s})$. Melting point: $61.6{ }^{\circ} \mathrm{C}$.

\section{E-hex-2-en-1-yl N-hydroxycarbamate $(E-1 \mathrm{j})$}<smiles>CCC/C=C/COC(=O)NO</smiles>

According to the representative general procedure, $E$-hex-2-en-1-ol $(1.0 \mathrm{~g}, 9.98 \mathrm{mmol})$ was reacted. The crude was purified via column chromatography on silica gel $\left(n\right.$-Hep/EtOAc $3: 1 ; R_{f}=0.36(1: 1 n$ Hep/EtOAc)) to yield E-1j as a colorless oil $(1.07 \mathrm{~g}, 6.73 \mathrm{mmol}, 159.19 \mathrm{~g} / \mathrm{mol}, 67 \%)$. Spectral data are in agreement with literature precedent. ${ }^{[1]}$

${ }^{1} \mathrm{H}-\mathrm{NMR}\left(400 \mathrm{MHz}, \mathrm{CDCl}_{3}\right): \delta[\mathrm{ppm}]=7.35(\mathrm{~s}, 1 \mathrm{H},-\mathrm{NH}-), 7.19(\mathrm{~s}, 1 \mathrm{H},-\mathrm{OH}), 5.86-5.76(\mathrm{~m}, 1 \mathrm{H}), 5.63-5.53$ $(\mathrm{m}, 1 \mathrm{H}), 4.61(\mathrm{~d}, J=6.6 \mathrm{~Hz}, 2 \mathrm{H}), 2.05(\mathrm{q}, J=7.0 \mathrm{~Hz}, 2 \mathrm{H}), 1.49-1.37(\mathrm{~m}, 2 \mathrm{H}), 0.92(\mathrm{t}, J=7.4 \mathrm{~Hz}, 3 \mathrm{H})$. ${ }^{13} \mathrm{C}-\mathrm{NMR}\left(100 \mathrm{MHz}, \mathrm{CDCl}_{3}\right): \delta[\mathrm{ppm}]=159.4,137.3,123.5,67.0,34.3,22.0,13.6 . \mathbf{F T}-\mathrm{IR}(\mathrm{ATR}) \vee\left[\mathrm{cm}^{-1}\right]$ $=3300(\mathrm{w}), 2958(\mathrm{w}), 1707(\mathrm{~m}), 1457(\mathrm{w}), 1260(\mathrm{~m}), 1110(\mathrm{~s})$.

\section{Z-hex-2-en-1-yl N-hydroxycarbamate (Z-1j)}<smiles>O=C(NO)OC/C=C\CC[Al]</smiles>

According to the representative general procedure, Z-hex-2-en-1-ol $(1.0 \mathrm{~g}, 9.98 \mathrm{mmol})$ was reacted. The crude was purified via column chromatography on silica gel $\left(3: 1 n\right.$-Hep/EtOAc; $R_{f}=0.2(1: 1 n$ Hep/EtOAc)) to yield Z-1j as a colorless oil $(1.28 \mathrm{~g}, 8.75 \mathrm{mmol}, 159.19 \mathrm{~g} / \mathrm{mol}, 88 \%)$. Spectral data are in agreement with literature precedent. ${ }^{[1]}$ 
${ }^{1} \mathrm{H}-\mathrm{NMR}\left(400 \mathrm{MHz}, \mathrm{CDCl}_{3}\right): \delta[\mathrm{ppm}]=7.23(\mathrm{~s}, 1 \mathrm{H},-\mathrm{NH}-), 6.79(\mathrm{~s}, 1 \mathrm{H},-\mathrm{OH}), 5.72-5.62(\mathrm{~m}, 1 \mathrm{H}), 5.58-5.49$ $(\mathrm{m}, 1 \mathrm{H}), 4.71(\mathrm{~d}, J=6.9 \mathrm{~Hz}, 2 \mathrm{H}), 2.08(\mathrm{q}, J=7.3 \mathrm{~Hz}, 2 \mathrm{H}), 1.47-1.34(\mathrm{~m}, 2 \mathrm{H}), 0.91(\mathrm{t}, J=7.4 \mathrm{~Hz}, 3 \mathrm{H})$. ${ }^{13}$ C-NMR $\left(100 \mathrm{MHz}, \mathrm{CDCl}_{3}\right): \delta[\mathrm{ppm}]=159.5,135.9,122.9,62.0,29.5,22.5,13.6$. FT-IR $(\mathrm{ATR}) \vee\left[\mathrm{cm}^{-1}\right]$ = $3294(\mathrm{w}), 2960(\mathrm{w}), 1706(\mathrm{~m}), 1458(\mathrm{w}), 1259(\mathrm{~m}), 1108(\mathrm{~s})$.

\section{4-methylenehex-5-en-1-yl N-hydroxycarbamate (1k)}<smiles>C=CC(=C)CCCOC(=O)NO</smiles>

4-methylenehex-5-en-1-ol was prepared from myrcene according to literature precedent. ${ }^{[10]}$ According to the representative general procedure, freshly prepared 4-methylenehex-5-en-1-ol (50 mg, $0.45 \mathrm{mmol}$ ) was reacted. The crude was purified via column chromatography on silica gel $\left(5: 1 n\right.$-Hep/EtOAc; $R_{f}=$ $0.34(1: 1 \mathrm{n}$-Hep/EtOAc)) to yield $1 \mathrm{k}$ as a colorless oil $(37.4 \mathrm{mg}, 0.22 \mathrm{mmol}, 171.2 \mathrm{~g} / \mathrm{mol}, 49 \%)$. Spectral data are in agreement with literature precedent. ${ }^{[11]}$

${ }^{1} \mathrm{H}-\mathrm{NMR}\left(400 \mathrm{MHz}, \mathrm{CDCl}_{3}\right): \delta[\mathrm{ppm}]=7.24(\mathrm{~s}, 1 \mathrm{H},-\mathrm{NH}-), 6.79(\mathrm{bs}, 1 \mathrm{H},-\mathrm{OH}), 6.37$ (dd, J = 17.6, $10.8 \mathrm{~Hz}$, $1 \mathrm{H}), 5.21(\mathrm{~d}, J=17.6 \mathrm{~Hz}, 1 \mathrm{H}), 5.07(\mathrm{~d}, J=11.0 \mathrm{~Hz}, 1 \mathrm{H}), 5.02(\mathrm{~d}, J=19.2 \mathrm{~Hz}, 2 \mathrm{H}), 4.19$, (t, $J=6.5 \mathrm{~Hz}$, 2H), 2.31-2.25 (m, 2H), 1.8-1.9 (m, 2H). ${ }^{13} \mathrm{C}-\mathrm{NMR}\left(100 \mathrm{MHz}, \mathrm{CDCl}_{3}\right): \delta[\mathrm{ppm}]=159.5,145.0,138.5$, 116.3, 113.5, 66.0, 27.4, 27.2. FT-IR (ATR) v [ $\left.\mathrm{cm}^{-1}\right]=3279(\mathrm{w}), 2961(\mathrm{vw}), 1712(\mathrm{~m}), 1455(\mathrm{w}), 1259$ (m), $1112(\mathrm{~s})$.

\section{N-hydroxy-2-(2-methylprop-1-en-1-yl)benzamide (1I)}<smiles>CC(C)=Cc1ccccc1C(=O)NO</smiles>

Step 1/3: A solution of methyl 2-bromobenzoate (1 g, $4.65 \mathrm{mmol}, 1.0$ eq.), 4,4,5,5-tetramethyl-2-(2methylprop-1-en-1-yl)-1,3,2-dioxaborolane (1.27 g, $6.98 \mathrm{mmol}, 1.5$ eq.) and $\mathrm{Cs}_{2} \mathrm{CO}_{3}(3 \mathrm{~g}, 9.5 \mathrm{mmol}, 2.0$ eq.) in $11 \mathrm{~mL}$ dioxane/ $\mathrm{H}_{2} \mathrm{O}(4: 1)$ was degassed with Argon for $0 \mathrm{~min}$. $\mathrm{Pd}(\mathrm{dppf}) \mathrm{Cl}_{2} \cdot \mathrm{DCM}(380 \mathrm{mg}, 0.47$ $\mathrm{mmol}, 0.1$ eq.) was added and the reaction mixture was heated to $100{ }^{\circ} \mathrm{C}$ for $3 \mathrm{~h}$. The mixture was cooled down and filtered through celite using EtOAc. The filtrate was washed with brine, dried over $\mathrm{Na}_{2} \mathrm{SO}_{4}$, filtered and the solvent was removed under reduced pressure. The crude was purified via column chromatography on silica gel $\left(10: 1 n\right.$-Hep/EtOAc; $R_{f}=0.62(5: 1 n$-Hep/EtOAc) $)$ to yield methyl 2-(2methylprop-1-en-1-yl)benzoate (799.2 mg, $4.2 \mathrm{mmol}, 190.24 \mathrm{~g} / \mathrm{mol}, 90 \%$ ).

${ }^{1} \mathrm{H}-\mathrm{NMR}\left(400 \mathrm{MHz}, \mathrm{CDCl}_{3}\right): \delta[\mathrm{ppm}]=7.92-7.87(\mathrm{~m}, 1 \mathrm{H}), 7.45(\mathrm{td}, J=7.6,1.4 \mathrm{~Hz}, 1 \mathrm{H}), 7.26(\mathrm{t}, J=7.4$ $\mathrm{Hz}, 2 \mathrm{H}), 6.66(\mathrm{~s}, 1 \mathrm{H}), 3.87(\mathrm{~s}, 3 \mathrm{H}), 1.93(\mathrm{~d}, J=1.2 \mathrm{~Hz}, 3 \mathrm{H}), 1.71(\mathrm{~d}, J=1.2 \mathrm{~Hz}, 3 \mathrm{H}) .{ }^{13} \mathrm{C}-\mathrm{NMR}(100 \mathrm{MHz}$, $\left.\mathrm{CDCl}_{3}\right): \delta[\mathrm{ppm}]=167.9,140.1,134.8,131.4,131.3,130.2,129.3,126.0,124.7,51.9,26.3,19.3$.

Step 2/3: To a solution of methyl 2-(2-methylprop-1-en-1-yl)benzoate $(546 \mathrm{mg}, 2.87 \mathrm{mmol})$ in $40 \mathrm{~mL}$ $\mathrm{MeOH}$ was added $22 \mathrm{~mL} 1 \mathrm{M} \mathrm{NaOH}$. The reaction mixture was stirred overnight and was then slightly acidified with diluted $\mathrm{HCl}$. The aqueous phase was extracted $3 \mathrm{x}$ with EtOAc. The combined organic 
phases were dried over $\mathrm{Na}_{2} \mathrm{SO}_{4}$, filtered and the solvent was removed under reduced pressure. The crude was purified via silica pad filtration to yield 2-(2-methylprop-1-en-1-yl)benzoic acid (503.9 mg, $2.64 \mathrm{mmol}, 191.23 \mathrm{~g} / \mathrm{mol}, 92 \%$ ).

${ }^{1} \mathrm{H}-\mathrm{NMR}\left(400 \mathrm{MHz}, \mathrm{CDCl}_{3}\right): \delta[\mathrm{ppm}]=8.05(\mathrm{~d}, J=7.8 \mathrm{~Hz}, 1 \mathrm{H}), 7.53-7.44(\mathrm{~m}, 1 \mathrm{H}), 7.35-7.27(\mathrm{~m}, 2 \mathrm{H})$, $6.71(\mathrm{~s}, 1 \mathrm{H}), 1.93(\mathrm{~s}, 3 \mathrm{H}), 1.73(\mathrm{~s}, 3 \mathrm{H}) \cdot{ }^{13} \mathrm{C}-\mathrm{NMR}\left(100 \mathrm{MHz}, \mathrm{CDCl}_{3}\right): \delta[\mathrm{ppm}]=140.7,140.1,135.3,132.2$, $131.5,131.2,126.2,124.7,26.3,19.4$.

Step 3/3: To a solution of yield 2-(2-methylprop-1-en-1-yl)benzoic acid (200 mg, $1.05 \mathrm{mmol}, 1.0 \mathrm{eq}$.) and a catalytic amount of DMF in $5 \mathrm{~mL}$ DCM was added oxalyl chloride $\left(400 \mathrm{mg}, 3.15 \mathrm{mmol}, 3.0 \mathrm{eq}\right.$.) at $0{ }^{\circ} \mathrm{C}$. The solvent was removed after $3 \mathrm{~h}$ and the residue was again dissolved in $1 \mathrm{~mL} \mathrm{DCM} . \mathrm{NaHCO}_{3}(198$ $\mathrm{mg}, 2.36 \mathrm{mmol}, 2.25$ eq.) was dissolved in $1.2 \mathrm{~mL} \mathrm{H}_{2} \mathrm{O}$ and cooled to $0{ }^{\circ} \mathrm{C}$. Hydroxylamine hydrochloride (91 $\mathrm{mg}, 1.31 \mathrm{mmol}, 1.25$ eq.) was added and the mixture was stirred for $30 \mathrm{~min}$. before the residue in $\mathrm{DCM}$ was added. The mixture was stirred at $0{ }^{\circ} \mathrm{C}$ for $30 \mathrm{~min}$. and was then allowed to warm to room temperature. After $2 \mathrm{~h}$, EtOAc and $\mathrm{H}_{2} \mathrm{O}$ was added to the reaction mixture and the aqueous phase was extracted $2 x$ with EtOAc. The combined organic phases were washed with brine, dried over $\mathrm{Na}_{2} \mathrm{SO}_{4}$, filtered and the solvent was removed under reduced pressure. The crude was purified via column chromatography on silica gel $\left(5: 1 \rightarrow 1: 1 n\right.$-Hep/EtOAc; $R_{f}=0.18(1: 1 n$-Hep/EtOAc)) to yield $1 \mathrm{l}$ as a white solid (126.1 mg, $0.66 \mathrm{mmol}, 191.23 \mathrm{~g} / \mathrm{mol}, 63 \%$ ).

${ }^{1} \mathrm{H}-\mathrm{NMR}\left(400 \mathrm{MHz}, \mathrm{CDCl}_{3}\right): \delta[\mathrm{ppm}]=8.94(\mathrm{~s}, 2 \mathrm{H}), 7.81(\mathrm{~d}, J=5.4 \mathrm{~Hz}, 1 \mathrm{H}), 7.46(\mathrm{t}, J=7.5 \mathrm{~Hz}, 1 \mathrm{H}), 7.33$ $(\mathrm{t}, J=7.4 \mathrm{~Hz}, 1 \mathrm{H}), 7.22(\mathrm{~d}, J=7.6 \mathrm{~Hz}, 1 \mathrm{H}), 6.44(\mathrm{~s}, 1 \mathrm{H}), 1.95(\mathrm{~s}, 3 \mathrm{H}), 1.75(\mathrm{~s}, 3 \mathrm{H}) \cdot{ }^{13} \mathrm{C}-\mathrm{NMR}(100 \mathrm{MHz}$, $\left.\mathrm{CDCl}_{3}\right): \delta[\mathrm{ppm}]=139.3,136.6,131.0,131.0,130.8,129.1,126.9,123.1,26.1,19.4$. FT-IR (ATR) $\vee\left[\mathrm{cm}^{-}\right.$ $\left.{ }^{1}\right]=3303(\mathrm{w}), 2906(\mathrm{vw}), 1633(\mathrm{~m}), 1514(\mathrm{~m}), 1019(\mathrm{~m})$. Melting point: $129.9^{\circ} \mathrm{C}$. HRMS (ESI): $\mathrm{m} / \mathrm{z}$ $\left[\mathrm{M}+\mathrm{H}^{+}\right]$calcd for $\mathrm{C}_{11} \mathrm{H}_{13} \mathrm{NO}_{2}: 192.1019$; found: 192.1030 . 


\subsection{GOx/HRP mediated intramolecular nitroso ene reactions}

General procedure with GOx/HRP: To a $10 \mathrm{mM}$ solution of substrate in $7 \mathrm{~mL}$ phosphate buffer (100 mM, $\mathrm{pH}$ 7.0), if neccessary including $10 \mathrm{vol} \%$ of desired cosolvent (dioxane or EtOAc), was added $70 \mathrm{U}$ horseradish peroxidase and $70 \mathrm{U}$ glucose oxidase (Aspergillus Niger). D-glucose $(50 \mathrm{mM})$ was added and the reaction was incubated at $25^{\circ} \mathrm{C}$. After full conversion of starting material (followed by TLC), the reaction mixture was extracted $3 x$ with EtOAc. The combined organic phases were dried over $\mathrm{Na}_{2} \mathrm{SO}_{4}$, filtered and the solvent was removed under reduced pressure. The crude was purified via silica pad filtration or flash column chromatography on silica gel.

\section{3-Hydroxy-4-(prop-1-en-2-yl)oxazolidin-2-one (2a)}<smiles>C=C(C)C1COC(=O)N1O</smiles>

According to the general procedure with GOx/HRP, 1a was reacted and full conversion was observed after $2 \mathrm{~h}$. The crude was purified via silica pad filtration with EtOAc to yield $2 \mathrm{a}$ as colorless crystals $(9.7 \mathrm{mg}, 0.068 \mathrm{mmol}, 143.14 \mathrm{~g} / \mathrm{mol}, 97 \%)$. Spectral data are in agreement with literature precedent. ${ }^{[2]}$

${ }^{1} \mathrm{H}-\mathrm{NMR}\left(400 \mathrm{MHz}, \mathrm{CDCl}_{3}\right): \delta 8.29$ (bs, $\left.1 \mathrm{H}\right), 5.10$ (dd, $\left.J=8.4,7.1 \mathrm{~Hz}, 2 \mathrm{H}\right), 4.49-4.30(\mathrm{~m}, 2 \mathrm{H}), 4.08-3.97$ (m, 1H), 1.81-1.76 (m, 3H). ${ }^{13} \mathrm{C}-N M R\left(100 \mathrm{MHz}, \mathrm{CDCl}_{3}\right): \delta 160.9,139.0,117.0,65.7,64.8,16.9$. FT-IR $(A T R) \vee\left[\mathrm{cm}^{-1}\right]=3236(\mathrm{w}), 2923(\mathrm{w}), 1743(\mathrm{~s}), 1215(\mathrm{~m}), 1095(\mathrm{~m})$. Melting point: $73.0^{\circ} \mathrm{C}$.

\section{3-Hydroxy-4-(d $d_{5}$-prop-1-en-2-yl)oxazolidin-2-one (2a-d $\left.d_{5}\right)$}<smiles>[R6][14CH3]</smiles>

According to the general procedure with GOx/HRP, $1 a-d_{6}$ was reacted and full conversion was observed

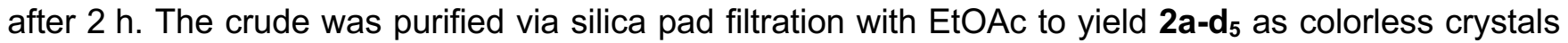
(9.4 mg, $0.063 \mathrm{mmol}, 148.17 \mathrm{~g} / \mathrm{mol}, 91 \%, D_{5} \geq 99 \%$ ).

${ }^{1} \mathrm{H}-\mathrm{NMR}\left(400 \mathrm{MHz}, \mathrm{CDCl}_{3}\right): \delta[\mathrm{ppm}]=8.26(\mathrm{bs}, 1 \mathrm{H},-\mathrm{OH}), 4.46-4.36(\mathrm{~m}, 2 \mathrm{H}), 4.07-3.97(\mathrm{~m}, 1 \mathrm{H})$. FT-IR $(A T R) \vee\left[\mathrm{cm}^{-1}\right]=3183(\mathrm{w}), 2924(\mathrm{vw}), 1748(\mathrm{~s}), 1103(\mathrm{~s}), 1007(\mathrm{~m})$. Melting point: $67.5^{\circ} \mathrm{C}$. HRMS (ESI): $\mathrm{m} / \mathrm{z}\left[\mathrm{M}+\mathrm{Na}^{+}\right]$calcd for $\mathrm{C}_{6} \mathrm{H}_{4} \mathrm{D}_{5} \mathrm{NO}_{3}: 171.0788$; found: 171.0801 . 


\section{3-Hydroxy-4-(1,1-d $\mathrm{d}_{2}$-prop-1-en-2-yl)oxazolidin-2-one (2a-d $\left.\mathrm{d}_{2}\right)$}<smiles>CC(=[18O])C1COC(=O)N1O</smiles>

According to the general procedure with GOx/HRP, E-1a-d $d_{3}$ was reacted and full conversion was observed after $2 \mathrm{~h}$. The crude was purified via silica pad filtration with EtOAc to yield $\mathbf{2 a}-\mathbf{d}_{\mathbf{2}}(9.5 \mathrm{mg}$, $0.065 \mathrm{mmol}, 145.15 \mathrm{~g} / \mathrm{mol}, 93 \%, D_{2} \geq 95 \%$ ).

${ }^{1} \mathrm{H}-\mathrm{NMR}\left(400 \mathrm{MHz}, \mathrm{CDCl}_{3}\right): \delta[\mathrm{ppm}]=8.17(\mathrm{~s}, 1 \mathrm{H}), 4.46-4.37(\mathrm{~m}, 2 \mathrm{H}), 4.07-3.97(\mathrm{~m}, 1 \mathrm{H}), 1.78(\mathrm{~s}, 3 \mathrm{H})$.

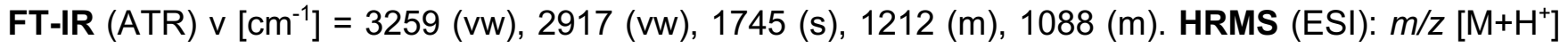
calcd for $\mathrm{C}_{6} \mathrm{H}_{7} \mathrm{D}_{2} \mathrm{NO}_{3}$ : 146.0781 ; found: 146.0784 .

\section{3-Hydroxy-4-(3,3,3-d 3 -prop-1-en-2-yl)oxazolidin-2-one (2a-d 3 )}<smiles>C=C(C)C1COC(=O)N1O</smiles>

According to the general procedure with GOx/HRP, Z-1a- $\mathrm{d}_{3}$ was reacted and full conversion was observed after $2 \mathrm{~h}$. The crude was purified via silica pad filtration with EtOAc to yield $2 \mathrm{a}-\mathrm{d}_{3}(9.1 \mathrm{mg}$, $0.062 \mathrm{mmol}, 146.15 \mathrm{~g} / \mathrm{mol}, 89 \%, \mathrm{D}_{3} \geq 95 \%$ ).

${ }^{1} \mathrm{H}-\mathrm{NMR}\left(400 \mathrm{MHz}, \mathrm{CDCl}_{3}\right): \delta[\mathrm{ppm}]=8.25(\mathrm{~s}, 1 \mathrm{H}), 5.13(\mathrm{~s}, 1 \mathrm{H}), 5.10(\mathrm{~d}, J=1.0 \mathrm{~Hz}, 1 \mathrm{H}), 4.45-4.37(\mathrm{~m}$, 2H), 4.05-3.98 (m, 1H). FT-IR (ATR) v [cm $\left.{ }^{-1}\right]=3259(\mathrm{vw}), 2917(\mathrm{vw}), 1747(\mathrm{~s}), 1212(\mathrm{~m}), 1089(\mathrm{~m})$. HRMS (ESI): $\mathrm{m} / \mathrm{z}\left[\mathrm{M}+\mathrm{Na}^{+}\right]$calcd for $\mathrm{C}_{6} \mathrm{H}_{6} \mathrm{D}_{3} \mathrm{NO}_{3}: 147.0844$; found: 146.0842 .

\section{1-hydroxy-5-(prop-1-en-2-yl)pyrrolidin-2-one (2b)}<smiles>C=C(C)C1CCC(=O)N1O</smiles>

According to the general procedure with GOx/HRP, 1b was reacted in phosphate buffer containing $10 \%$ dioxane and full conversion was observed after $3 \mathrm{~h}$. The crude was purified via column chromatography $\left(\mathrm{DCM}+5 \% \mathrm{MeOH}+1 \% \mathrm{TEA} ; \mathrm{R}_{\mathrm{f}}=0.34(\mathrm{DCM}+5 \% \mathrm{MeOH})\right)$ to yield $\mathbf{2 b}$ as white solid $(7.6 \mathrm{mg}$, $0.054 \mathrm{mmol}, 141.17 \mathrm{~g} / \mathrm{mol}, 77 \%)$. Spectral data are in agreement with literature precedent. ${ }^{[12]}$

${ }^{1} \mathrm{H}-\mathrm{NMR}\left(400 \mathrm{MHz}, \mathrm{CDCl}_{3}\right): \delta[\mathrm{ppm}]=9.44(\mathrm{bs}, 1 \mathrm{H},-\mathrm{OH}), 5.00(\mathrm{~d}, J=15.5 \mathrm{~Hz}, 2 \mathrm{H}), 4.28(\mathrm{dd}, J=8.4$, $5.6 \mathrm{~Hz}, 1 \mathrm{H}), 2.51-2.31(\mathrm{~m}, 2 \mathrm{H}), 2.29-2.16(\mathrm{~m}, 1 \mathrm{H}), 1.86-1.75(\mathrm{~m}, 1 \mathrm{H}), 1.73(\mathrm{~s}, 3 \mathrm{H}) .{ }^{13} \mathrm{C}-\mathrm{NMR}(100 \mathrm{MHz}$, $\left.\mathrm{CDCl}_{3}\right): \delta[\mathrm{ppm}]=142.4,114.2,65.0,27.2,21.5,16.9$. FT-IR $(\mathrm{ATR}) \vee\left[\mathrm{cm}^{-1}\right]=3085(\mathrm{vw}), 2497(\mathrm{w}), 1668$ (s), $1456(\mathrm{~m}), 926(\mathrm{~s})$. Melting point: $91.3^{\circ} \mathrm{C}$. 


\section{3-hydroxy-4-vinyloxazolidin-2-one (2c)}<smiles>C=CC1COC(=O)N1O</smiles>

According to the general procedure with GOx/HRP, 1c was reacted and full conversion was observed after $2 \mathrm{~h}$. The crude was purified via column chromatography $\left(5: 1 \mathrm{n}\right.$-Hep/EtOAc; $R_{\mathrm{f}}=0.23(1: 1 \mathrm{n}$ $\mathrm{Hep} / \mathrm{EtOAc})$ ) to yield $2 \mathrm{c}$ as a white solid with a diastereomeric ratio of $68 \%(4.8 \mathrm{mg}, 0.037 \mathrm{mmol}$, $129.12 \mathrm{~g} / \mathrm{mol}, 53 \%)$. Spectral data are in agreement with literature precedent. ${ }^{[2]}$

${ }^{1} \mathrm{H}-\mathrm{NMR}\left(400 \mathrm{MHz}, \mathrm{CDCl}_{3}\right): \delta[\mathrm{ppm}]=6.78(\mathrm{bs}, 1 \mathrm{H},-\mathrm{OH}), 5.81(\mathrm{ddd}, J=17.2,10.2,7.8 \mathrm{~Hz}, 1 \mathrm{H}), 5.47$ (dd, $J=23.3,13.6 \mathrm{~Hz}, 2 \mathrm{H}$ ), $4.43(\mathrm{t}, J=8.2 \mathrm{~Hz}, 1 \mathrm{H}), 4.33(\mathrm{dd}, J=16.7,8.2 \mathrm{~Hz}, \mathrm{H}-1), 3.99(\mathrm{t}, J=8.2 \mathrm{~Hz}$, 1H). ${ }^{13} \mathrm{C}-\mathrm{NMR}\left(100 \mathrm{MHz}, \mathrm{CDCl}_{3}\right): \delta[\mathrm{ppm}]=160.5,132.3,122.3,66.3,62.8$. FT-IR $($ ATR $) \vee\left[\mathrm{cm}^{-1}\right]=3244$ (w), $2922(\mathrm{vw}), 1726(\mathrm{~s}), 1471(\mathrm{w}), 1090(\mathrm{~m})$. Melting point: $55.0^{\circ} \mathrm{C}$.

\section{3-hydroxy-4-methyl-4-(prop-1-en-2-yl)oxazolidin-2-one (2d)}<smiles>C=C(C)C1(C)COC(=O)N1O</smiles>

According to the general procedure with GOx/HRP, 1d was reacted and full conversion was observed after $2 \mathrm{~h}$. The crude was purified via silica pad filtration with EtOAc to yield $\mathbf{2 d}$ as colorless oil $(9.1 \mathrm{mg}$, $0.064 \mathrm{mmol}, 143.14 \mathrm{~g} / \mathrm{mol}, 91 \%)$.

${ }^{1} \mathrm{H}-\mathrm{NMR}\left(400 \mathrm{MHz}, \mathrm{CDCl}_{3}\right): \delta[\mathrm{ppm}]=7.65(\mathrm{bs}, 1 \mathrm{H},-\mathrm{OH}), 5.91(\mathrm{dd}, J=17.5,10.8 \mathrm{~Hz}, 1 \mathrm{H}), 5.45-5.19(\mathrm{~m}$, 2H), $4.12(\mathrm{~d}, J=8.4 \mathrm{~Hz}, 1 \mathrm{H}), 4.06(\mathrm{~d}, J=8.4 \mathrm{~Hz}, 1 \mathrm{H}), 1.47(\mathrm{~d}, J=5.5 \mathrm{~Hz}, 3 \mathrm{H}) .{ }^{13} \mathrm{C}-\mathrm{NMR}(100 \mathrm{MHz}$, $\left.\mathrm{CDCl}_{3}\right): \delta[\mathrm{ppm}]=159.7,136.6,118.1,72.6,64.1,18.9 . \mathrm{FT}-\mathrm{IR}(\mathrm{ATR}) \vee\left[\mathrm{cm}^{-1}\right]=3260(\mathrm{w}), 2976(\mathrm{vw})$, 1746 (s), 1101 (m), 990 (m). HRMS (ESI): m/z [M+H'] calcd for $\mathrm{C}_{6} \mathrm{H}_{9} \mathrm{NO}_{3}: 144.0656$; found: 144.0657.

\section{3-hydroxy-5-methyl-4-vinyloxazolidin-2-one (2e)}<smiles>C=CC1C(C)OC(=O)N1O</smiles>

According to the general procedure with GOx/HRP, 1e was reacted in phosphate buffer containing $10 \%$ EtOAc and full conversion was observed after $5 \mathrm{~h}$. The crude was purified via column chromatography $\left(5: 1 n\right.$-Hep/EtOAc; $R_{f}=0.29 \& 0.21(1: 1 n$-Hep/EtOAc) $)$ to yield $2 e$ colorless oil with a diastereomeric ratio of $68 \%(5.2 \mathrm{mg}, 0.036 \mathrm{mmol}, 143.14 \mathrm{~g} / \mathrm{mol}, 52 \%)$. Spectral data are in agreement with literature precedent. $^{[5]}$

Major diastereomer: ${ }^{1} \mathrm{H}-\mathrm{NMR}\left(400 \mathrm{MHz}, \mathrm{CDCl}_{3}\right): \delta[\mathrm{ppm}]=7.80(\mathrm{bs}, 1 \mathrm{H},-\mathrm{OH}), 5.87-5.71(\mathrm{~m}, 1 \mathrm{H}), 5.53-$ $5.38(\mathrm{~m}, 2 \mathrm{H}), 4.75-4.65(\mathrm{~m}, 1 \mathrm{H}), 4.33(\mathrm{t}, J=8.0 \mathrm{~Hz}, 1 \mathrm{H}), 1.32(\mathrm{~d}, J=6.6 \mathrm{~Hz}, 3 \mathrm{H}) .{ }^{13} \mathrm{C}-\mathrm{NMR}(100 \mathrm{MHz}$, $\left.\mathrm{CDCl}_{3}\right): \delta[\mathrm{ppm}]=130.1,122.9,75.1,65.8,16.0$. 
Minor diastereomer (selected signals): ${ }^{1} \mathrm{H}-\mathrm{NMR}\left(400 \mathrm{MHz}, \mathrm{CDCl}_{3}\right): \delta[\mathrm{ppm}]=4.22(\mathrm{dq}, J=9.3,6.2 \mathrm{~Hz}$, 1H), 3.92-3.81 (m, 1H), $1.44(\mathrm{~d}, J=6.2 \mathrm{~Hz}, 3 \mathrm{H}) .{ }^{13} \mathrm{C}-\mathrm{NMR}\left(100 \mathrm{MHz}, \mathrm{CDCl}_{3}\right): \delta[\mathrm{ppm}]=132.4,122.5$, 73.4, 70.3, 17.8 .

FT-IR (ATR) v [cm $\left.\left.{ }^{-1}\right]=3280(\mathrm{vw}), 2936(\mathrm{vw}), 1748(\mathrm{~s}), 1220(\mathrm{~m}), 1057 \mathrm{~m}\right)$.

\section{4-(cyclohex-1-en-1-yl)-3-hydroxyoxazolidin-2-one (2f)}

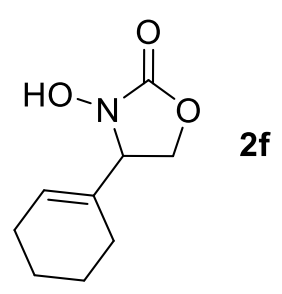

According to the general procedure with GOx/HRP, 1f was reacted in phosphate buffer containing $10 \%$ EtOAc and full conversion was observed after $2 \mathrm{~h}$. The crude was purified via column chromatography $\left(4: 1 \mathrm{n}\right.$-Hep/EtOAc; $\mathrm{R}_{\mathrm{f}}=0.35(1: 1 \mathrm{n}$-Hep/EtOAc) $)$ to yield $\mathbf{2 f}$ as colorless crystals $(9.9 \mathrm{mg}, 0.054 \mathrm{mmol}$, $183.21 \mathrm{~g} / \mathrm{mol}, 77 \%)$. Spectral data are in agreement with literature precedent. ${ }^{[5]}$

${ }^{1} \mathrm{H}-\mathrm{NMR}\left(400 \mathrm{MHz}, \mathrm{CDCl}_{3}\right): \delta[\mathrm{ppm}]=8.09(\mathrm{bs}, 1 \mathrm{H},-\mathrm{OH}), 5.83(\mathrm{~s}, 1 \mathrm{H}), 4.38-4.28(\mathrm{~m}, 2 \mathrm{H}), 4.08-3.97(\mathrm{~m}$, $1 \mathrm{H}), 2.14-1.86(\mathrm{~m}, 4 \mathrm{H}), 1.72-1.50(\mathrm{~m}, 4 \mathrm{H}) .{ }^{13} \mathrm{C}-\mathrm{NMR}\left(100 \mathrm{MHz}, \mathrm{CDCl}_{3}\right): \delta[\mathrm{ppm}]=160.9,131.6,129.4$,

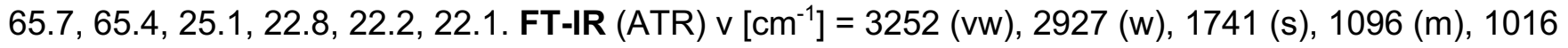
(m). Melting point: $90.1^{\circ} \mathrm{C}$.

\section{R-1-hydroxy-8-(prop-1-en-2-yl)-3-oxa-1-azaspiro[4.5]dec-6-en-2-one (2g)}

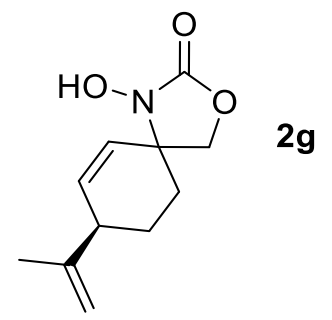

According to the general procedure with GOx/HRP, $\mathbf{1 g}$ was reacted in phosphate buffer containing $10 \%$ EtOAc and full conversion was observed after $4 \mathrm{~h}$. The crude was purified via column chromatography $\left(3: 1 n\right.$-Hep/EtOAc; $R_{f}=0.44(1: 1 n$-Hep/EtOAc) $)$ to yield $\mathbf{2} \mathbf{g}$ as a colorless oil with diastereomeric ratio of $92 \%$ (14.2 mg, $0.068 \mathrm{mmol}, 209.25 \mathrm{~g} / \mathrm{mol}, 97 \%$ ).

Major diastereomer: ${ }^{1} \mathrm{H}-\mathrm{NMR}\left(400 \mathrm{MHz}, \mathrm{CDCl}_{3}\right): \delta[\mathrm{ppm}]=8.03(\mathrm{bs}, 1 \mathrm{H},-\mathrm{OH}), 5.99(\mathrm{dd}, J=10.0,3.8$ $\mathrm{Hz}, 1 \mathrm{H}), 5.67(\mathrm{dd}, J=10.1,1.5 \mathrm{~Hz}, 1 \mathrm{H}), 4.82(\mathrm{~d}, J=34.0 \mathrm{~Hz}, 2 \mathrm{H}), 4.11-3.99(\mathrm{~m}, 2 \mathrm{H}), 2.68(\mathrm{~d}, J=4.9 \mathrm{~Hz}$, $1 \mathrm{H}), 2.30-2.15(\mathrm{~m}, 1 \mathrm{H}), 1.90$ (ddd, $J=13.0,8.0,4.2 \mathrm{~Hz}, 1 \mathrm{H}), 1.76(\mathrm{~s}, 3 \mathrm{H}), 1.78-1.68(\mathrm{~m}, 1 \mathrm{H}), 1.64-1.53$ $(\mathrm{m}, 1 \mathrm{H}) .{ }^{13} \mathrm{C}-\mathrm{NMR}\left(100 \mathrm{MHz}, \mathrm{CDCl}_{3}\right): \delta[\mathrm{ppm}]=159.5,145.7,137.8,126.2,112.7,71.7,62.3,41.3,25.9$, 23.4, 21.7.

Minor diastereomer (selected signals): ${ }^{1} \mathrm{H}-\mathrm{NMR}\left(400 \mathrm{MHz}, \mathrm{CDCl}_{3}\right): \delta[\mathrm{ppm}]=6.09(\mathrm{~d}, J=10.2 \mathrm{~Hz}, 1 \mathrm{H})$, $5.59(\mathrm{~d}, J=9.3 \mathrm{~Hz}, 1 \mathrm{H}), 2.86-2.79(\mathrm{~m}, 1 \mathrm{H}) .{ }^{13} \mathrm{C}-\mathrm{NMR}\left(100 \mathrm{MHz}, \mathrm{CDCl}_{3}\right): \delta[\mathrm{ppm}]=147.2,138.4,126.6$, 111.0, 71.5, 63.0, 42.5, 26.9, 25.2, 20.7. 
FT-IR (ATR) v [ $\left.\mathrm{cm}^{-1}\right]=3263(\mathrm{vw}), 2935(\mathrm{vw}), 1748(\mathrm{~s}), 1451(\mathrm{w}), 1088(\mathrm{~m})$. HRMS (ESI): m/z [M+H'] calcd for $\mathrm{C}_{11} \mathrm{H}_{15} \mathrm{NO}_{3}$ : 210.1125, found: 210.1128 .

\section{E-4-(but-1-en-1-yl)-3-hydroxyoxazolidin-2-one (2j)}<smiles>CC/C=C/C1COC(=O)N1O</smiles>

According to the general procedure with GOx/HRP, E-1j was reacted in phosphate buffer containing $10 \%$ EtOAc and full conversion was observed after $2 \mathrm{~h}$. The crude was purified via column chromatography (4:1 $n$-Hep/EtOAc; $R_{f}=0.34(1: 1 n$-Hep/EtOAc)) to yield $2 \mathbf{j}$ as a colorless oil with $E / Z$ ratio of $75: 25(7.3 \mathrm{mg}, 0.046 \mathrm{mmol}, 157.17 \mathrm{~g} / \mathrm{mol}, 66 \%)$. Spectral data are in agreement with literature precedent. ${ }^{[2]}$

E-Isomer: ${ }^{1} \mathrm{H}-\mathrm{NMR}\left(400 \mathrm{MHz}, \mathrm{CDCl}_{3}\right): \delta[\mathrm{ppm}]=7.72(\mathrm{bs}, 1 \mathrm{H},-\mathrm{OH}), 5.94(\mathrm{dt}, J=15.3,6.3 \mathrm{~Hz}, 1 \mathrm{H}, 5.38$ (ddt, $J=15.4,8.3,1.6 \mathrm{~Hz}, 1 \mathrm{H}), 4.39(\mathrm{t}, J=8.1 \mathrm{~Hz}, 1 \mathrm{H}), 4.30(\mathrm{dd}, J=16.8,8.3 \mathrm{~Hz}, 1 \mathrm{H}), 3.95(\mathrm{t}, J=8.1$ $\mathrm{Hz}, 1 \mathrm{H}), 2.26-2.04(\mathrm{~m}, 2 \mathrm{H}), 1.02(\mathrm{t}, J=7.4 \mathrm{~Hz}, 3 \mathrm{H}) .{ }^{13} \mathrm{C}-\mathrm{NMR}\left(100 \mathrm{MHz}, \mathrm{CDCl}_{3}\right): \delta[\mathrm{ppm}]=159.4,137.3$, $123.5,67.0,34.3,22.0,13.6$.

Z-Isomer (selected signals): ${ }^{1} \mathrm{H}-\mathrm{NMR}\left(400 \mathrm{MHz}, \mathrm{CDCl}_{3}\right): \delta[\mathrm{ppm}]=5.84(\mathrm{dt}, \mathrm{J}=10.7,7.7 \mathrm{~Hz}, 1 \mathrm{H}), 4.72$ (q, $J=9.1 \mathrm{~Hz}, 1 \mathrm{H}), 1.01(\mathrm{t}, J=7.5 \mathrm{~Hz}, 3 \mathrm{H}) .{ }^{13} \mathrm{C}-\mathrm{NMR}\left(100 \mathrm{MHz}, \mathrm{CDCl}_{3}\right): \delta[\mathrm{ppm}]=66.6,22.5,14.0$.

FT-IR (ATR) v [cm $\left.{ }^{-1}\right]=3265(\mathrm{vw}), 2965(\mathrm{vw}), 1754(\mathrm{~s}), 1462(\mathrm{w}), 1210(\mathrm{w}), 1081(\mathrm{~m})$.

\section{2-hydroxy-3-(2-hydroxypropan-2-yl)isoindolin-1-one (7)}<smiles>CC(C)(O)C1c2ccccc2C(=O)N1O</smiles>

According to the general procedure with GOx/HRP, 1 ( (was reacted in phosphate buffer containing $10 \%$ EtOAc. The reaction mixture was extracted after $30 \mathrm{~h}$. The crude of four reactions was combined and purified via column chromatography $\left(1: 1 n\right.$-Hep/EtOAc; $R_{f}=0.11(1: 1 n$-Hep/EtOAc) $)$ to yield 7 as a white solid (7.7 mg, $0.041 \mathrm{mmol}, 207.23 \mathrm{~g} / \mathrm{mol}, 13 \%)$ and reisolate $1 \mathrm{l}(33.2 \mathrm{mg}, 0.174 \mathrm{mmol}, 62 \%)$.

${ }^{1} \mathrm{H}-\mathrm{NMR}\left(400 \mathrm{MHz}, \mathrm{CD}_{3} \mathrm{OD}\right): \delta[\mathrm{ppm}]=7.86(\mathrm{~d}, J=7.7 \mathrm{~Hz}, 1 \mathrm{H}), 7.74(\mathrm{~d}, J=7.5 \mathrm{~Hz}, 1 \mathrm{H}), 7.61(\mathrm{td}, J=$ 7.6, 1.2 Hz, 1H), $7.51(\mathrm{t}, J=7.5 \mathrm{~Hz}, 1 \mathrm{H}), 5.02(\mathrm{~s}, 1 \mathrm{H}), 1.62(\mathrm{~s}, 3 \mathrm{H}), 0.78(\mathrm{~s}, 3 \mathrm{H}) .{ }^{13} \mathrm{C}-\mathrm{NMR}(100 \mathrm{MHz}$, $\left.\mathrm{CD}_{3} \mathrm{OD}\right): \delta[\mathrm{ppm}]=168.4,142.0,133.0,131.5,129.6,126.9,123.6,84.0,67.5,24.6,19.2$.

HRMS (ESI): $\quad \mathrm{m} / \mathrm{z}\left[\mathrm{M}+\mathrm{H}^{+}\right]$calcd for $\mathrm{C}_{11} \mathrm{H}_{14} \mathrm{NO}_{3}: 208.0969$, found: 208.0968 .

$\mathrm{m} / \mathrm{z}\left[\mathrm{M}+\mathrm{Na}^{+}\right]$calcd for $\mathrm{C}_{11} \mathrm{H}_{13} \mathrm{NO}_{3} \mathrm{Na:} 230.0787$, found: 230.0789 .

$\mathrm{m} / \mathrm{z}\left[\mathrm{M}-\mathrm{iPrOH}+\mathrm{H}^{+}\right]$calcd for $\mathrm{C}_{8} \mathrm{H}_{6} \mathrm{NO}_{2}: 148.0394$, found: 148.0394 .

$\mathrm{m} / \mathrm{z}$ [M-iPrOH$\left.+\mathrm{Na}^{+}\right]$calcd for $\mathrm{C}_{8} \mathrm{H}_{5} \mathrm{NO}_{2} \mathrm{Na:}$ 170.0213, found: 170.0212 . 


\subsection{GOx/HRP mediated nitroso-Diels-Alder reactions}

\section{3,10-dioxa-1-azabicyclo[5.3.1] undec-7-en-2-one (6)}<smiles>O=C1OCCC2=CCON1C2</smiles>

According to the general procedure with GOx/HRP, 1k was reacted and full conversion was observed after $4 \mathrm{~h}$. The crude was purified via column chromatography $\left(3: 1 n\right.$-Hep/EtOAc: $R_{f}=0.45(1: 1 n$ Hep/EtOAc)) to yield 6 as colorless crystals $(4.3 \mathrm{mg}, 0.026 \mathrm{mmol}, 169.18 \mathrm{~g} / \mathrm{mol}, 36 \%)$. Spectral data are in agreement with literature precedent. ${ }^{[13]}$

${ }^{1} \mathrm{H}-\mathrm{NMR}\left(400 \mathrm{MHz}, \mathrm{CDCl}_{3}\right): \delta[\mathrm{ppm}]=5.79-5.74(\mathrm{~m}, 1 \mathrm{H}), 4.73(\mathrm{dd}, J=14.3,5.5 \mathrm{~Hz}, 1 \mathrm{H}), 4.44-4.33(\mathrm{~m}$, 2H), 2.20 (dd, $J=15.0,2.0 \mathrm{~Hz}, 1 \mathrm{H}), 4.15-4.04(\mathrm{~m}, 1 \mathrm{H}), 3.49(\mathrm{~d}, J=15.0 \mathrm{~Hz}, 1 \mathrm{H}), 2.56-2.39(\mathrm{~m}, 1 \mathrm{H})$, 2.35-2.16 (m, 2H), 1.97-1.84 (m, 1H). ${ }^{13} \mathrm{C}-\mathrm{NMR}\left(100 \mathrm{MHz}, \mathrm{CDCl}_{3}\right): \delta[\mathrm{ppm}]=164.2,142.1,123.0,71.8$, 67.3, 52.6, 31.8, 27.4. FT-IR (ATR) $\vee\left[\mathrm{cm}^{-1}\right]=2928(\mathrm{vw}), 1742$ (s), 1443 (w), 1159 (s), 1050 (s). Melting point: $38.0^{\circ} \mathrm{C}$.

\subsection{GOx/HRP mediated intermolecular nitroso ene reaction}

\section{Benzyl (2,3-dimethylbut-3-en-2-yl)(hydroxy)carbamate (5)}<smiles>C=C(C)C(C)(C)N(O)C(=O)OC(C)(C)C</smiles>

To a $10 \mathrm{mM}$ solution of 3 in $7 \mathrm{~mL}$ phosphate buffer $(100 \mathrm{mM}, \mathrm{pH} 7.0)$ including 10 vol\% of EtOAc was added 2,3-dimethylbut-2-ene. $70 \mathrm{U}$ horseradish peroxidase and $70 \mathrm{U}$ glucose oxidase (Aspergillus Niger). D-glucose $(50 \mathrm{mM})$ was added and the reaction was incubated at $25^{\circ} \mathrm{C}$. After full conversion of starting material (followed by TLC), the reaction mixture was extracted $3 \times$ with EtOAc. The combined organic phases were dried over $\mathrm{Na}_{2} \mathrm{SO}_{4}$, filtered and the solvent was removed under reduced pressure. The crude was purified via flash column chromatography on silica gel (12:1 $n$-Hep/EtOAc; $R_{f}=0.68(1: 1$ $n$-Hep/EtOAc)) to afford $\mathbf{5}$. Spectral data are in agreement with literature precedent. ${ }^{[2]}$

${ }^{1} \mathrm{H}-\mathrm{NMR}\left(400 \mathrm{MHz}, \mathrm{CDCl}_{3}\right): \delta[\mathrm{ppm}]=7.37-7.30(\mathrm{~m}, 5 \mathrm{H}), 6.23(\mathrm{bs}, 1 \mathrm{H}), 5.17(\mathrm{~s}, 2 \mathrm{H}), 4.85(\mathrm{~s}, 1 \mathrm{H}), 4.77$ (s, 1H), $1.75(\mathrm{~s}, 3 \mathrm{H}), 1.48(\mathrm{~s}, 6 \mathrm{H}) .{ }^{13} \mathrm{C}-\mathrm{NMR}(100 \mathrm{MHz}, \mathrm{CDCl} 3): \delta[\mathrm{ppm}]=158.1,149.5,135.8,128.5$, 128.3, 128.2, 109.4, 68.0, 66.0, 25.4, 19.1. FT-IR (ATR) v [cm $\left.{ }^{-1}\right]=3298(\mathrm{vw}), 2925(\mathrm{vw}), 1681(\mathrm{~m}), 1326$ (m), $1096(\mathrm{~m})$.

Table S1. Screening of 2,3-dimethylbut-2-ene loading.

\begin{tabular}{ccc}
\hline Entry & 2,3-dimethylbut-2-ene & yield [\%] ${ }^{[\mathrm{a}]}$ \\
\hline 1 & $1.0 \mathrm{eq}$. & 30 \\
2 & $1.5 \mathrm{eq}$. & 51 \\
3 & $5.0 \mathrm{eq}$. & 55 \\
4 & as cosolvent $^{[\mathrm{b}]}$ & 86 \\
\hline
\end{tabular}

[a] isolated yield. [b] $10 \mathrm{vol} \%$; instead of EtOAc. 


\section{Peroxidase Screening}

General procedure for peroxidase screenings: To a $10 \mathrm{mM}$ solution of 1a in $7 \mathrm{~mL}$ phosphate buffer (100 mM, pH 7.0), was added $70 \mathrm{U}$ peroxidase and $70 \mathrm{U}$ glucose oxidase (Aspergillus Niger). D-glucose $(50 \mathrm{mM})$ was added and the reaction was incubated at $25^{\circ} \mathrm{C}$. The conversion was followed by TLC. After full conversion, the reaction mixture was extracted $3 \times$ with EtOAc. The combined organic phases were dried over $\mathrm{Na}_{2} \mathrm{SO}_{4}$, filtered and the solvent was removed under reduced pressure. The crude was purified via silica pad filtration or flash column chromatography on silica gel. Reactions with lactoperoxidase and chloroperoxidase were performed in citrate buffer $(100 \mathrm{mM}, \mathrm{pH} 5.5)$.

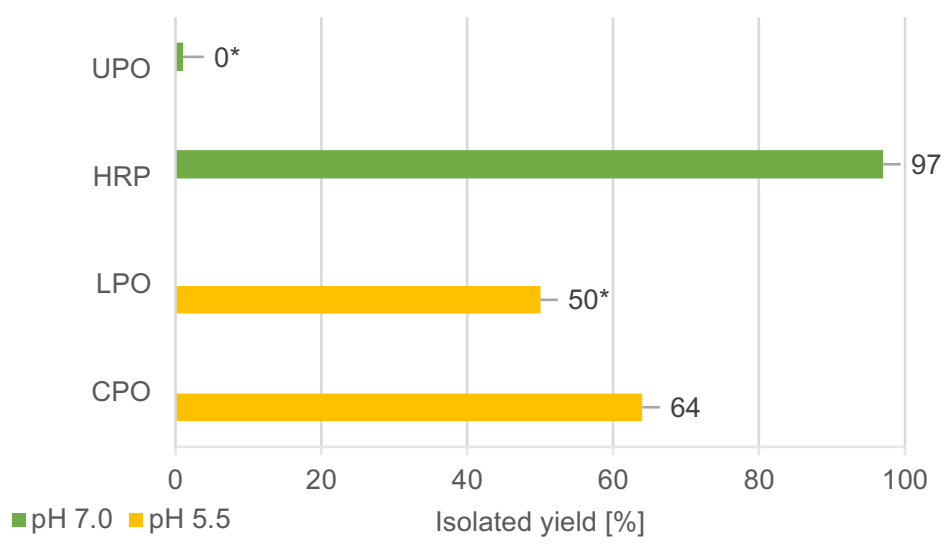

Figure S1. Screening of different peroxidases in the nitroso-ene reaction of 1a. $\left.{ }^{\star}\right]$ Conversion; yield not determined.

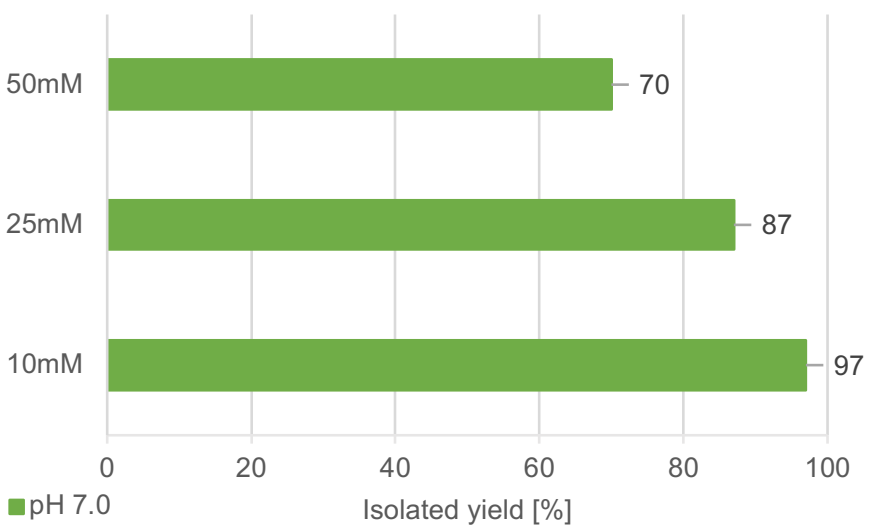

Figure S2. Screening of different substrate loadings in the nitroso-ene reaction of 1a. 


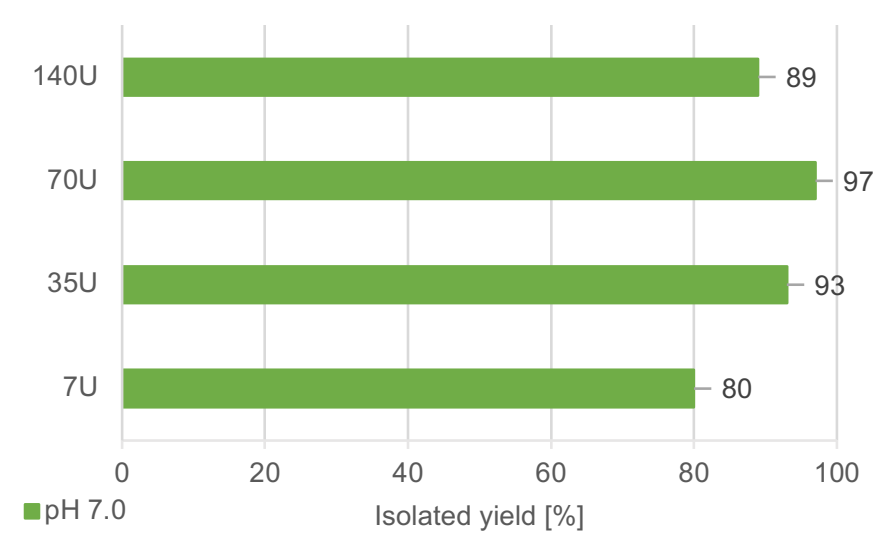

Figure S3. Screening of different GOx loadings at in the nitroso ene reaction of 1a.

\section{Laccase Screening}

General procedure for laccase screenings: To a $10 \mathrm{mM}$ solution of $1 \mathrm{a}$ in $7 \mathrm{~mL}$ buffer was added $100 \mathrm{U}$ laccase and the reaction was incubated at $20^{\circ} \mathrm{C}$. Full conversion of starting material was followed by TLC, the reaction mixture was extracted $3 \times$ with EtOAc. The combined organic phases were dried over $\mathrm{Na}_{2} \mathrm{SO}_{4}$, filtered and the solvent was removed under reduced pressure. The crude was purified via flash column chromatography (3:1 $n$-Hep/EtOAc) on silica gel to afford $\mathbf{2 a}$.

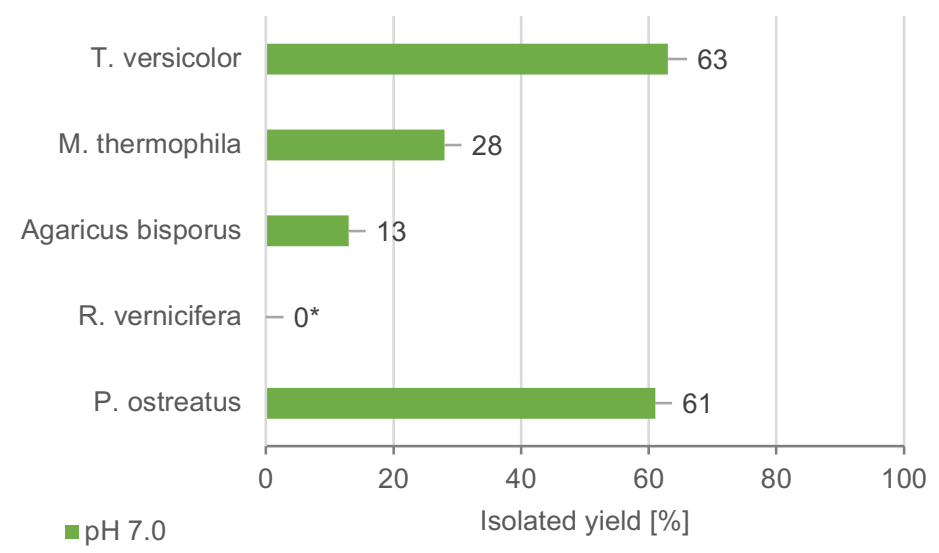

Figure S4. Screening of different laccases in the nitroso-ene reaction of 1a. $\left.{ }^{*}\right]$ no conversion. 


\section{Kinetic isotope studies}

Two reaction sets were run with $\mathbf{1 a}$ and $\mathbf{1} \mathbf{a}-\mathbf{d}_{\mathbf{6}}$ to calculate the kinetic isotope effect (KIE). To a $10 \mathrm{mM}$ solution of substrate in $7 \mathrm{~mL}$ phosphate buffer $(100 \mathrm{mM}, \mathrm{pH} 7.0)$ was added $3.5 \mathrm{U}$ horseradish peroxidase and $3.5 \mathrm{U}$ glucose oxidase (Aspergillus Niger). D-glucose $(6.25 \mathrm{mM})$ was added and the reaction was incubated at $25^{\circ} \mathrm{C}$. The reaction was stopped at different times $(5,10,15,20,25,30 \mathrm{~min})$ and worked up as followed. The reaction mixture was extracted $3 \times$ with EtOAc. The combined organic phases were dried over $\mathrm{Na}_{2} \mathrm{SO}_{4}$, filtered through a silica pad and the solvent was removed under reduced pressure. The conversion was determined by ${ }^{1} \mathrm{H}-\mathrm{NMR}$ analysis, from which the KIE was calculated. Both reaction sets were performed twice under the same conditions. The overall average KIE was determined as inverse $\beta$ secondary kinetic isotope effect $k_{H} / k_{D}=0.79 \pm 0.04$.

Table S2. Results of kinetic measurements of $1 \mathrm{a}$ and $1 \mathrm{a}-\mathrm{d}_{6}$.

\begin{tabular}{|c|c|c|c|c|c|c|c|c|}
\hline \multirow[t]{2}{*}{ Entry } & \multirow{2}{*}{$\begin{array}{c}\text { time } \\
\text { [min] }\end{array}$} & \multicolumn{4}{|c|}{ conversion $[\%]^{[a]}$} & \multicolumn{3}{|c|}{$\mathrm{kH}_{\mathrm{H}} / \mathrm{k}_{\mathrm{D}}$} \\
\hline & & $1 a$ & $1 a^{[b]}$ & $1 \mathbf{a}-d_{6}$ & $1 a-d 6^{[b]}$ & $1^{\text {st }}$ set & $2^{\text {nd }}$ set & averaged \\
\hline 1 & 5 & 4.0 & 3.8 & 6.9 & 5.8 & 0.57 & 0.66 & $0.61 \pm 0.05$ \\
\hline 2 & 10 & 7.6 & 8.4 & 9.2 & 10.9 & 0.82 & 0.77 & $0.8 \pm 0.03$ \\
\hline 3 & 15 & 11.8 & 14.1 & 13.1 & 14.2 & 0.9 & 0.99 & $0.95 \pm 0.05$ \\
\hline 4 & 20 & 13.0 & 16.8 & 19.3 & 21.0 & 0.68 & 0.8 & $0.74 \pm 0.06$ \\
\hline 5 & 25 & 16.5 & 18.4 & 22.7 & 26.3 & 0.73 & 0.7 & $0.71 \pm 0.02$ \\
\hline 6 & 30 & 23.9 & 25.0 & 27.4 & 26.3 & 0.87 & 0.95 & $0.91 \pm 0.04$ \\
\hline
\end{tabular}

[a] Determined by ${ }^{1} \mathrm{H}-\mathrm{NMR}$ analysis. [b] Second reaction set with identical conditions.

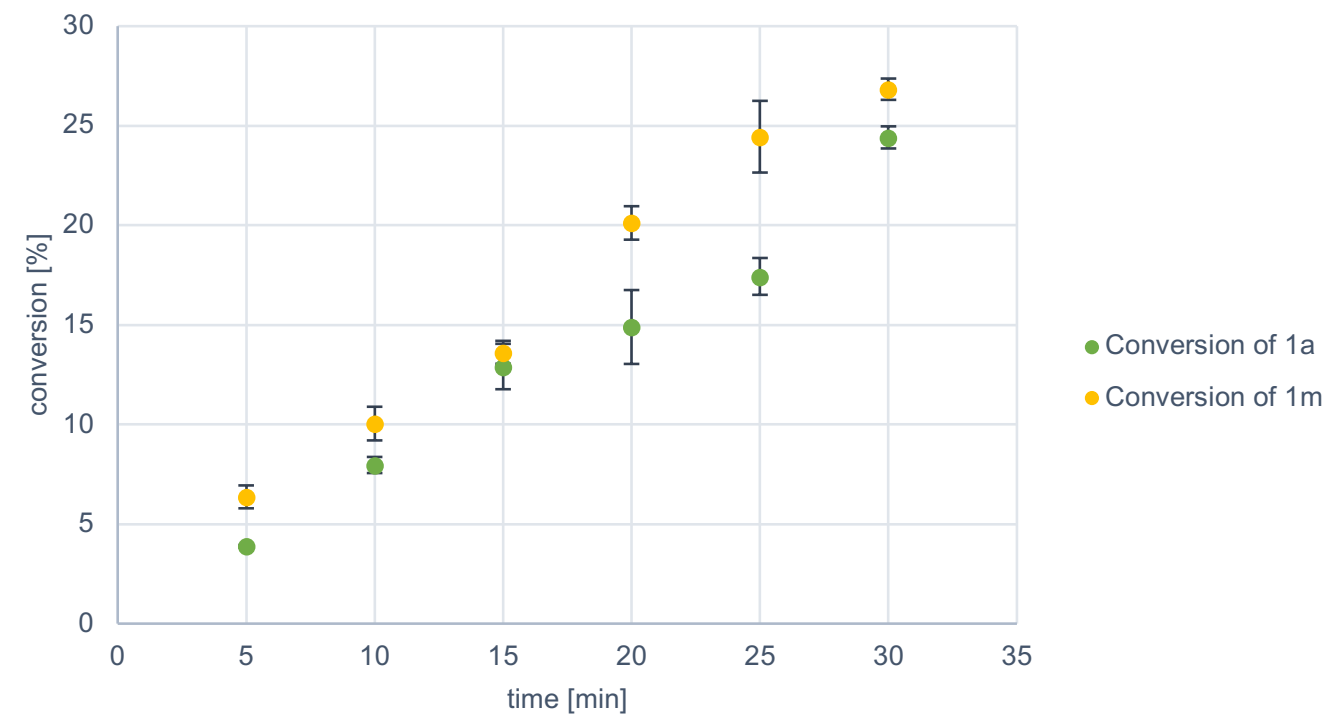

Figure S7. initial rates for the HRP-mediated conversions of $1 \mathrm{a}$ and $\mathbf{1 a -} \mathrm{d}_{6}$. 
6. NMR Spectra
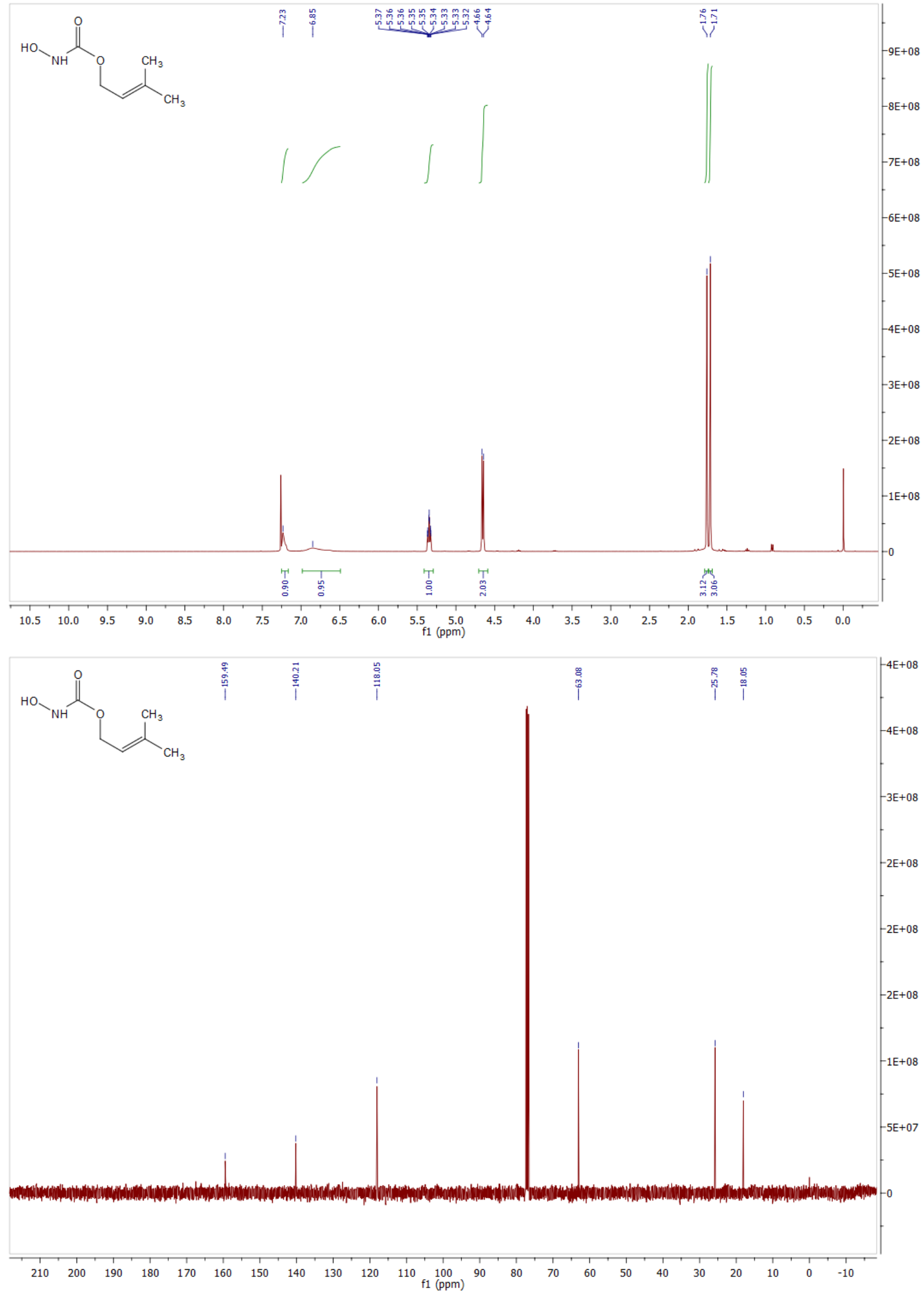


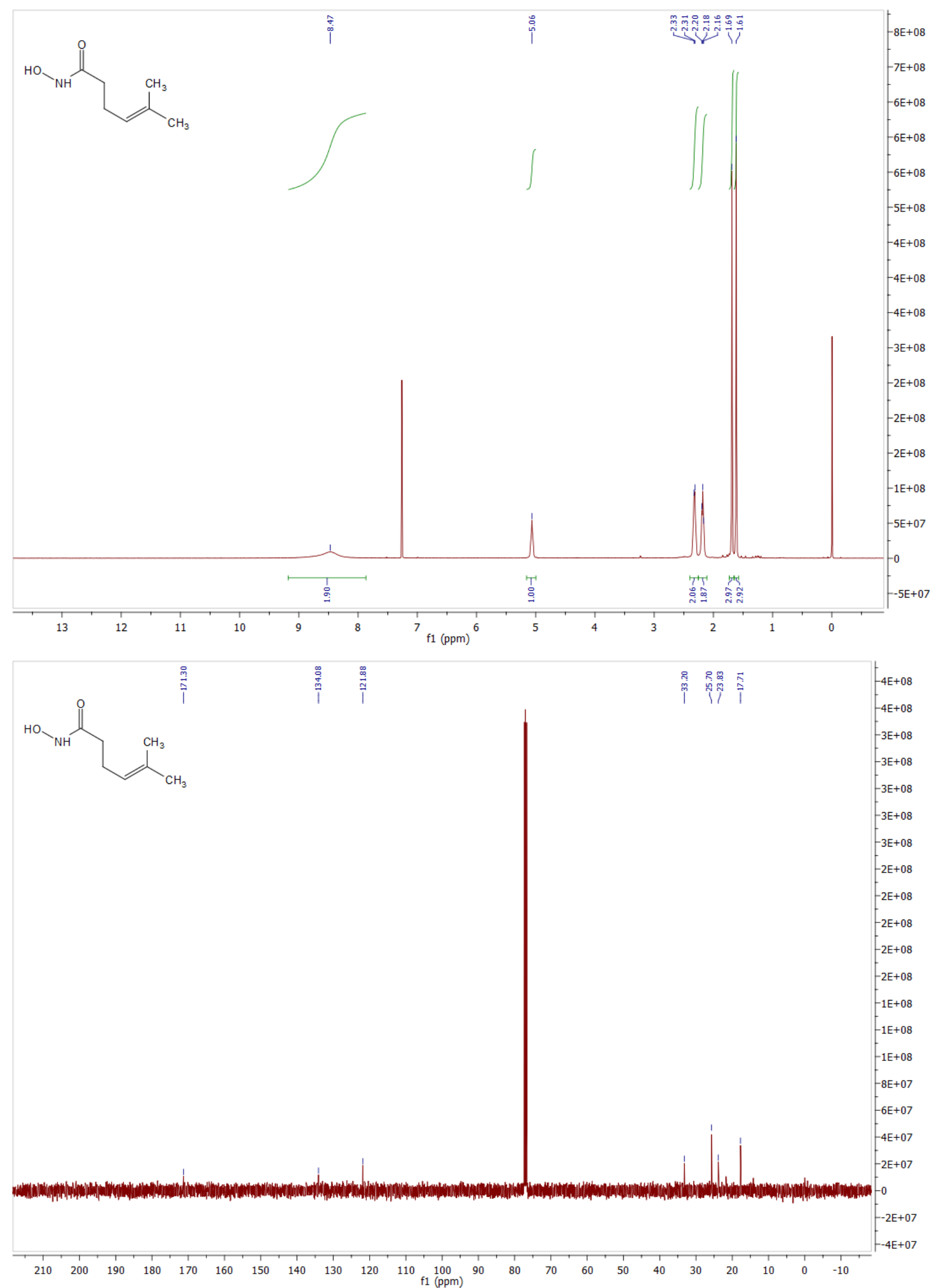



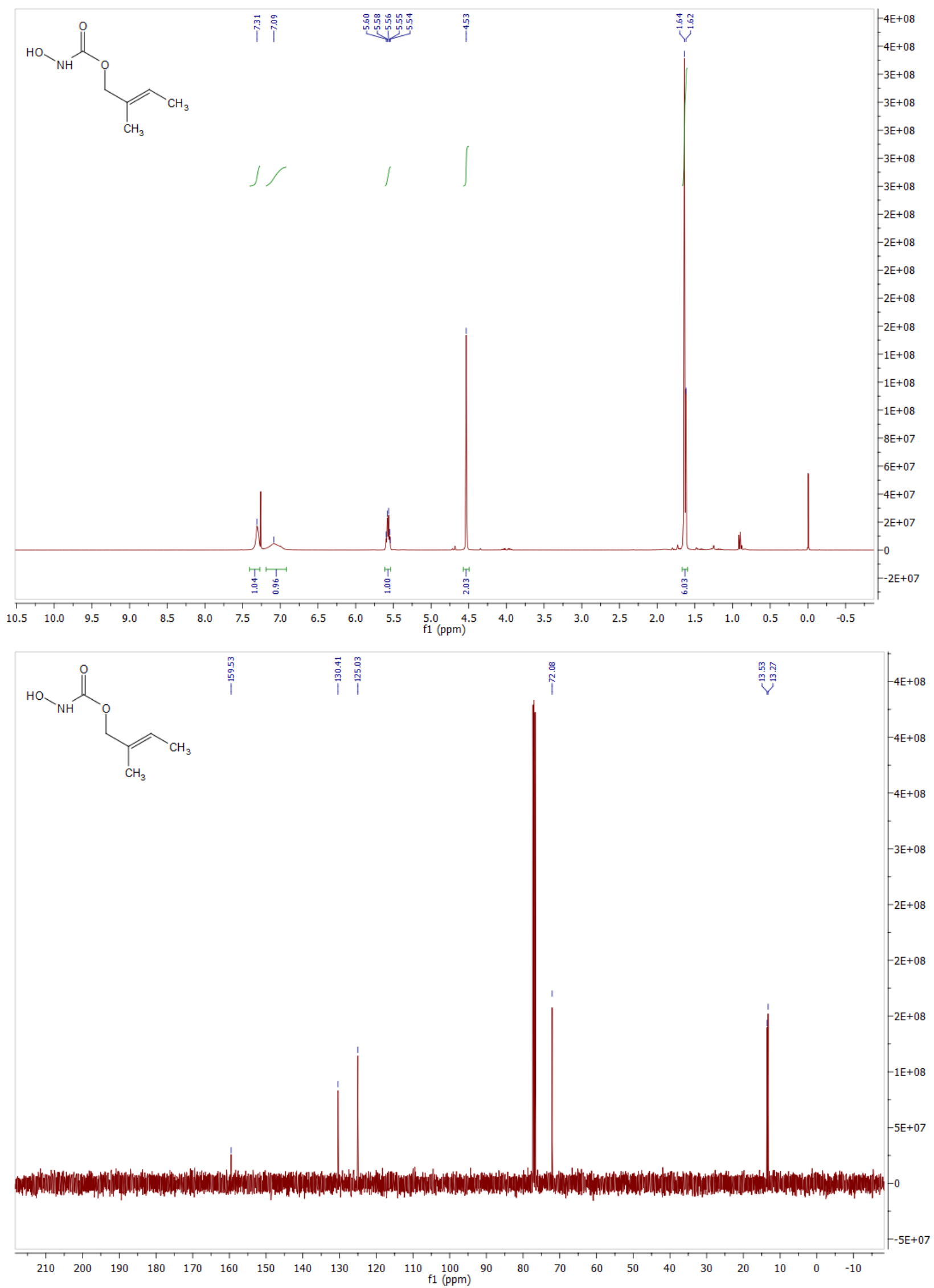


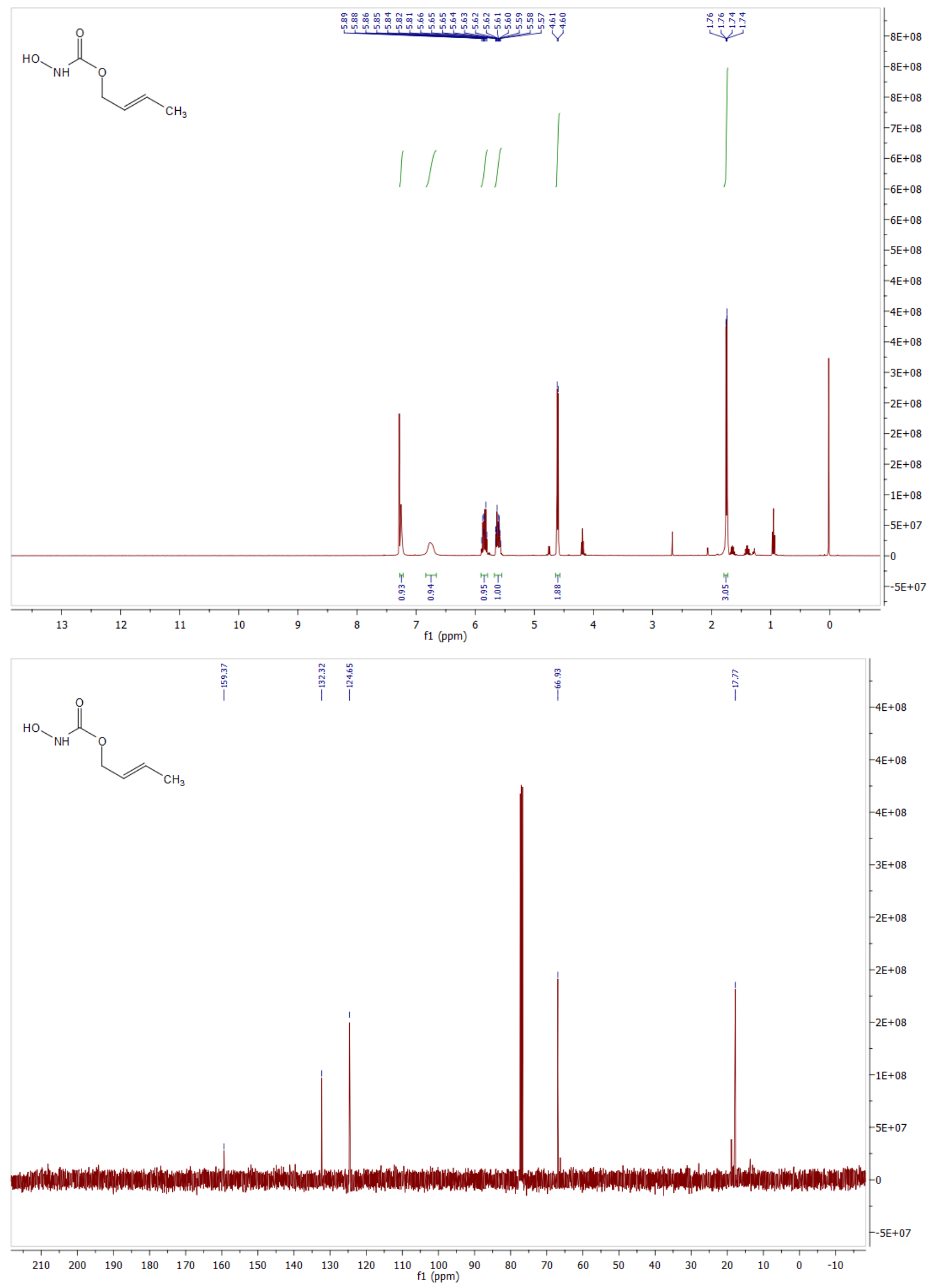




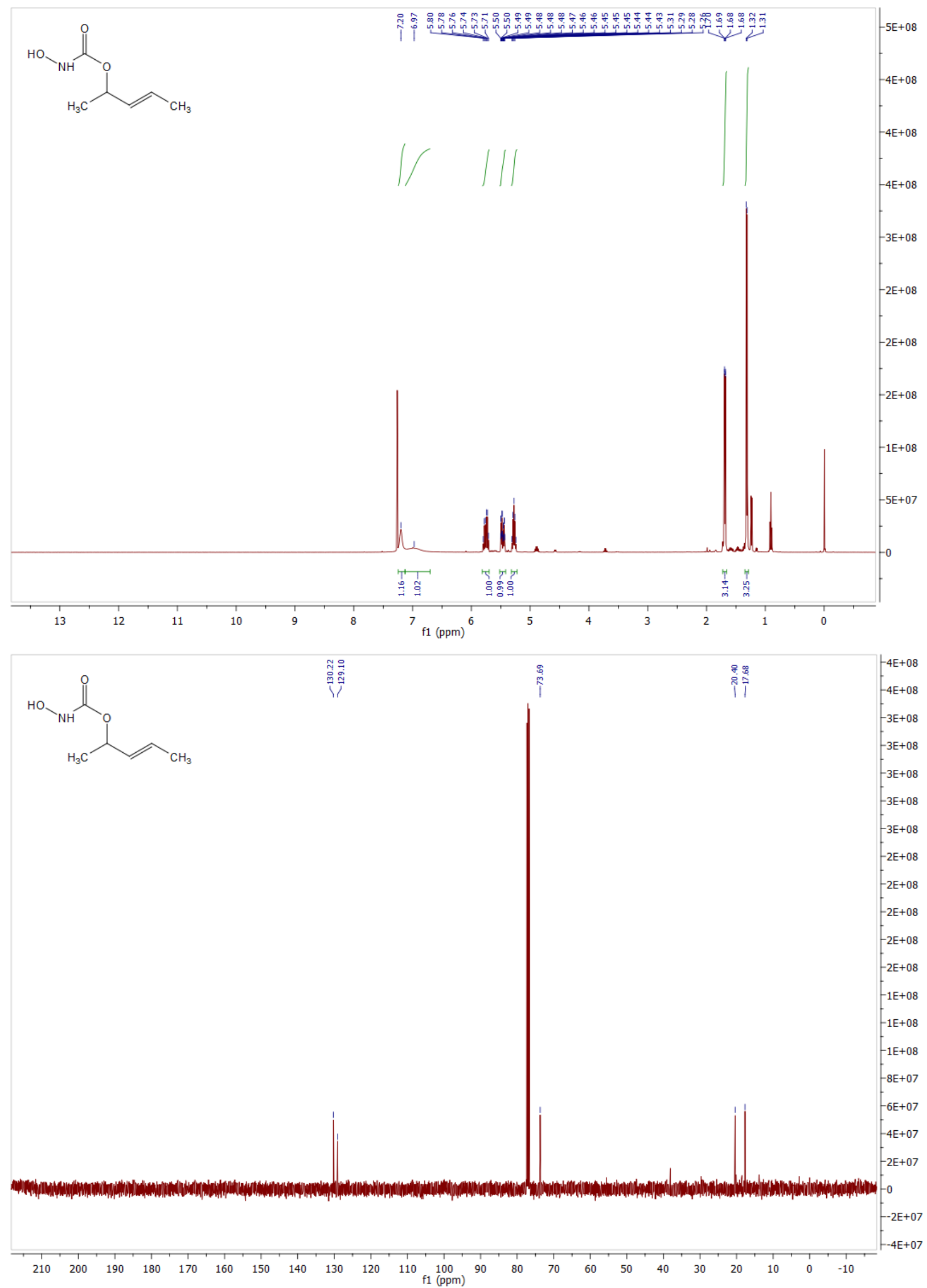



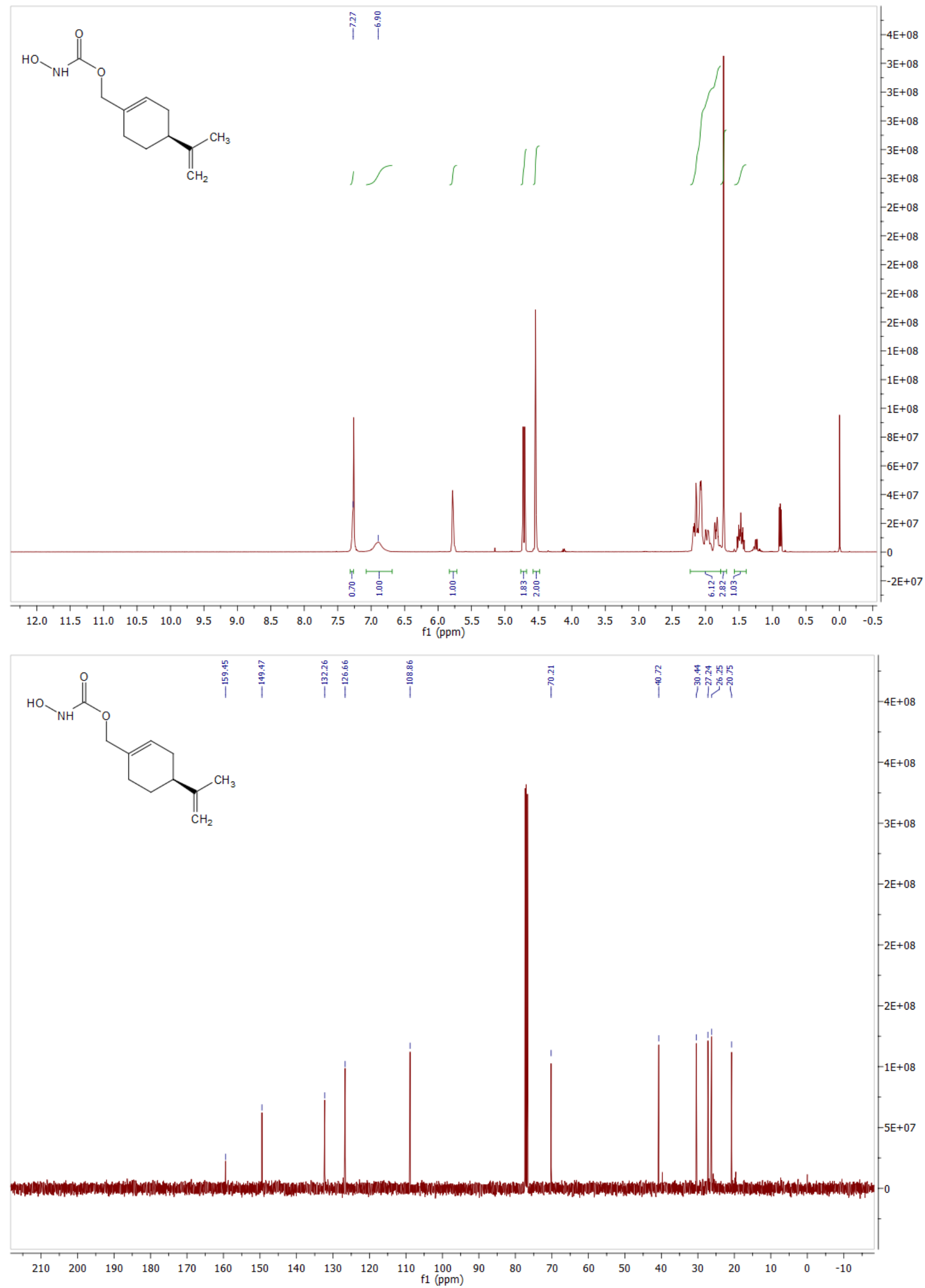

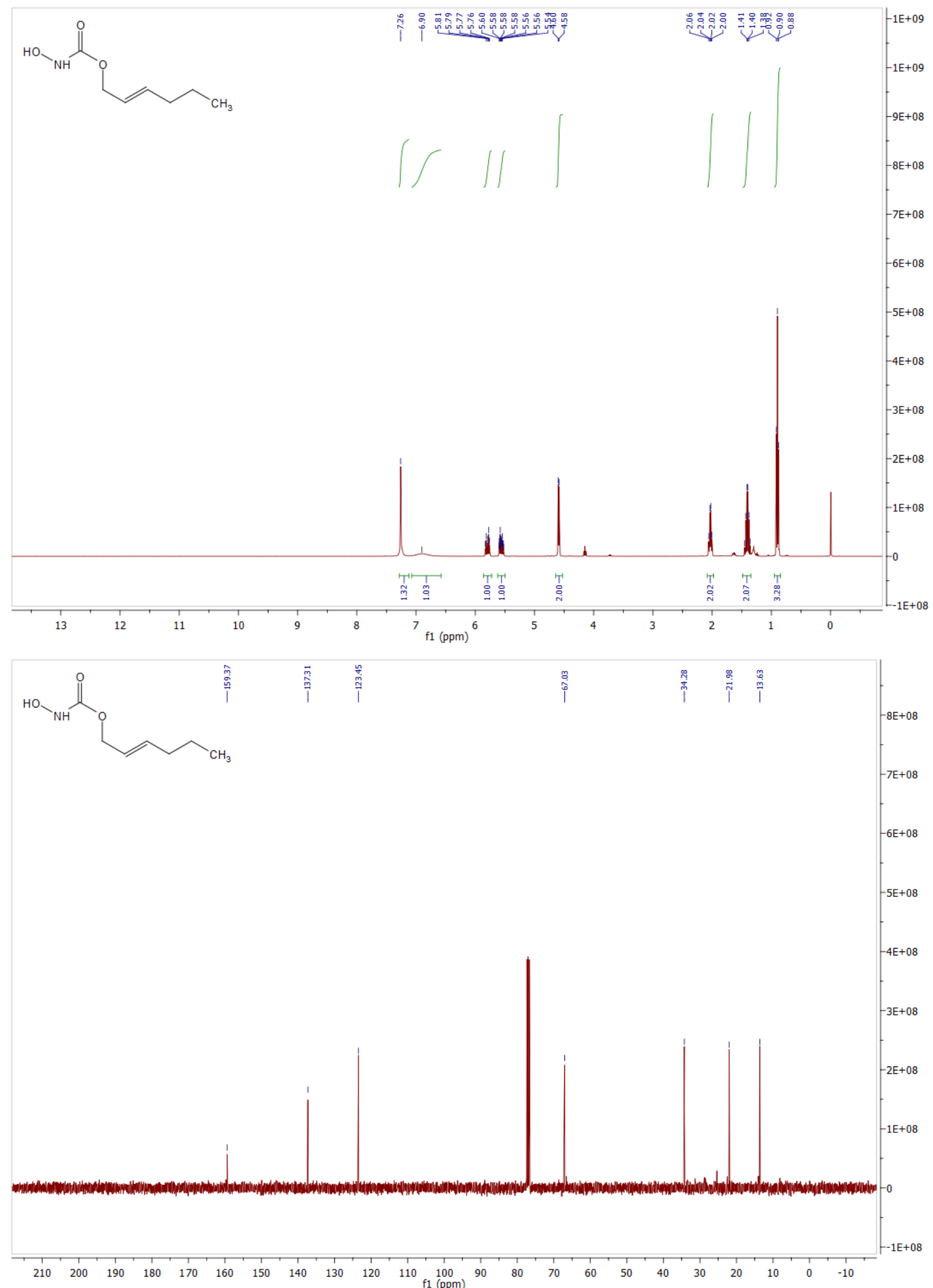


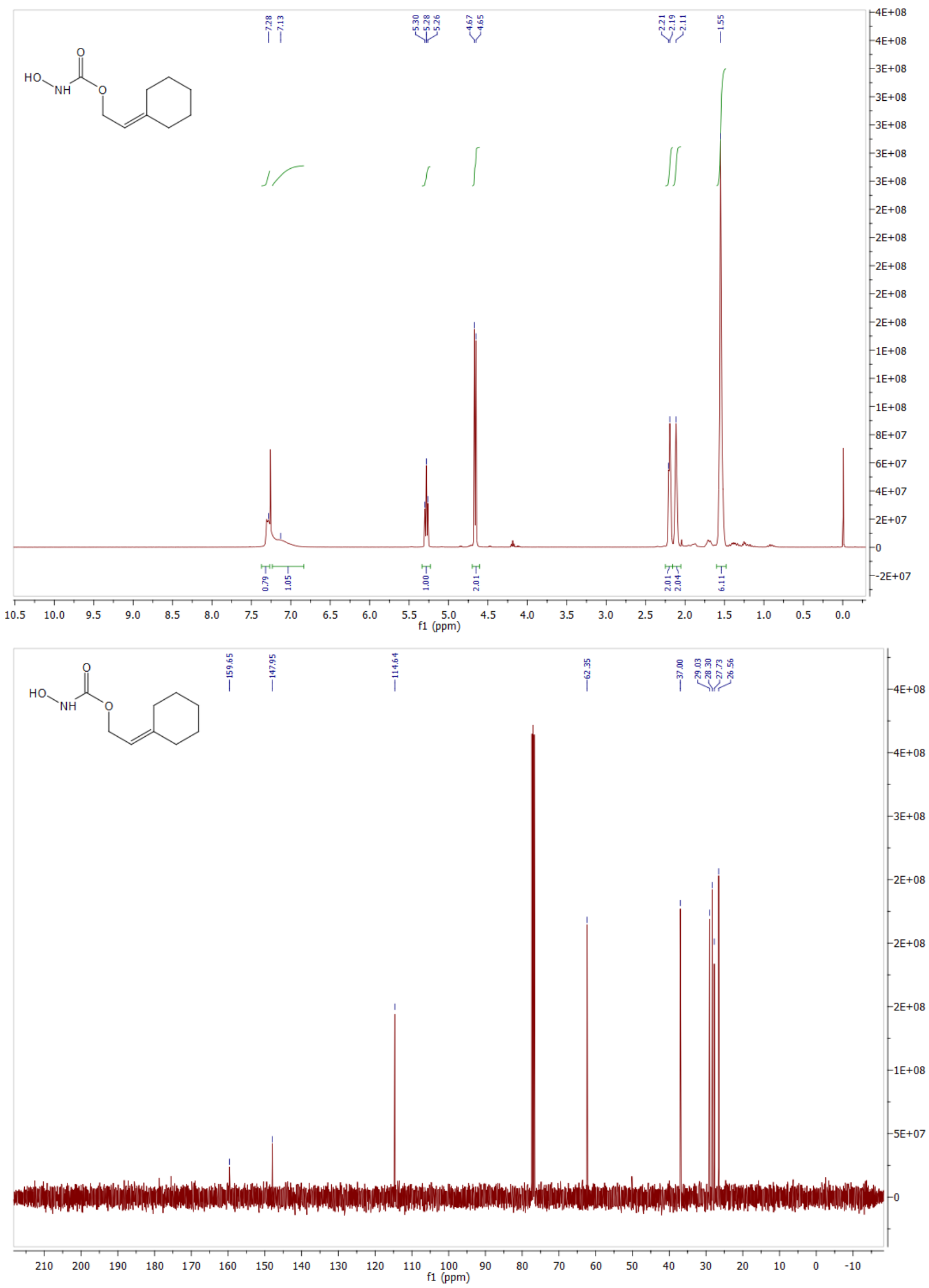



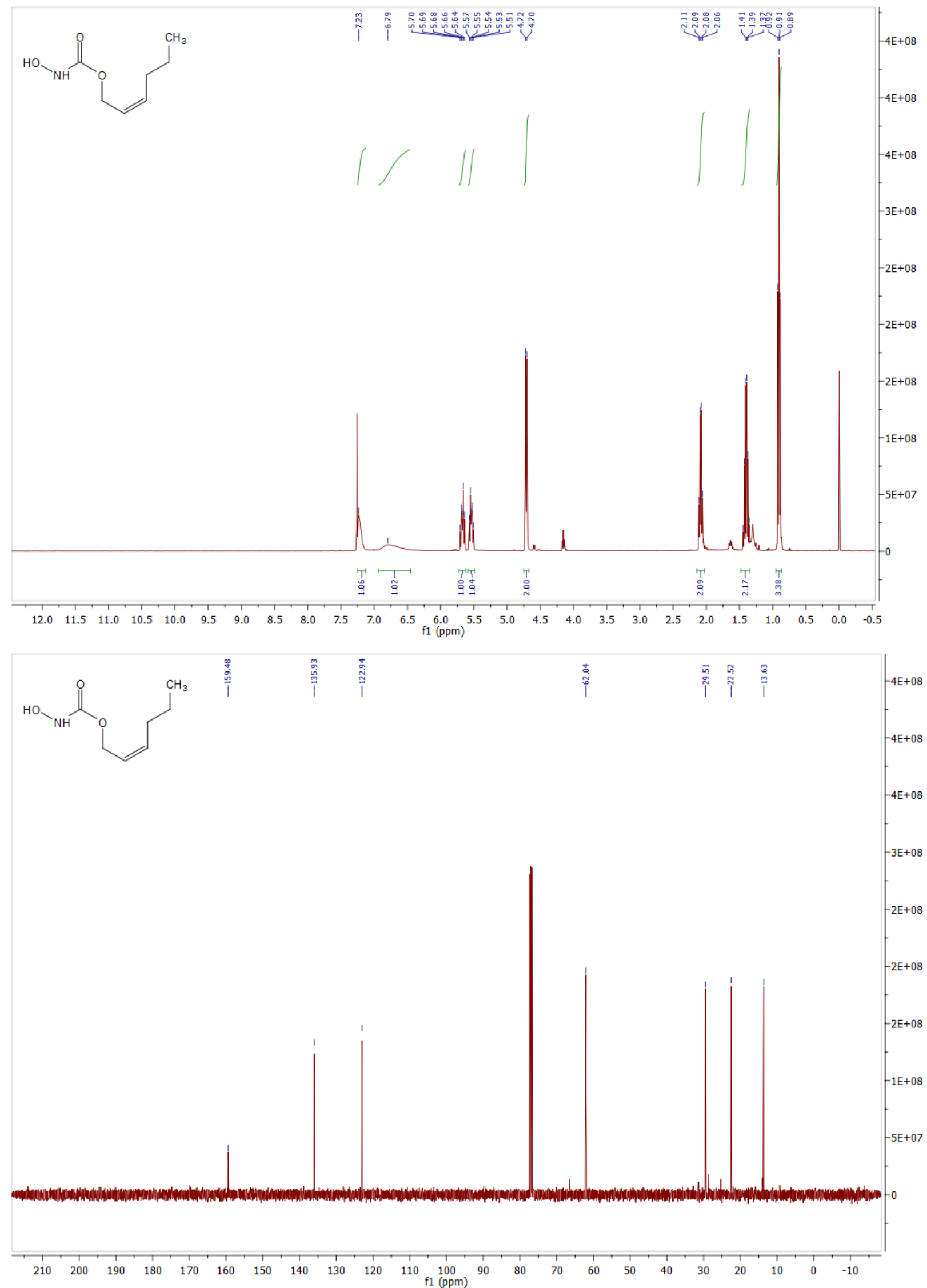

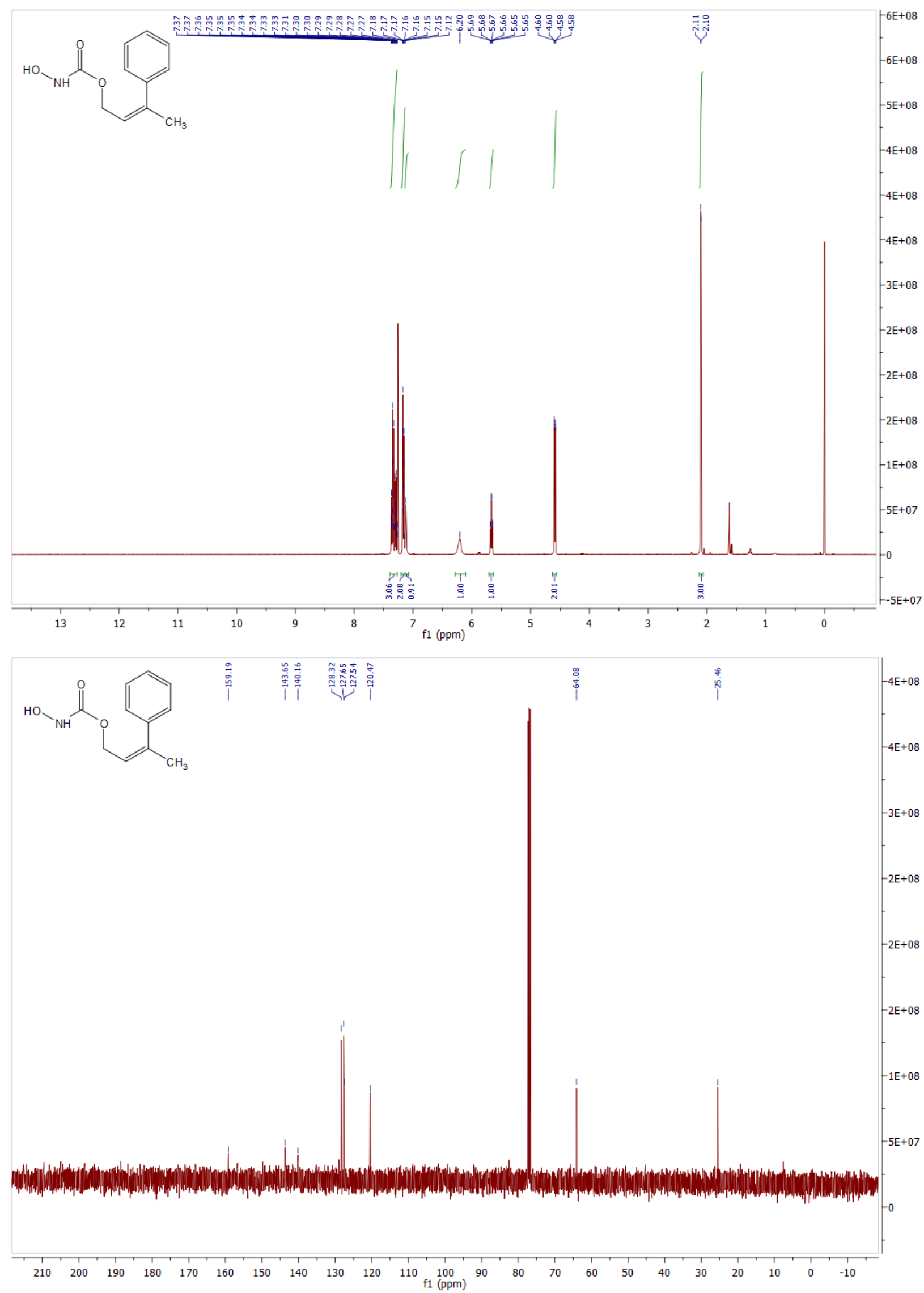


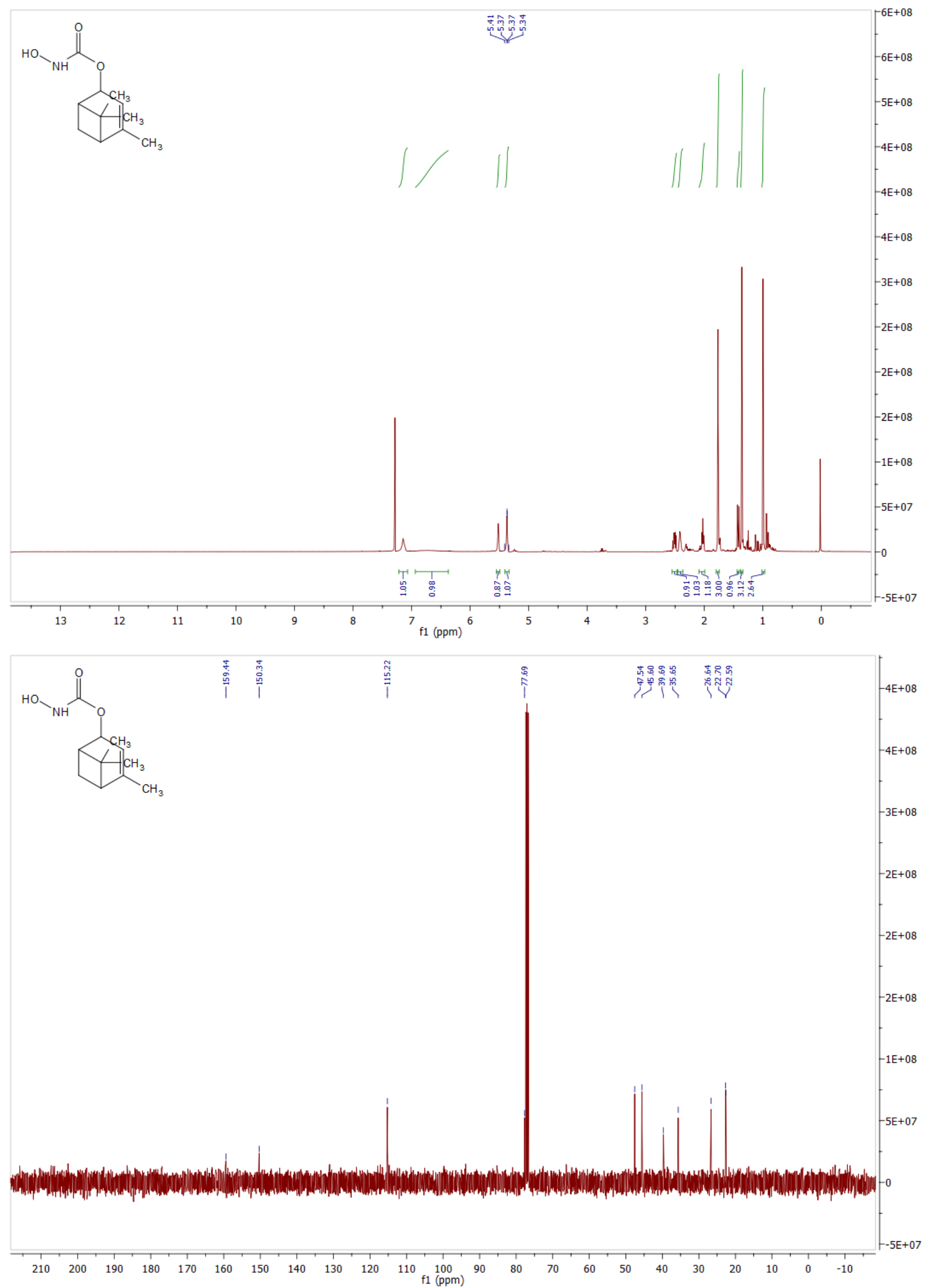



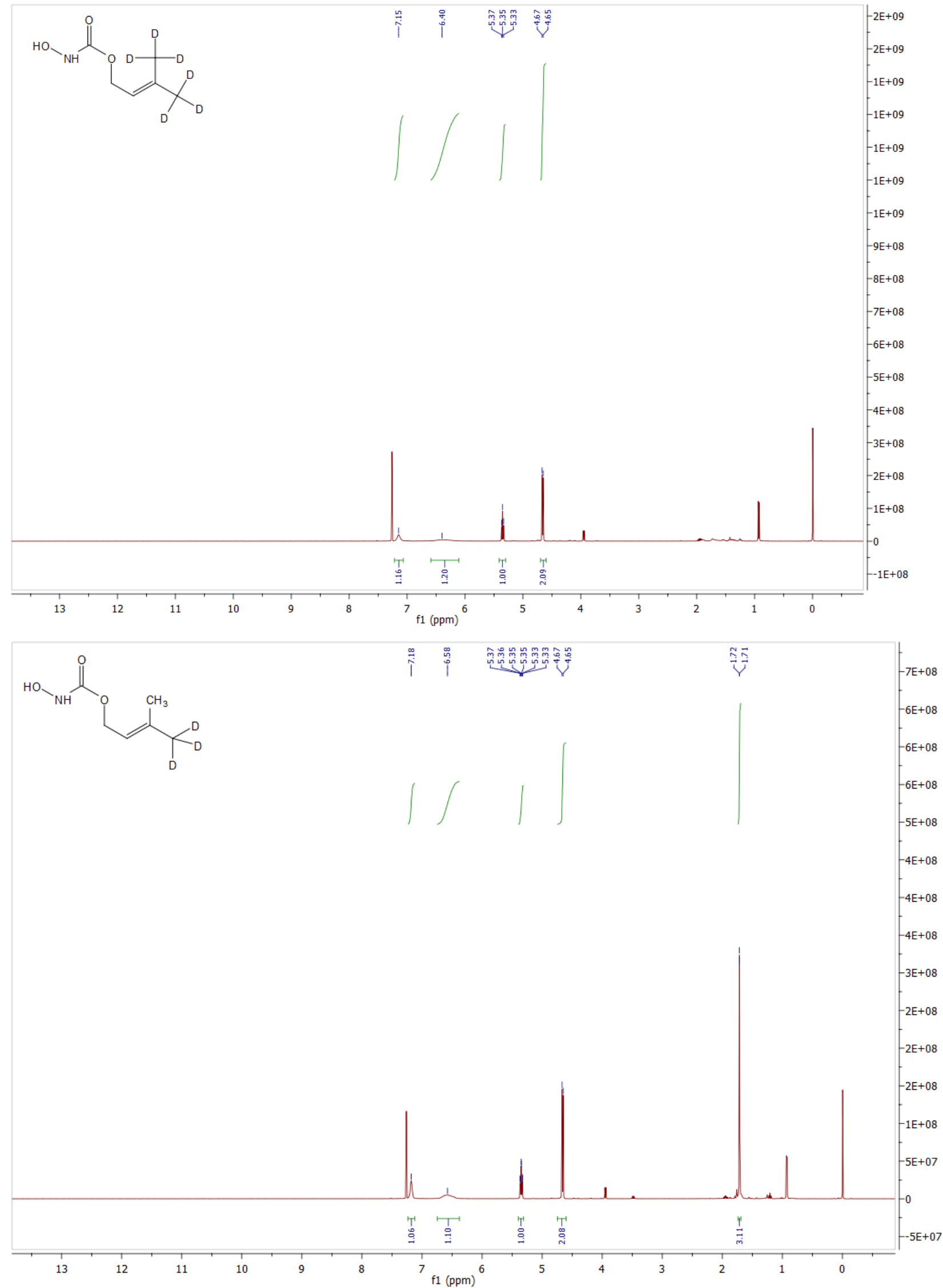


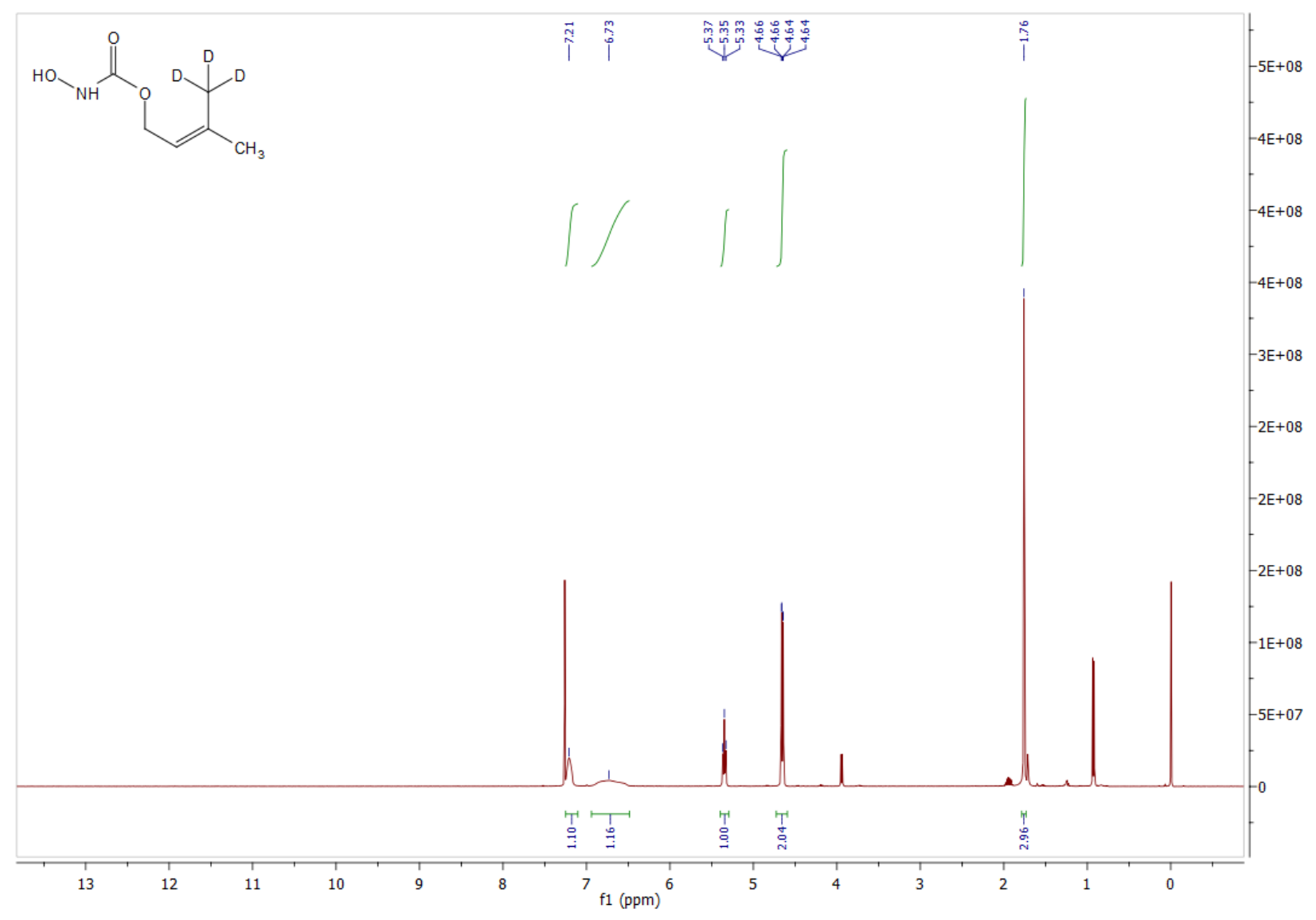



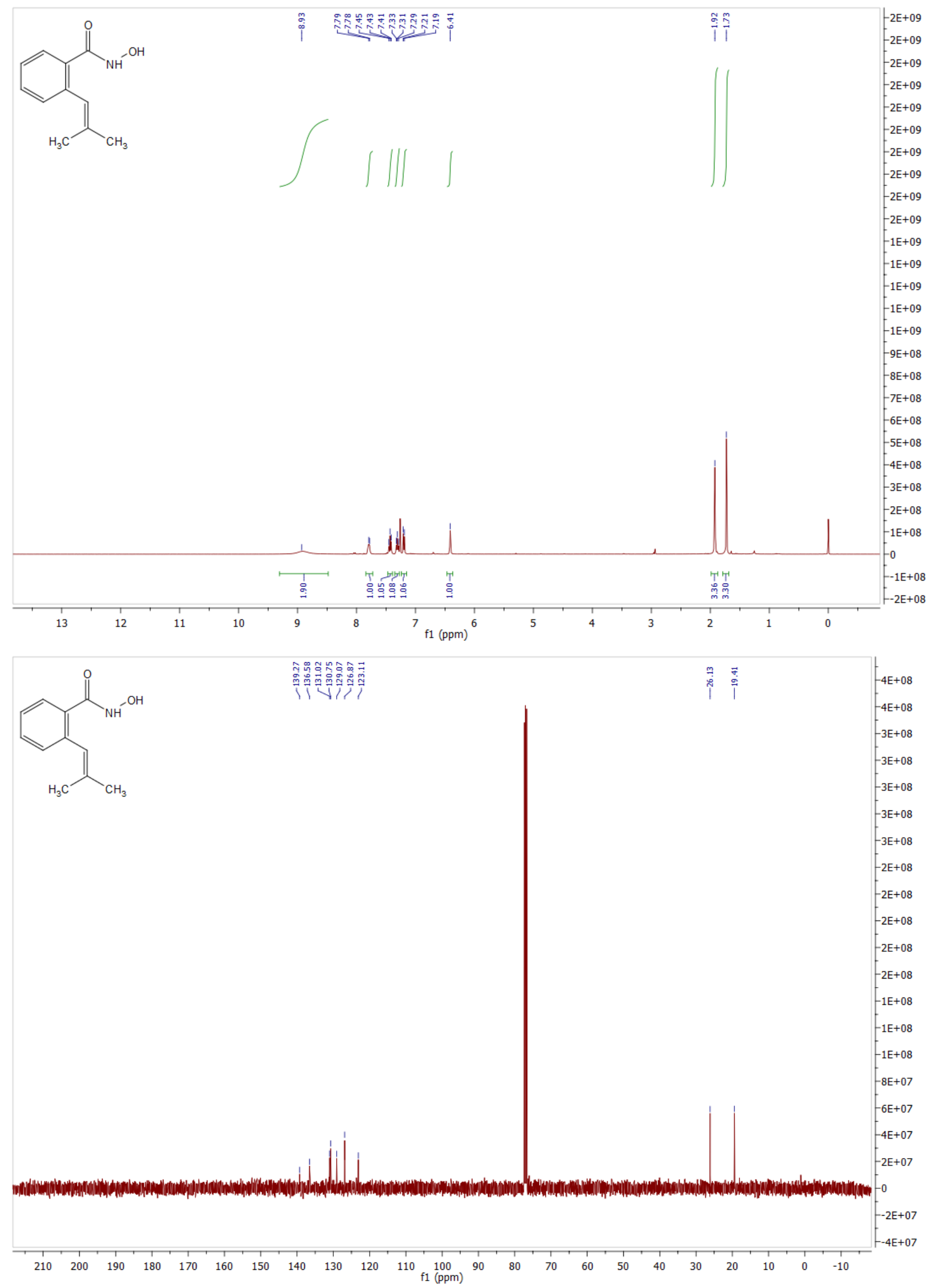


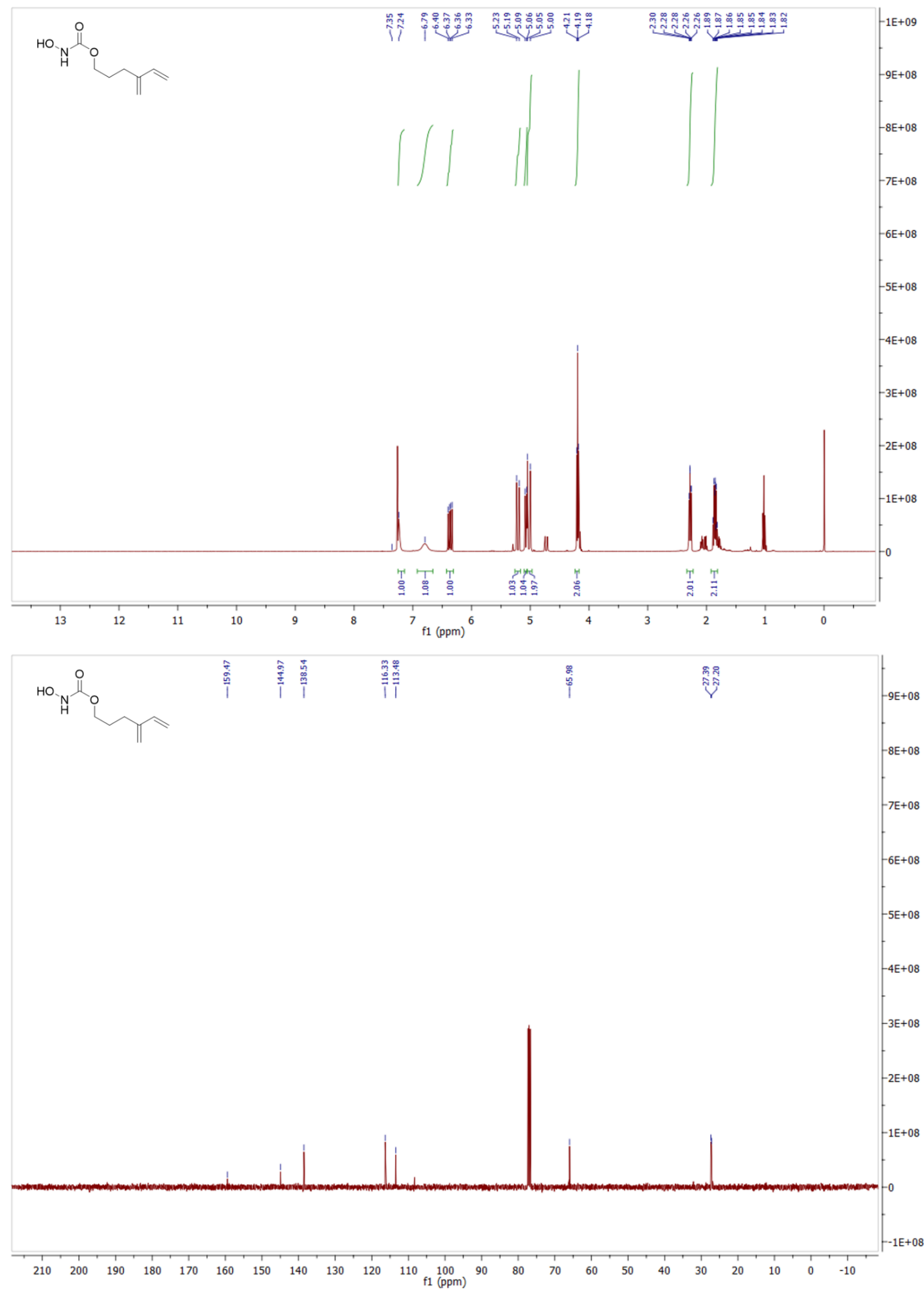




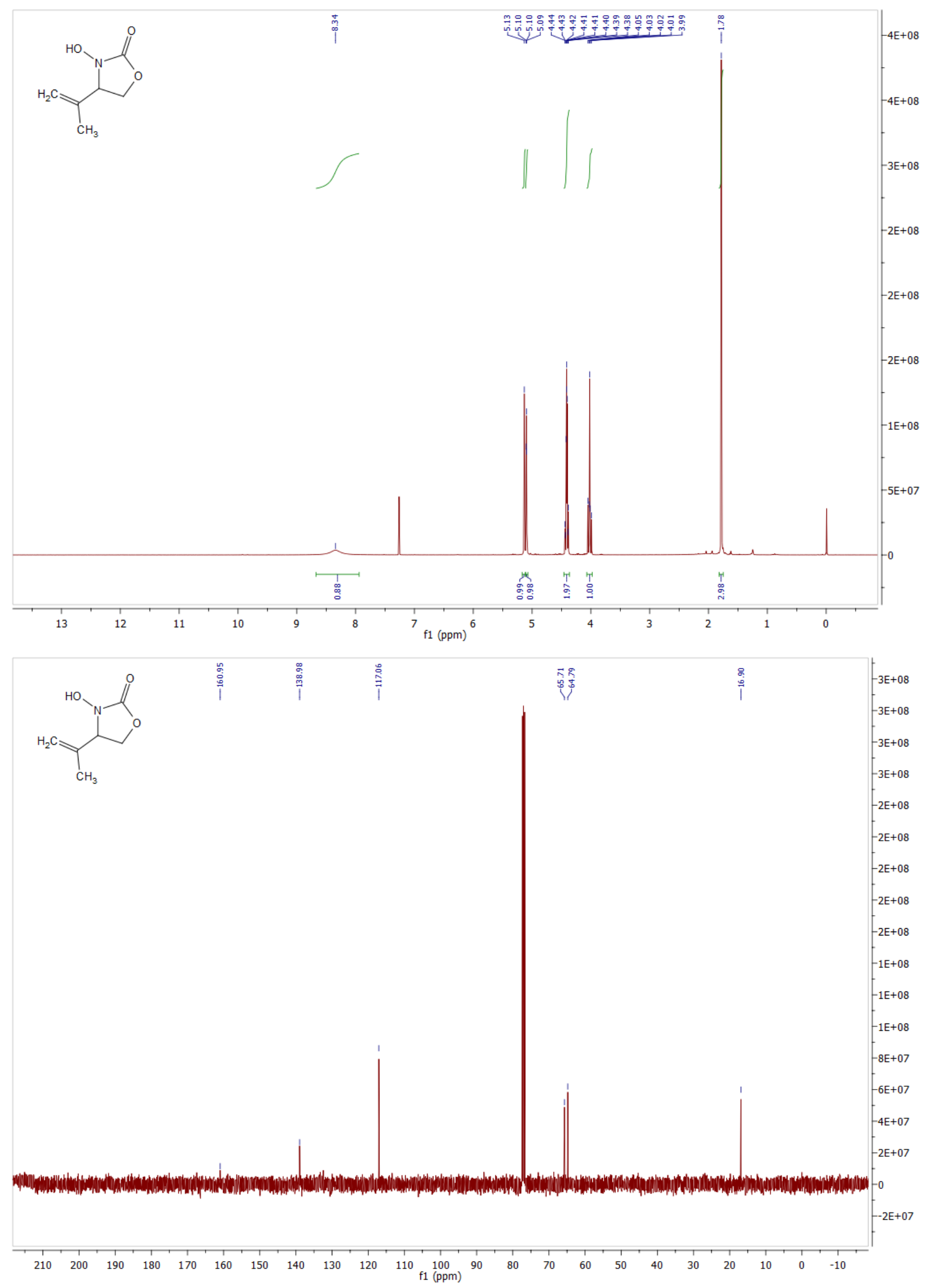




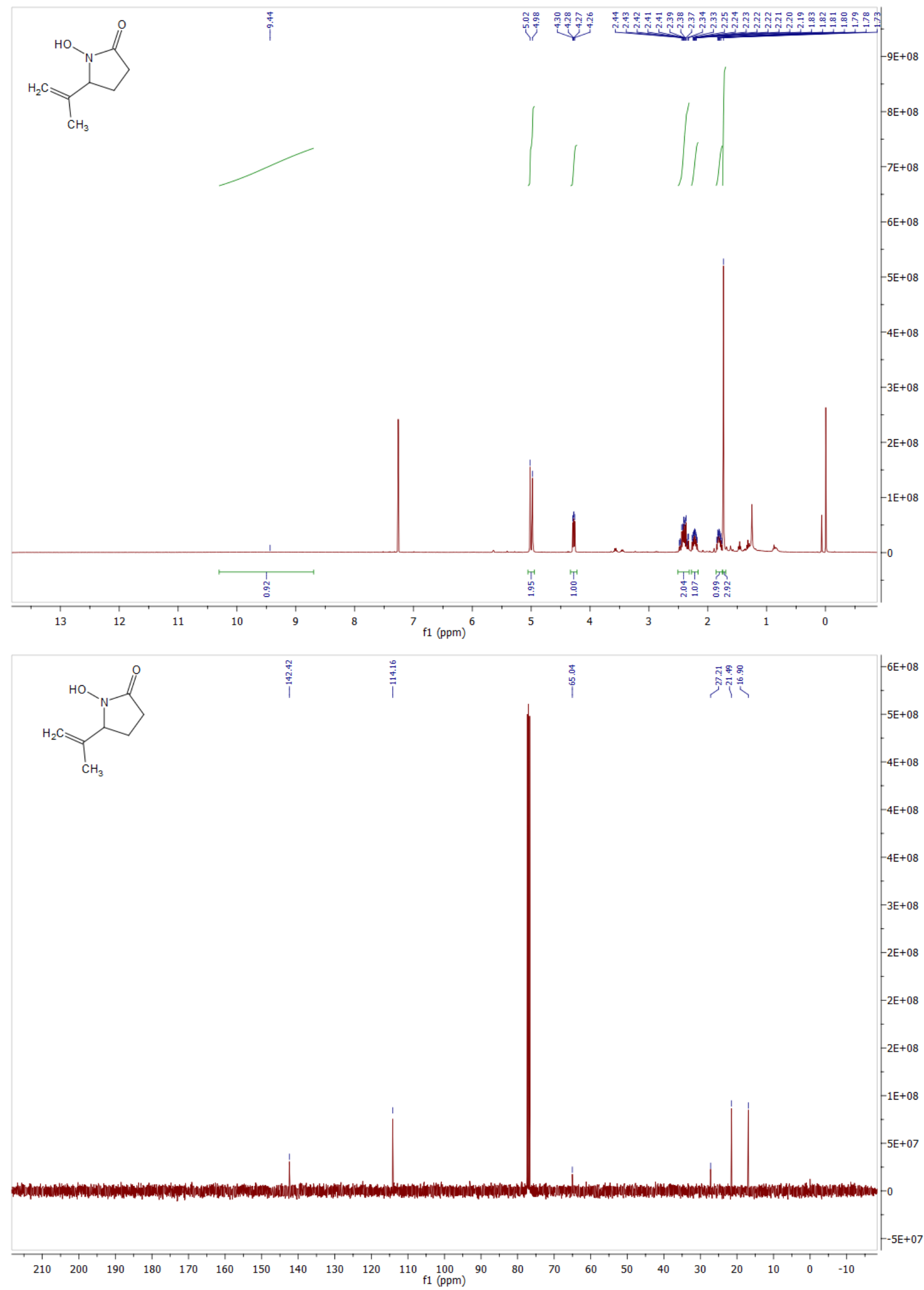



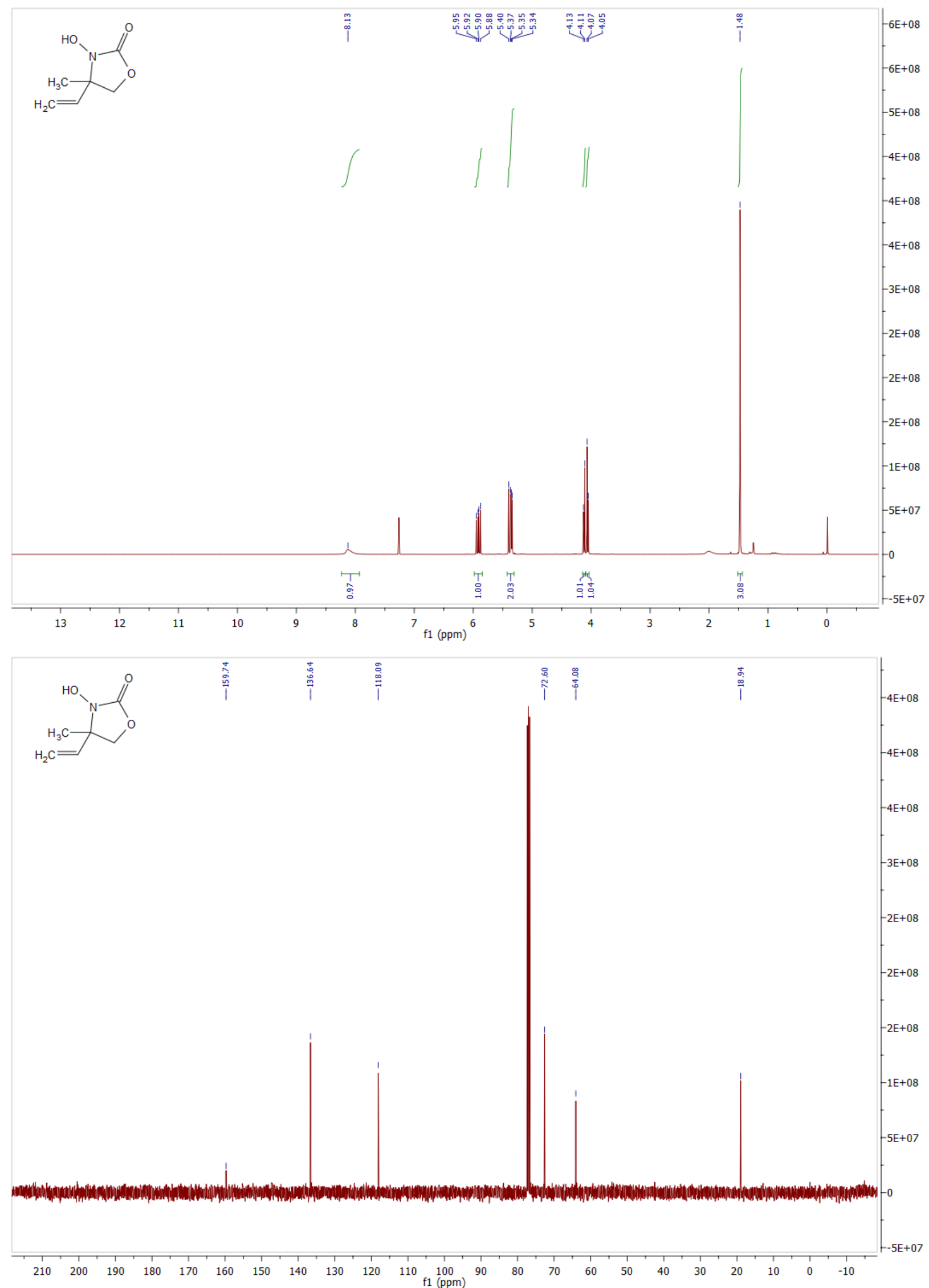


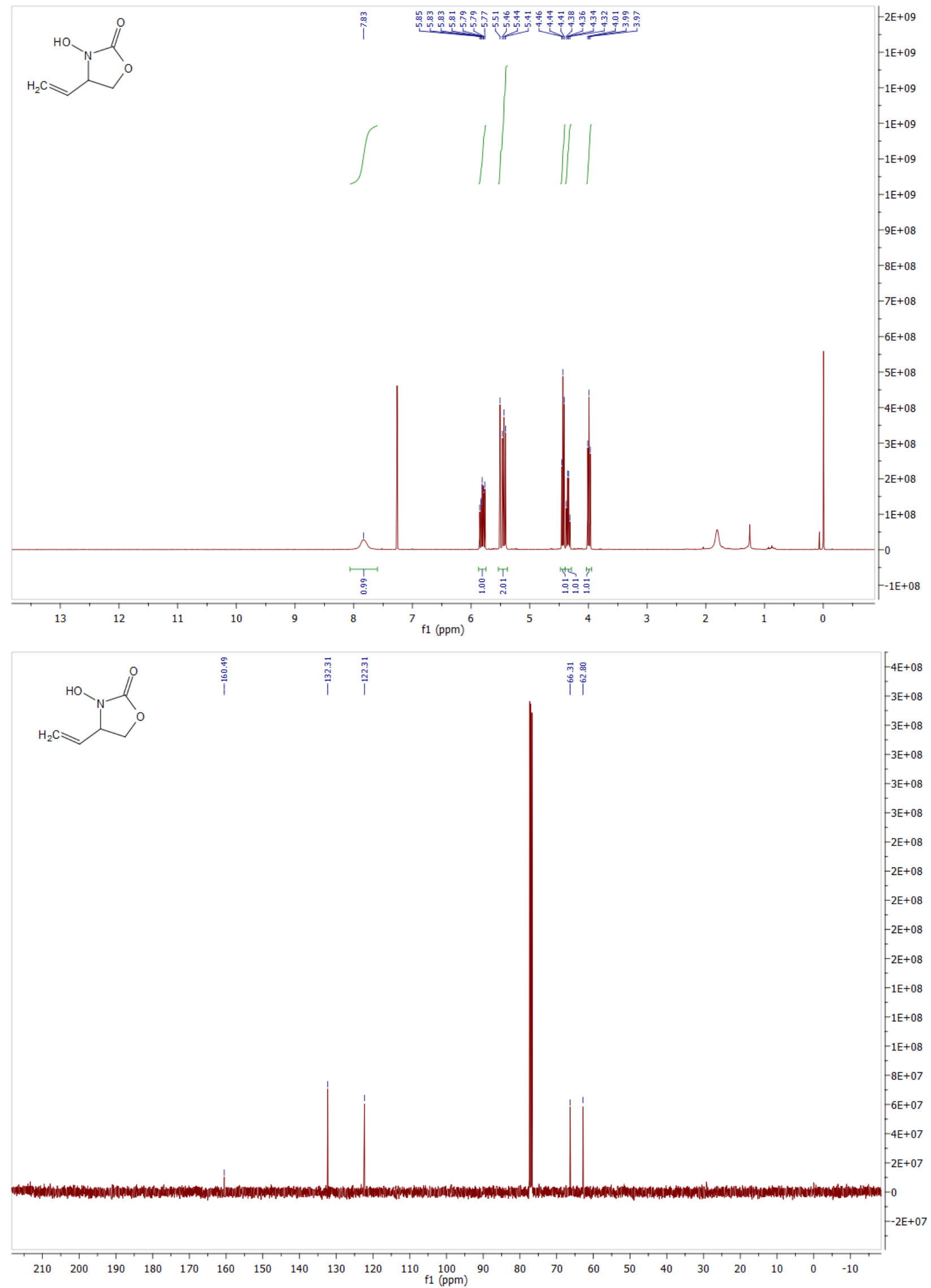




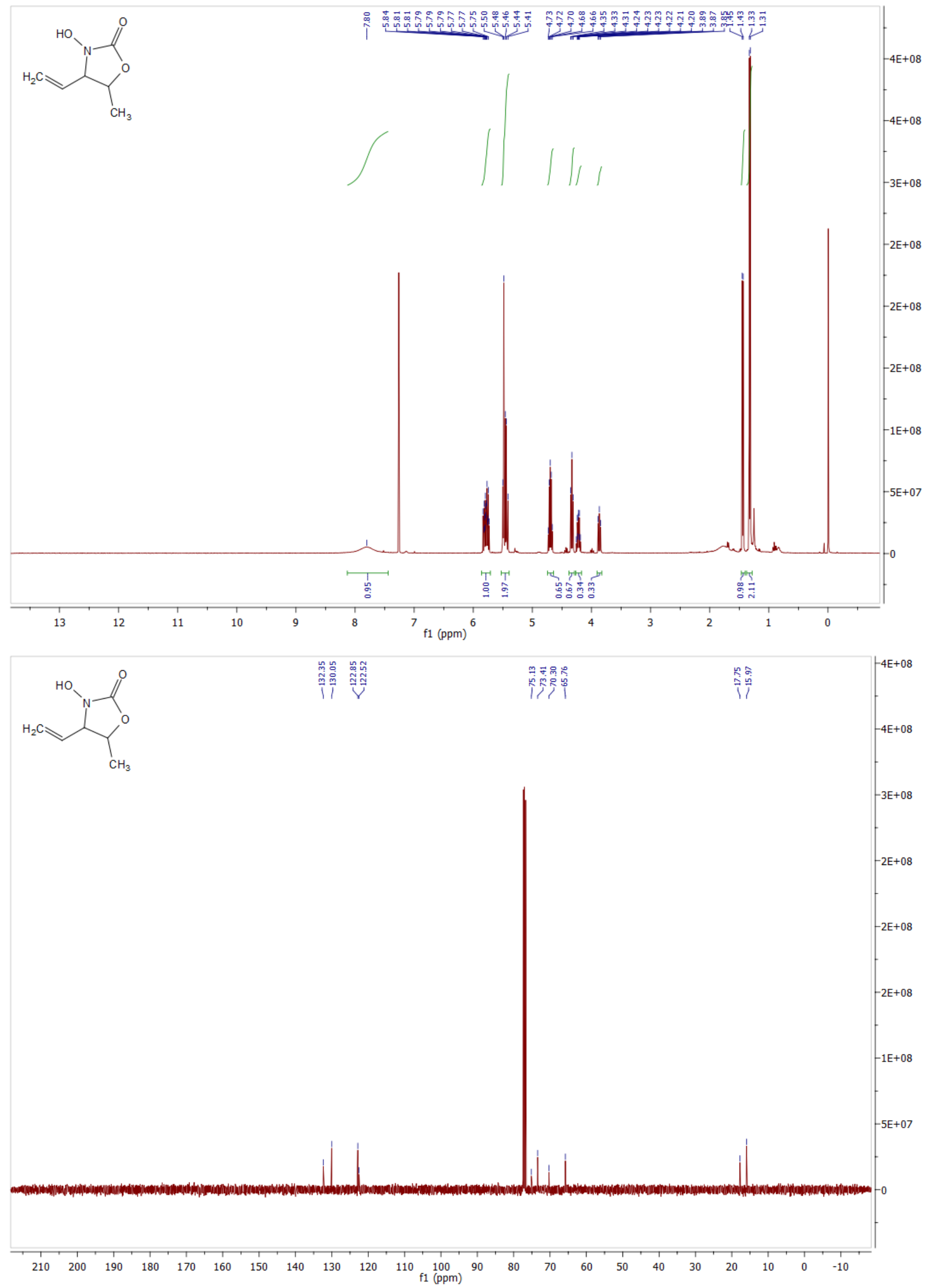



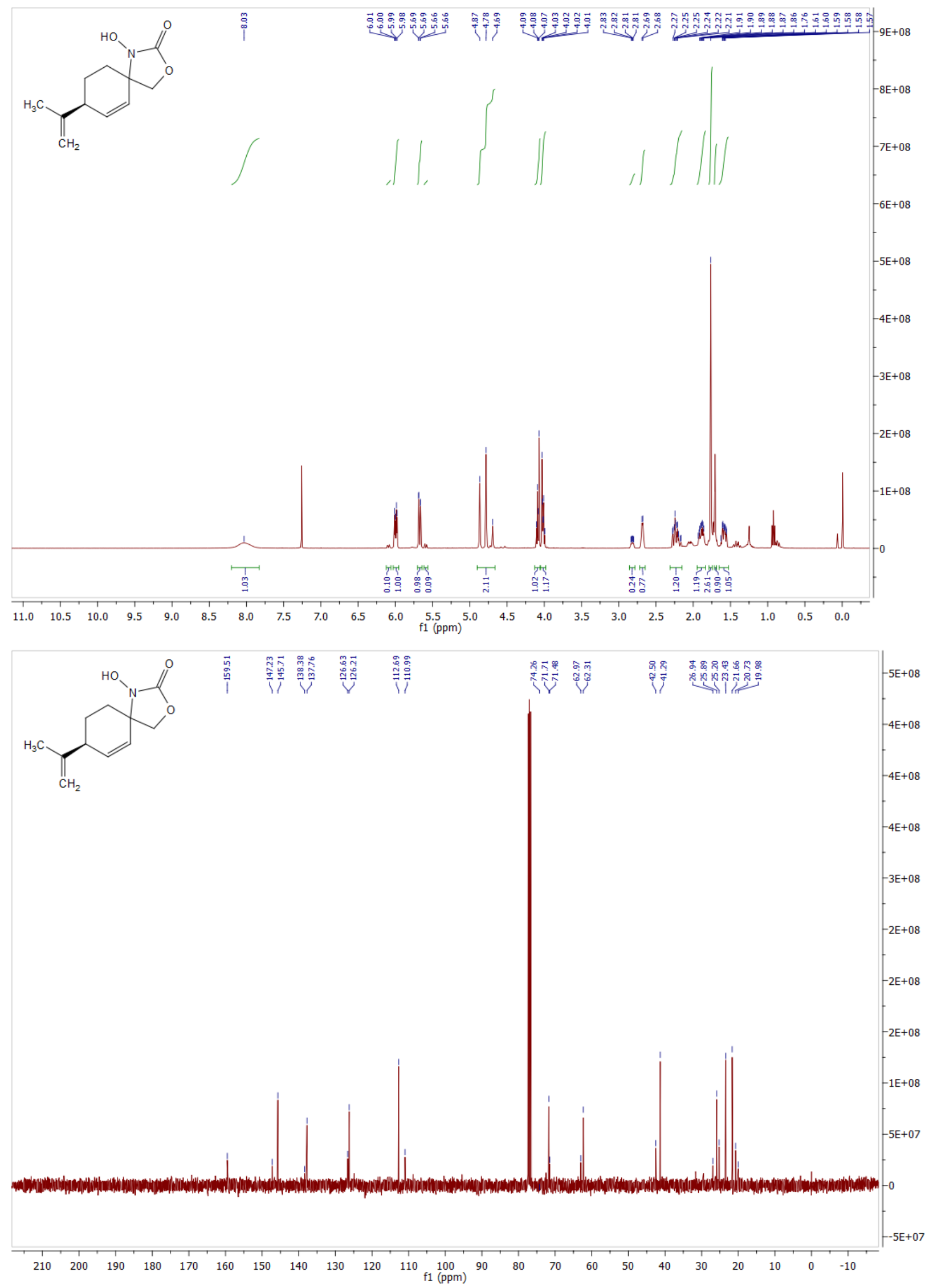

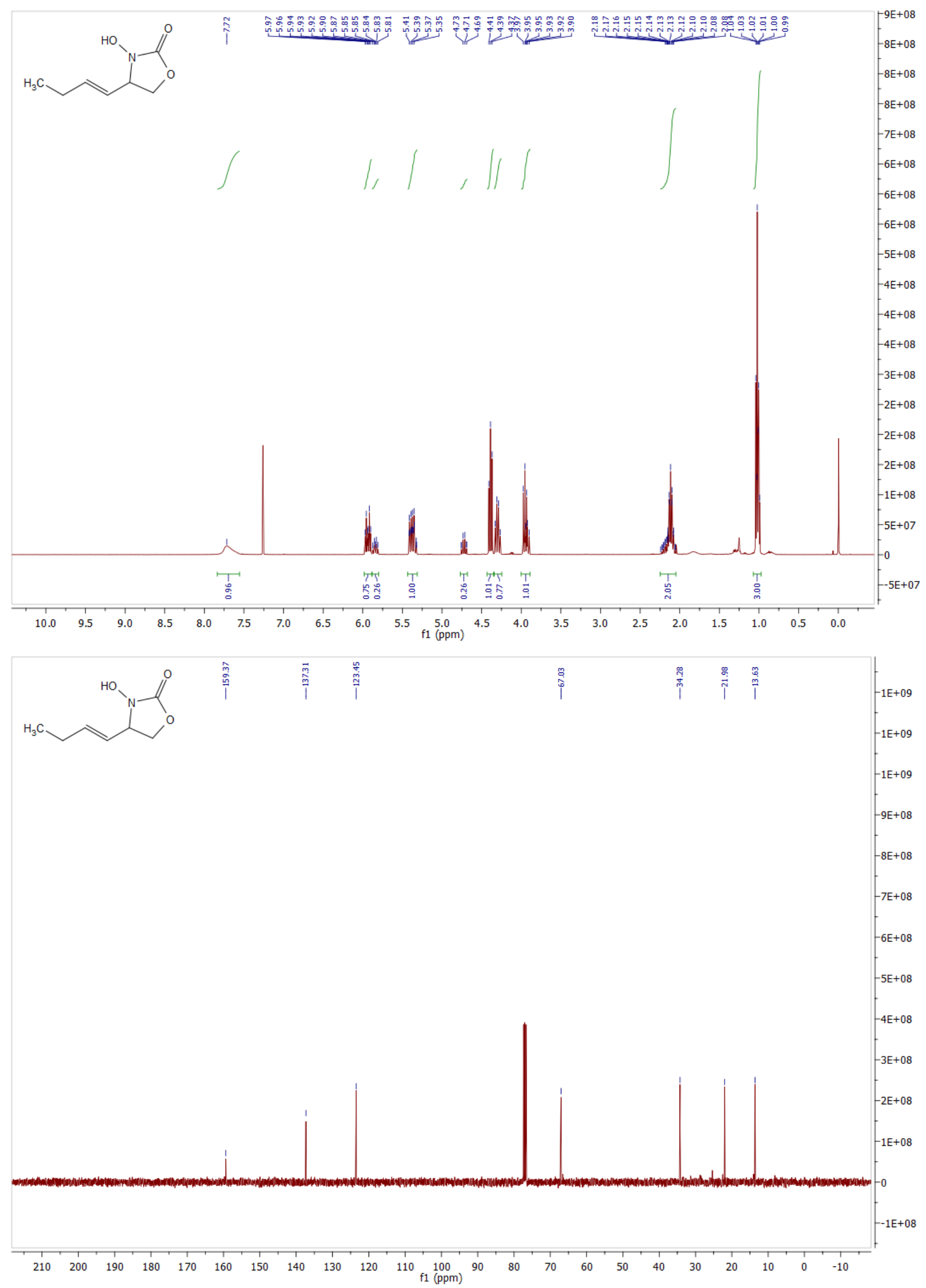


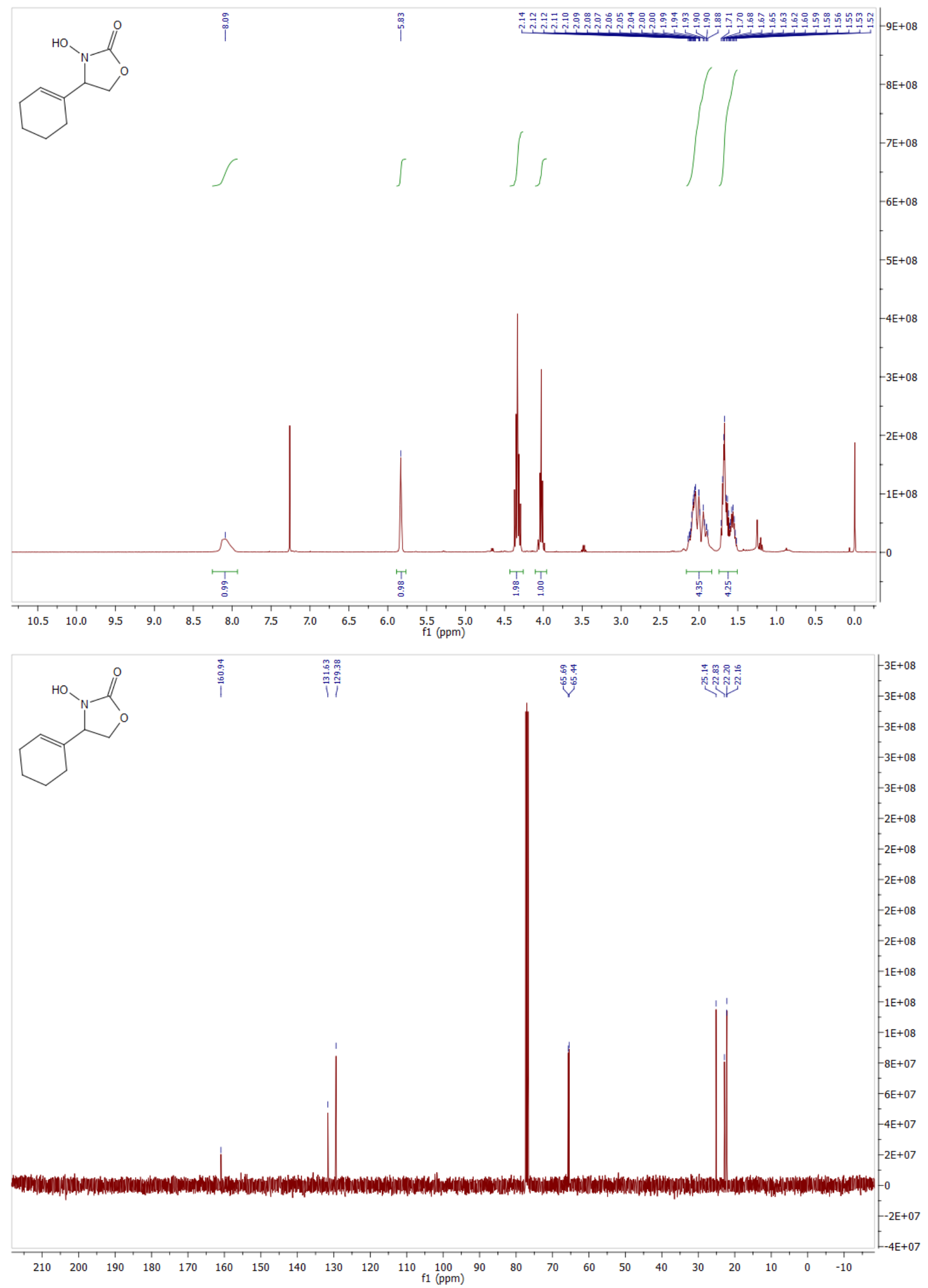



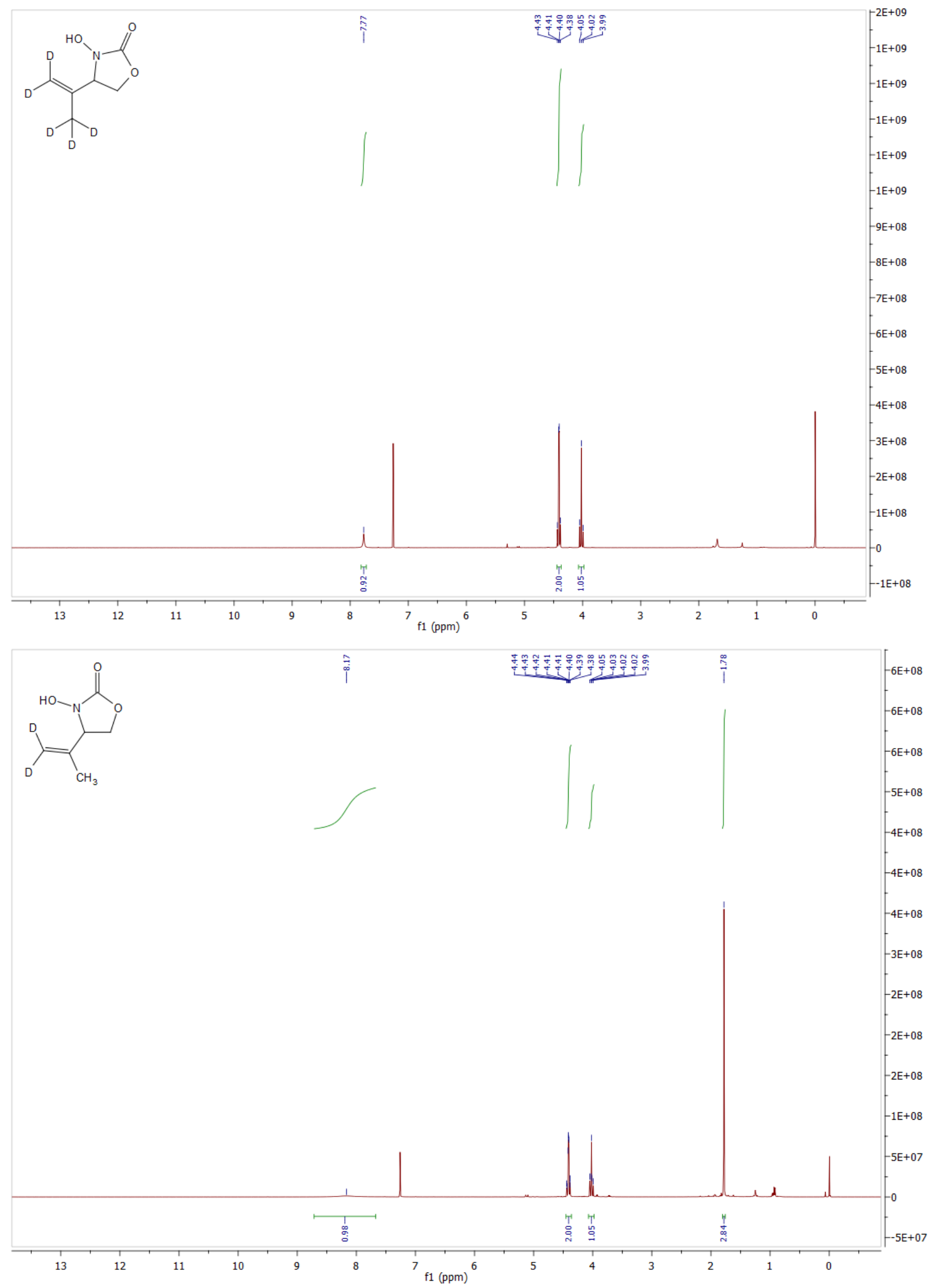


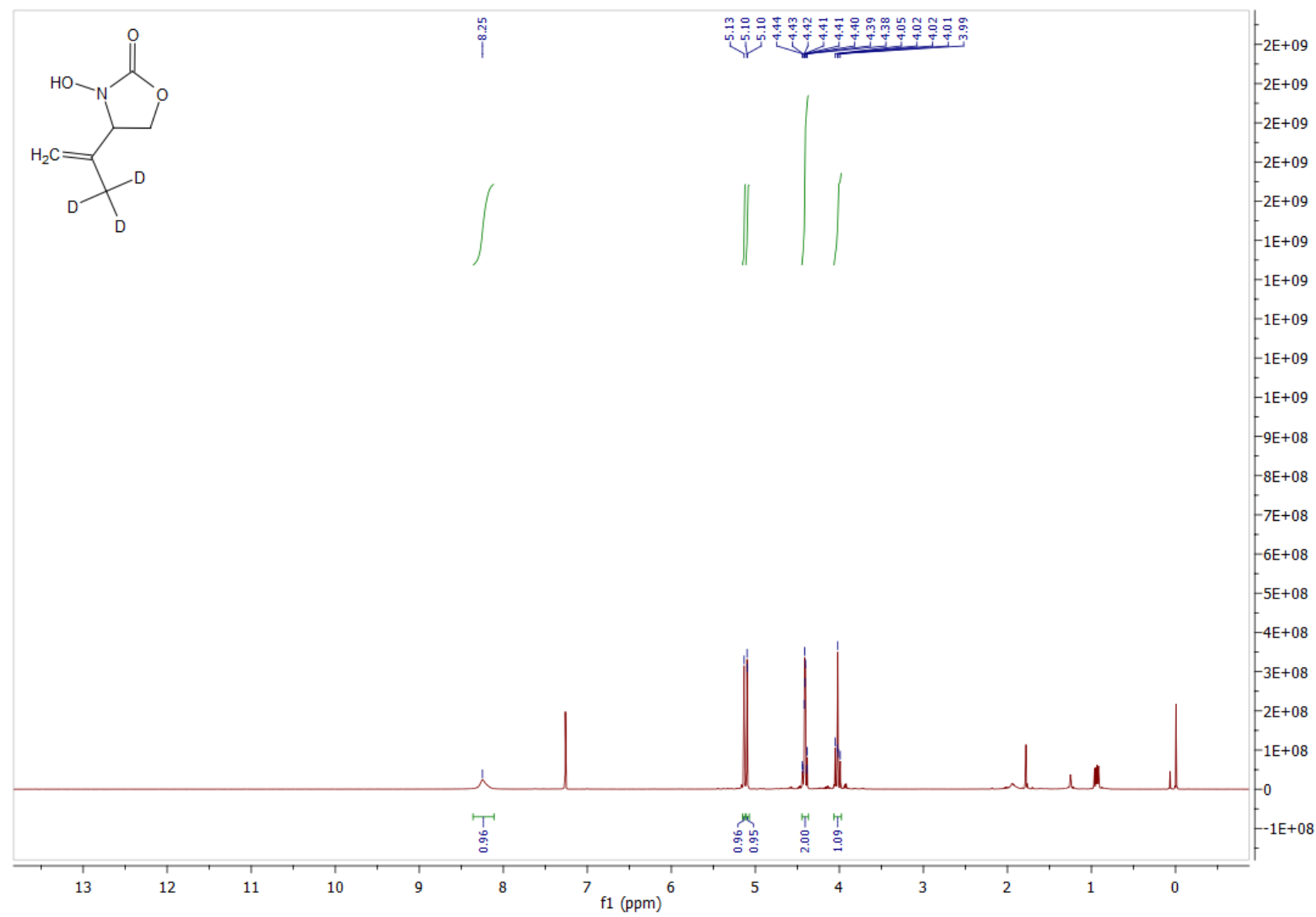



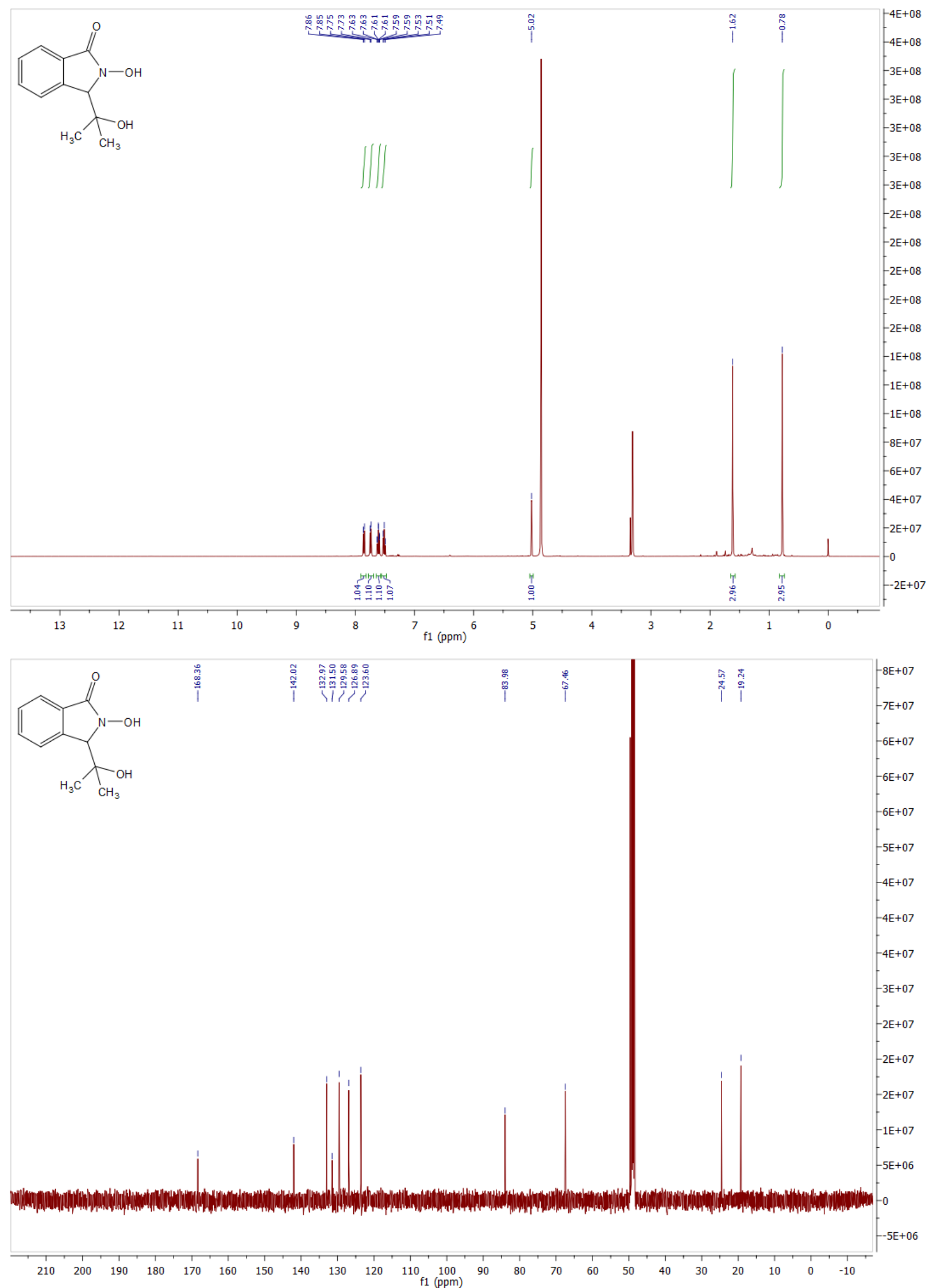


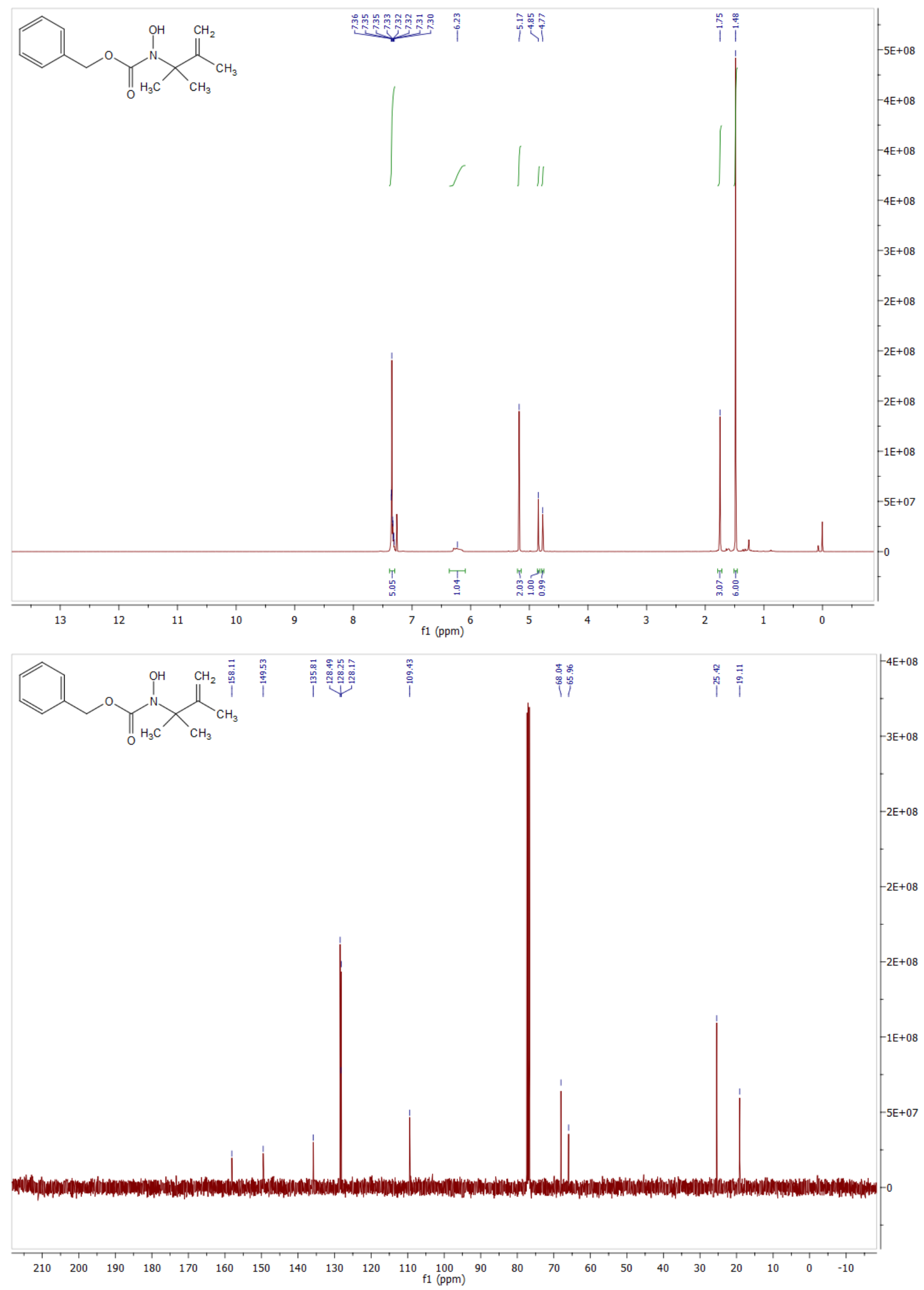




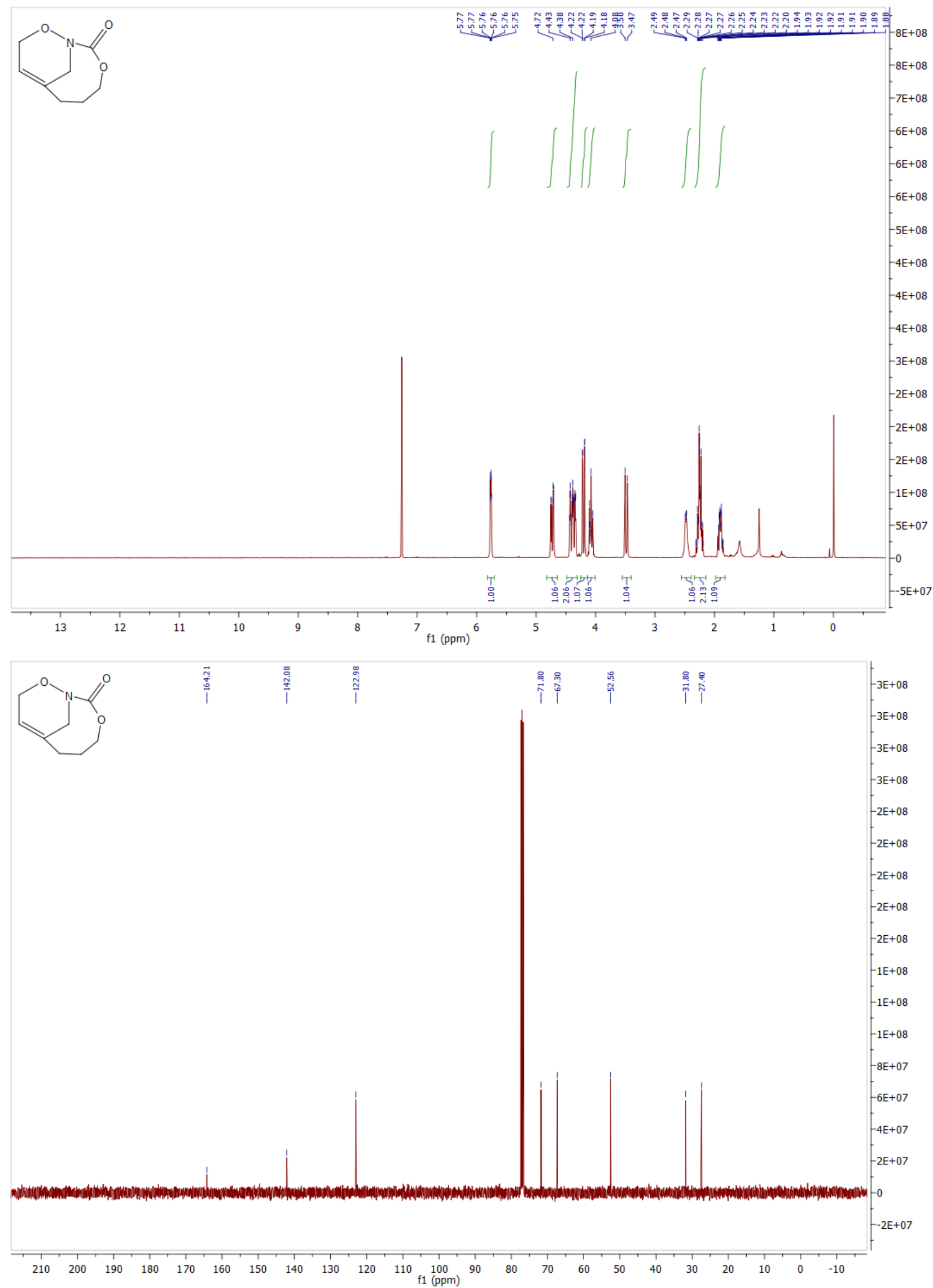




\section{References}

[1] R. Liu, S. R. Herron, S. A. Fleming, J. Org. Chem. 2007, 72, 5587-5591.

[2] C. P. Frazier, J. R. Engelking, J. Read de Alaniz, J. Am. Chem. Soc. 2011, 133,10430-10433.

[3] H. Lebel, K. Huard, S. Lectard, J. Am. Chem. Soc. 2005, 127,14198-14199.

[4] S. Y. Hong, S. Chang, J. Am. Chem. Soc. 2019, 141, 10399-10408.

[5] D. Atkinson, M. A. Kabeshov, M. Edgar, A. V. Malkov, Adv. Synth. Catal. 2011, 353, 3347-3351.

[6] D. Konrádová, H. Kozubíková, K. Doležal, J. Pospíšil, Eur. J. Org. Chem. 2017, 5204-5213.

[7] R. O. McCourt, E. M. Scanlan, Org. Lett. 2019, 21, 3460-3464.

[8] S.-R. Choi, M. Breugst, K. N. Houk, C. D. Poulter, J. Org. Chem. 2014, 79, 3572-3580.

[9] D. A. Candito, D. Dobrovolsky, M. Lautens, J. Am. Chem. Soc. 2012, 134, 15572-15580.

[10] J. Y. Wu, B. N. Stanzl, T. Ritter, J. Am. Chem. Soc. 2010, 132, 13214-13216.

[11] C. P. Chow, K. J. Shea, J. Am. Chem. Soc. 2005, 127, 3678-3679.

[12] G. E. Keck, R. R. Webb, J. B. Yates, Tetrahedron 1981, 37, 4007-4016.

[13] D. Chaiyaveij, L. Cleary, A. S. Batsanov, T. B. Marder, K. J. Shea, A. Whiting, Org. Lett. 2011, 13, 3442-3445.

[14] A. J. Mueller, M. P. Jennings, Org. Lett. 2007, 9, 5327-5329.

[15] C. Morill, R. H. Grubbs, J. Am. Chem. Soc. 2005, 127, 2842-2843.

[16] M. J. Fuchter, J.-N. Levy, Org. Lett. 2008, 10, 4919-4922.

[17] P. Bonilla, Y. P. Rey, C. M. Holden. P. Melchiorre, Angew. Chem. Int. Ed. 2018, 57, 12819-12823.

[18] H. V. Thulasiram, R. M. Phan, S. B. Rivera, C. D. Poulter, J. Org. Chem. 2006, 71, 1739-1741.

[19] G.-S. Liu, Y.-Q. Zhang, Y.-A. Yuan, H. Xu, J. Am. Chem. Soc. 2013, 135, 3343-3346. 
